WALDEN

UNIVERSITY

A higher degree. A higher purpose.

Walden University

ScholarWorks

1-1-2009

\title{
The intersection of punctuated equilibrium and leadership emergence within the framework of naturalistic decision making
}

Linda Moerschell

Walden University

Follow this and additional works at: https://scholarworks.waldenu.edu/dissertations

Part of the Business Administration, Management, and Operations Commons, Management Sciences and Quantitative Methods Commons, and the Organizational Behavior and Theory Commons

This Dissertation is brought to you for free and open access by the Walden Dissertations and Doctoral Studies Collection at ScholarWorks. It has been accepted for inclusion in Walden Dissertations and Doctoral Studies by an authorized administrator of ScholarWorks. For more information, please contact ScholarWorks@waldenu.edu. 


\section{Walden University}

COLLEGE OF MANAGEMENT AND TECHNOLOGY

This is to certify that the doctoral dissertation by

$$
\text { Linda Moerschell }
$$

has been found to be complete and satisfactory in all respects, and that any and all revisions required by the review committee have been made.

\section{Review Committee}

Dr. Teresa Lao, Committee Chairperson, Applied Management and Decision Sciences Faculty

Dr. Thea Singer, Committee Member, Applied Management and Decision Sciences Faculty

Dr. David Banner, Committee Member, Applied Management and Decision Sciences Faculty

Chief Academic Officer

Denise DeZolt, Ph.D.

Walden University 2009 


\begin{abstract} Framework of Naturalistic Decision Making

by

Linda Moerschell

Dissertation Submitted in Partial Fulfillment

of the Requirements for the Degree of

Doctor of Philosophy

Applied Management and Decision Sciences
\end{abstract}

The Intersection of Punctuated Equilibrium and Leadership Emergence Within the

Walden University

November 2008 


\begin{abstract}
Punctuated equilibrium, a theory of unexpected and sudden change arising out of evolutionary biology and paleontology, has been applied to decision sciences, physics, organizational theory, and group behavior but never to leadership emergence theories. The purpose of the study was to discover how leadership emerges during a period of punctuated equilibrium, a sudden and unexpected change event, using a naturalistic decision making framework. Thus, the research question probed how leadership emergence could be theoretically modeled in a critical event. This grounded theory study was particularly unique because it drew from, and helped unify the four scientific foundations of complexity science, leadership emergence, punctuated equilibrium theory, and naturalistic decision making. Data from 40 retrospective accounts, described in 15 interviews with critical incident intervention specialists, first responders, and wilderness leadership trainers residing in the northeastern region of the U.S. were supplemented by survey and observational data. Initial analyses employed a reflective coding matrix and a concept identification chart. Analysis of synthesized themes identified an event continuum model in which instinct, compassion, and responsibility served as motivating factors for leadership emergence that appeared in close proximity to the change event. Subsequent observable indicators of leadership emergence often included a sense of calm, quick situational assessment, and the tendency of individuals to ignore physical risk. This study found that punctuated equilibrium stimulated leadership emergence in individuals. The most profound implication for social change was that leadership arose in a time of need guided by compassion and a profound sense of responsibility toward one another regardless of formal position in the group.
\end{abstract}



The Intersection of Punctuated Equilibrium and Leadership Emergence Within the Framework of Naturalistic Decision Making

\author{
by
}

Linda Moerschell

Dissertation Submitted in Partial Fulfillment of the Requirements for the Degree of

Doctor of Philosophy

Applied Management and Decision Sciences

Walden University

November 2008 
UMI Number: 3342456

Copyright 2009 by

Moerschell, Linda

All rights reserved

INFORMATION TO USERS

The quality of this reproduction is dependent upon the quality of the copy submitted. Broken or indistinct print, colored or poor quality illustrations and photographs, print bleed-through, substandard margins, and improper alignment can adversely affect reproduction.

In the unlikely event that the author did not send a complete manuscript and there are missing pages, these will be noted. Also, if unauthorized copyright material had to be removed, a note will indicate the deletion.

\section{UMI}

UMI Microform 3342456

Copyright 2008 by ProQuest LLC

All rights reserved. This microform edition is protected against unauthorized copying under Title 17, United States Code.

ProQuest LLC

789 East Eisenhower Parkway

P.O. Box 1346

Ann Arbor, Ml 48106-1346 


\section{DEDICATION}

This dissertation is dedicated to my parents and my husband for their unwavering support, interest in my work, and faith in my ability. 


\section{ACKNOWLEDGMENTS}

It was an honor to work with a supportive committee from Walden University. Dr. Teresa Lao, my committee chairperson and mentor for almost 3 years leading to my final dissertation has guided me with strength, pushing me to reach higher levels of thinking and writing. Dr. David Banner provided great insight and direction serving as my assessor during a portion of my coursework and as the dissertation committee member who assessed the content of this work. I would like to acknowledge Dr. Thea Singer who served on my dissertation committee as the methods evaluator. I would also like to acknowledge the patience and commitment to scholarship shown by the Crumb Library staff at the State University of New York at Potsdam. 


\section{TABLE OF CONTENTS}

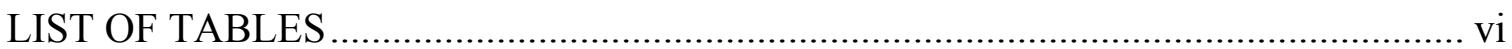

LIST OF FIGURES …........................................................................................ vii

CHAPTER 1: INTRODUCTION ..........................................................................

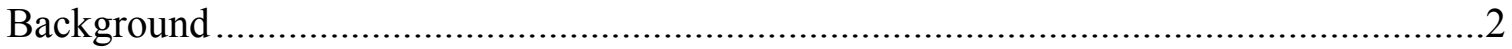

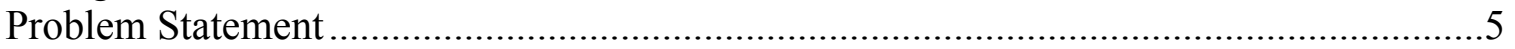

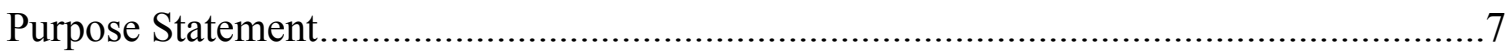

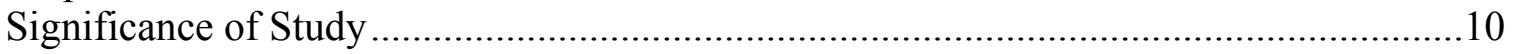

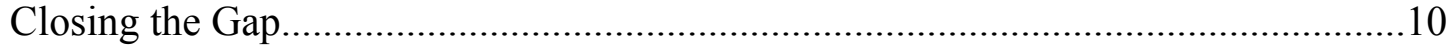

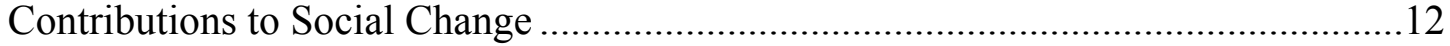

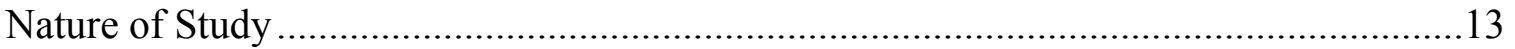

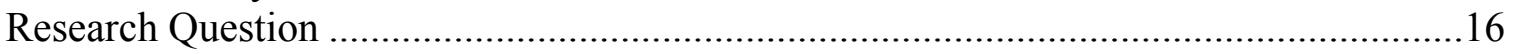

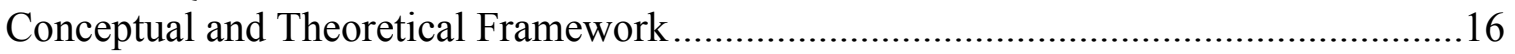

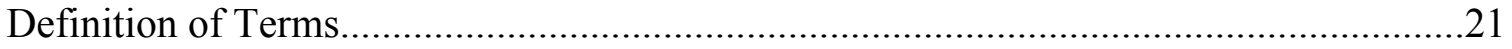

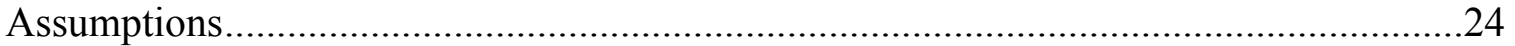

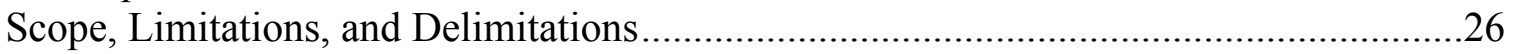

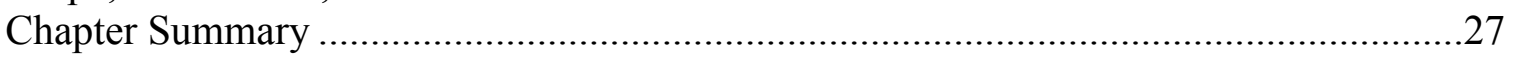

CHAPTER 2: LITERATURE REVIEW .................................................................29

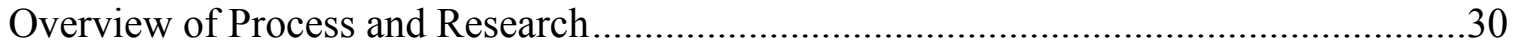

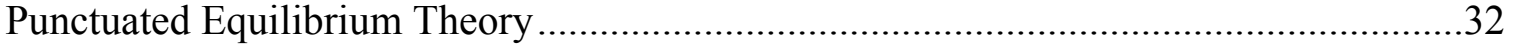

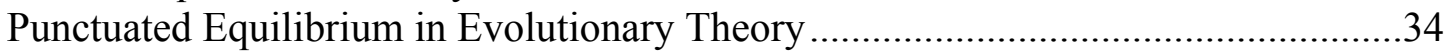

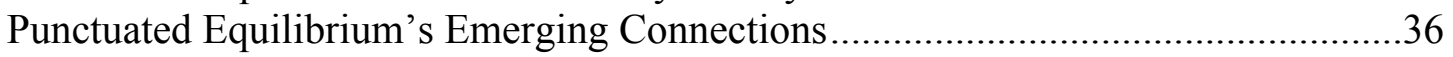

Robinson's Ideas about Organizational Decision Making.......................................39

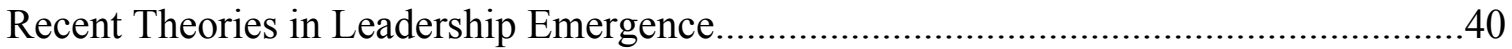

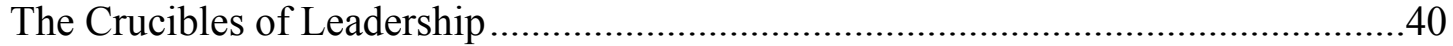

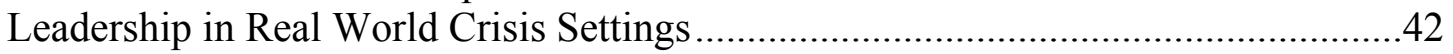

Traits that Describe a Punctuated Equilibrium Leader ............................................46

Naturalistic Decision Making and Critical Incidents .....................................................50

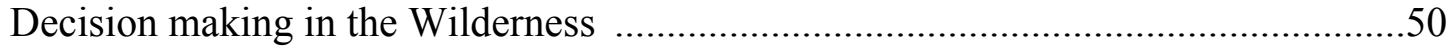

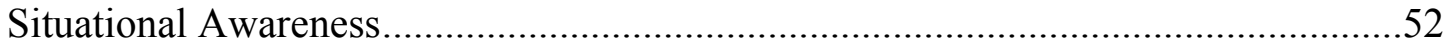

Complexity Science Views on Change, Time, and Leadership .....................................54

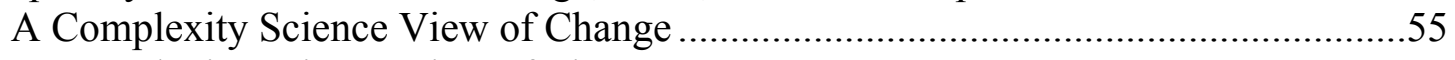

A Complexity Science View of Time ........................................................................58

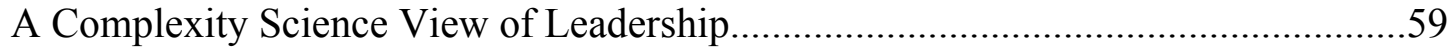

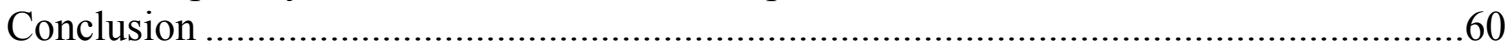

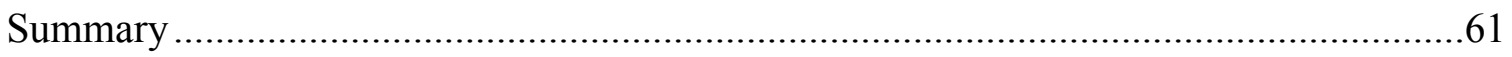

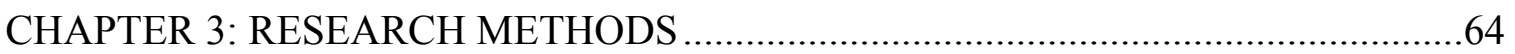

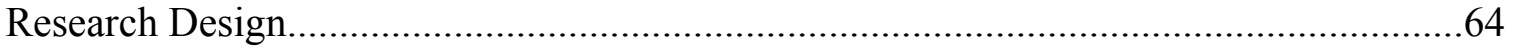

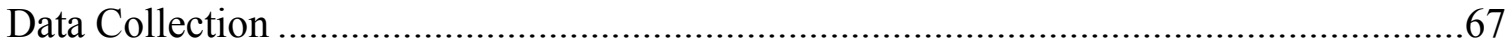

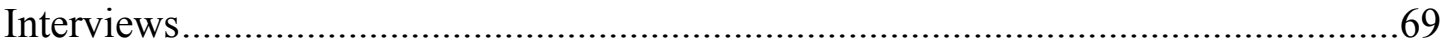




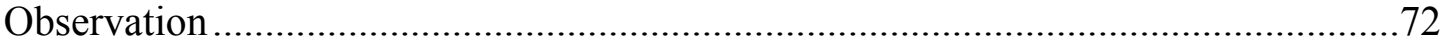

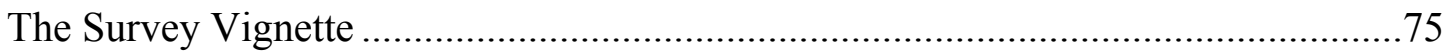

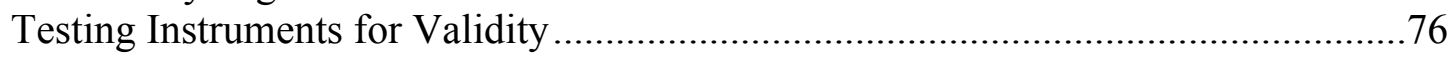

Grounded Theory Data Analysis ..................................................................................

Procedures to Address the Research Questions ........................................................79

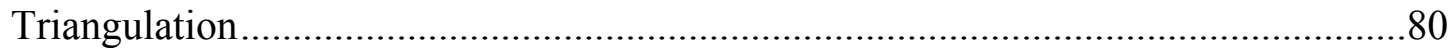

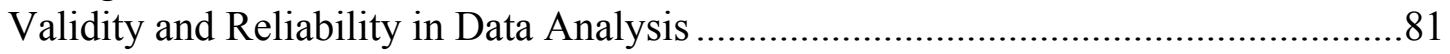

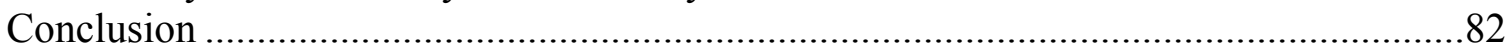

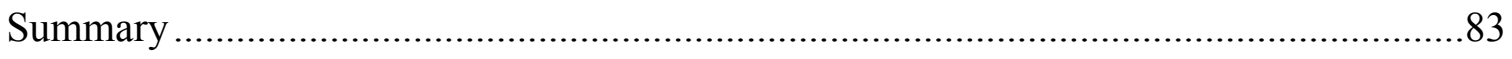

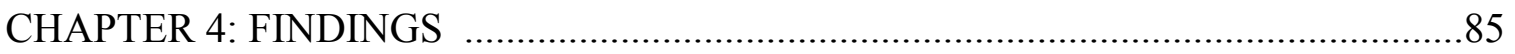

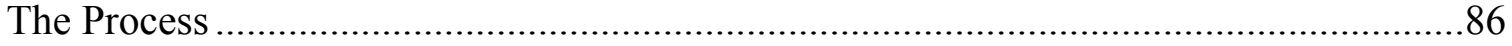

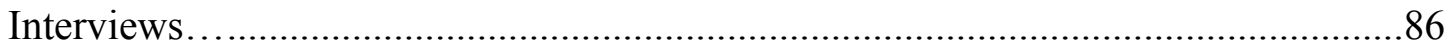

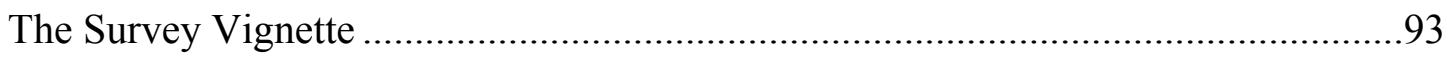

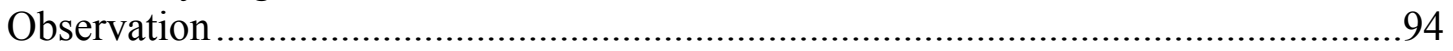

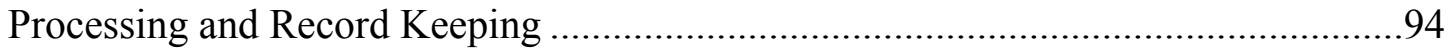

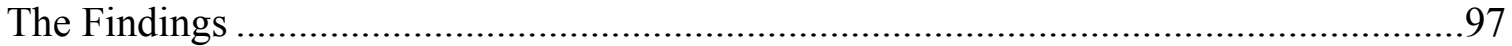

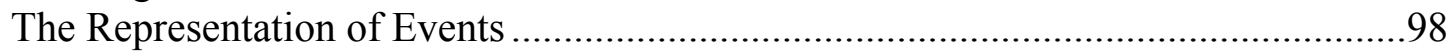

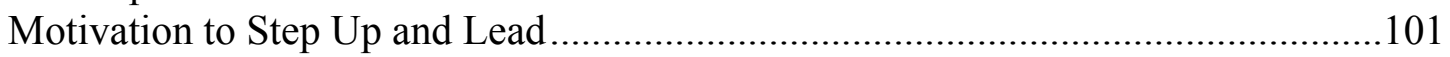

Prominent Characteristics of the Do-Somethings ....................................................102

Character Faults in the Emerging Leader ...............................................................106

Preliminary Findings Linking Sudden Change with Leadership Emergence.............107

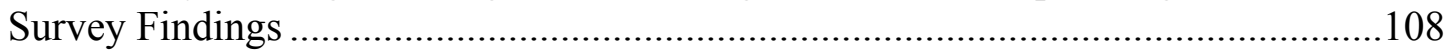

Preliminary Findings for Creativity, Courage, and Compassion................................110

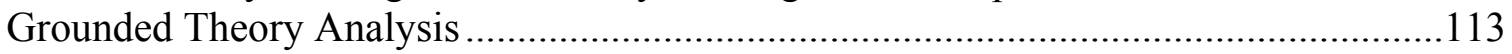

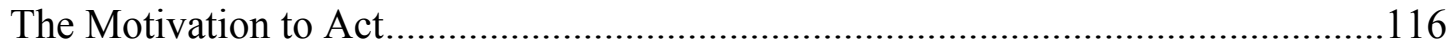

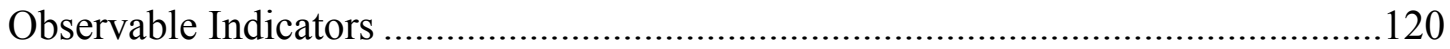

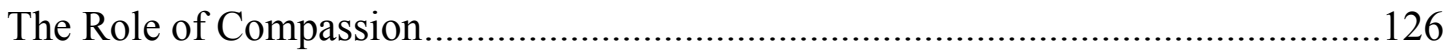

The Fit for Creativity and Courage .....................................................................128

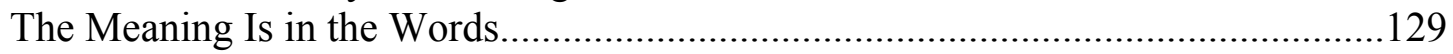

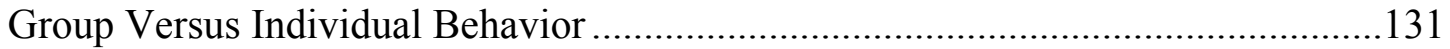

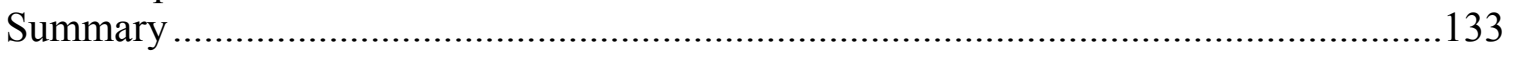

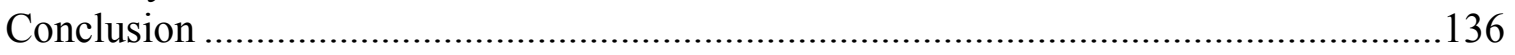

CHAPTER 5: RESULTS AND RECOMMENDATIONS ………………………........137

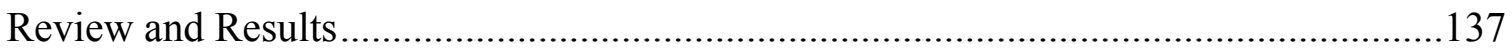

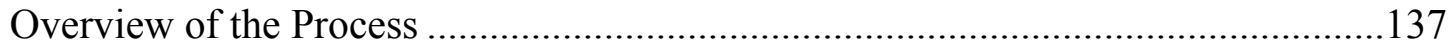

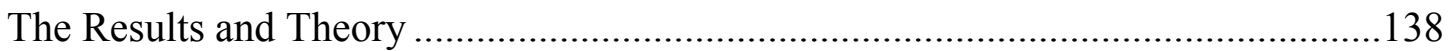

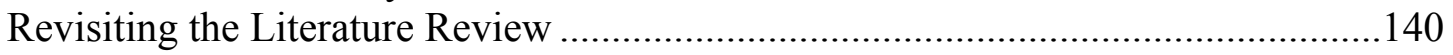

Implications for Leadership and Change Theories .................................................142

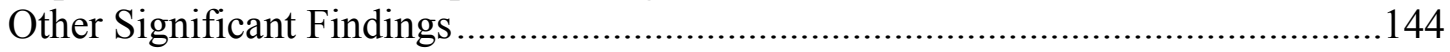

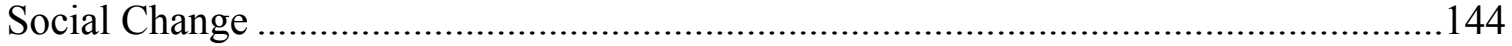

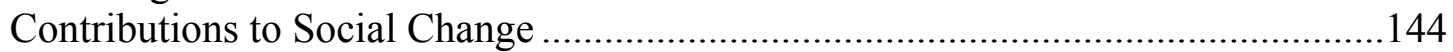

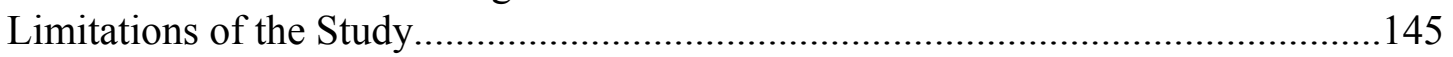


Recommendations for Future Research .............................................................146

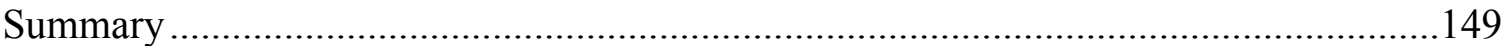

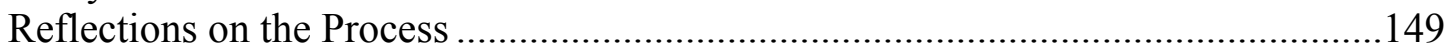

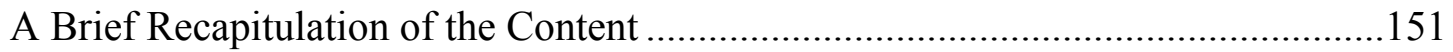

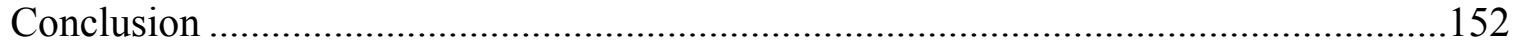

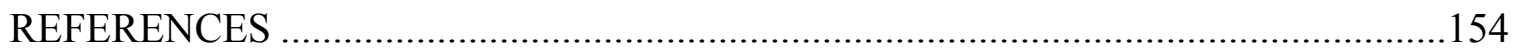

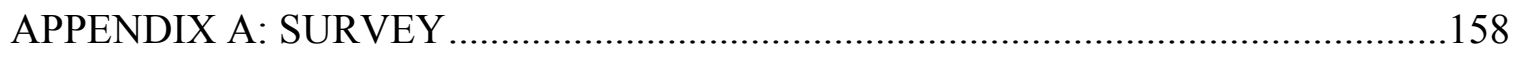

APPENDIX B: INTERVIEW GUIDE ……………………...................................167

APPENDIX C: CONCEPT IDENTIFICATION CHART ……………….....................170

APPENDIX D: SURVEY RESPONSES ALIGNED BY THEMES ..............................170

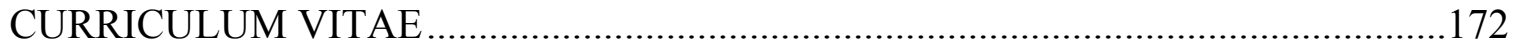




\section{LIST OF TABLES}

Table 1. Critical Incidents Grouped by Category ..................................................... 90

Table 2. Reflective Coding Matrix for Motivation to Act .........................................120

Table 3. Reflective Coding Matrix for Observable Indicators ....................................125

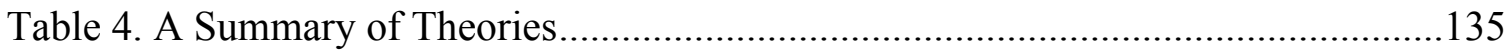




\section{LIST OF FIGURES}

Figure 1. The Event Continuum Perspective Indicating a Sequence of Events................101

Figure 2. The Event Continuum Perspective Illuminating Core Themes .........................115 


\section{CHAPTER 1: INTRODUCTION}

Organizational leadership studies have linked change with the function of leadership (Parry, 1998; Poole \& Van de Ven, 2004; Romanelli \& Tushman, 1985; Wheatley, 2006). These functions of leadership are characterized as adapting to, managing, anticipating, or leading change while change is thought of as something that can be stimulated, thwarted, or created by leadership (Antonakis, Cianciolo, \& Sternberg, 2004). The change event, incremental or sudden, typically occurs when a leader, specifically an executive or decision-making leader, is already in place. In terms of organization change, for example, leadership mediates or tries to makes sense out of a change event (Byrne, Caughron, Friedrich, \& Mumford, 2007; Romanelli \& Tushman). But what if this order was reversed and a sudden change event was the driver for leadership emergence? Could an unexpected change event be the ignition for sudden leadership emergence and if so, how could it be observed and identified?

Imagine every time a decision is made in an emergent circumstance that the path traveled by the individual splits in half. One of these mutually exclusive paths will define success or failure through the individual's ability. Since decision-making is implicit in this model, a model of decision making triggered by unexpected change was needed. I discovered that a naturalistic decision making (NDM) model was the best lens through which the intersection of leadership and punctuated change could be observed. The research conducted in this dissertation was an attempt to build a theory that defined emergent qualities of leadership as they intersected with a sudden change incident within 
a narrow timeframe. According to Parry (1998), "Change incidents can be the basis of investigation of the leadership process" (p. 86).

The first chapter begins with clarification of why the study of this phenomenon is of interest and importance to leadership and organizational change scholars. The problem and purpose statement articulated the parameters of the study. The potential contribution to leadership research will follow as the significance of the study is projected. The choice of grounded theory as the most appropriate research design is detailed in the nature of the study. The main research question and supporting questions set up a framework for the study and included a plan of how these questions will be approached. This is followed by the conceptual framework that explained what theories laid the foundation for this research. Terms and definitions were clarified, assumptions were addressed, and finally, potential limits and weaknesses of the study were anticipated. By the end of this chapter, the reader will have an understanding of how the intersection between leadership emergence and punctuated equilibrium was studied within a NDM frame. This research built a theory from the data that posited rapid and unexpected change is the stimulus for leadership emergence.

\section{Background}

Few studies have been found that link leadership emergence with punctuated equilibrium. Although executive leadership has been a component of punctuated equilibrium theory (PET) in organizations (Romanelli \& Tushman, 1985), an extensive literature review has yet to reveal the mechanism of immediate leadership emergence triggered by an unexpected change event. However, elements found everywhere in the 
leadership and change literature. For example, Wheatley (2006) has linked leadership emergence in individuals to natural disasters in terms of the self-organizing systems paradigm. Robinson (2007) linked punctuated equilibrium models with decision making in a policy-making setting. Galloway (2007) has linked critical decision making to a wilderness medical event, which is similar to a punctuated change event in an outdoor setting. Gersick (1991) has linked punctuated equilibrium to revolutionary change in several domains. Time is a critical variable in this investigation, and complexity science models give the most suitable interpretations of time (Poole \& Van de Ven, 2004). Complexity science introduces an alternative way of thinking about time and change. A rigorous description of these unique theories and others was provided in chapter 2 of this dissertation.

An empirical investigation was needed to define the event, or circumstance, that represented the intersection of leadership and change elements within a limited timeframe. This research contributes to the leadership and organizational change literature in such a way that it provides an understanding of an individual's potential to succeed or fail in a high stakes decision-making event. Three separate settings in which a critical incident could take place were chosen to study the phenomenon in which sudden change, decision making and leadership might be observed as one process. Data were collected from these three situations to form the foundation from which a theory was built.

The motivation to pursue this research study arose from three separate areas. The first of these was PET, which grew out of a complexity science perspective. The study of 
punctuated equilibrium was inspired by the collection of complexity science change models assembled in the Handbook of Organizational Change and Innovation (Poole \& Van de Ven, 2004). The second area of motivation grew from the study of leadership emergence from many disparate points of view that were often inconclusive. The final motivation was the belief that a distinction needs to be made between low performing and ill prepared individuals, who are leaders in name only, and the potential in every individual to rise up as a leader at the moment a leader is needed. The last factor for this research points to significant social issues and assumptions embedded in the study of leadership and change, and that is society's tolerance for individuals masquerading as leaders who fail to emerge in times of urgent need. It would be a significant contribution to society if this study revealed unique qualities that defined emerging leaders, identifiers that set them apart from others in times of critical need.

Complexity scientists' suggestion that order may lie beneath complexity is difficult to understand (Poole \& Van de Ven, 2004, p. 374). This idea represented a larger interconnected system that linked domains and ideas. It suggested that there could be multiple solutions to every question. It is from this idea, that the universe is as complicated as it is simple, that the passion for this study emerged.

Sparks of complexity knowledge and the nature of interconnectedness have radiated from quantum physics and other systems domains through the work of Einstein, Prigogine, and Capra. In the 1990s, Senge and Wheatley were among the first to connect concepts from quantum physics to organizational theory, thus taking a leap out of the box. In Gersick's (1991) comparison of punctuated equilibrium models, the author wrote 
that "the most important implications of the punctuated equilibrium paradigm are suggested by the very diversity of the fields that have been affected by it" (p. 33). Establishing the relationship proposed in this dissertation required a different kind of thinking. Change and its relationship to leadership must be seen as a complex event with a system of elements leading up to it and a series of consequences leading away from it.

\section{Problem Statement}

Punctuated equilibrium, a theory of unexpected and sudden change arising out of evolutionary biology and paleontology, has been applied to decision sciences, physics, organizational theory, and group behavior but never to leadership emergence theory. Although there is literature that has described leadership in terms of managing a punctuated equilibrium model of change, little has been found that described the mechanics of how sudden change, in a defining incident, triggers leadership to emerge or not to emerge resulting in a successful or failed response to an emergent need.

The research problem explored in this dissertation investigates how leadership emergence intersects with punctuated equilibrium, a sudden and unexpected change event, within a naturalistic decision making framework. The research problem that follows is whether leadership emergence can be observed and identified in these conditions and what characteristics can identify the emergence.

According to a significant collection of leadership literature, creativity, courage, and compassion are among the traits associated with leadership ability (Boyatzis \& McKee, 2006; Lengbeyer, 2005; McKee \& Massimilian, 2006; Martin, 2007; Sternberg, 2007; Zaccaro, 2007). With reference to the literature, the indicators of creativity, 
courage, and compassion were among indicators that were expected to appear immediately. The research was concerned with evidence of a rapid manifestation of these behaviors during a narrow timeframe. Research that could identify an individual's behavior during the few moments surrounding a critical incident was the best way to give form to an abstract idea. Because of similarities in structure and circumstance, studies on NDM supported the understanding of what happens in a critical incident (Klein, 2000).

To discover whether there was a relationship between leadership emergence and a sudden change event, a grounded theory design was selected. Data were collected from professionals trained in critical incidents and others who were trained in outdoor adventure challenges. The data collected from retrospective accounts (Klein, 2000) were categorized and coded in way that identified emerging leadership behaviors. The other populations that data were collected from were members in a national wilderness education program. The faculty/professional group from the program was interviewed for its remembrance and perception of events, and the wilderness education members were given a survey distributed via the organization's Website.

This grounded theory study was needed because there was a gap in the understanding of the mechanism that described how leadership emergence, rapid change, and decision making converged. A research path that could compare two events, punctuated change and leadership emergence, enabled a new theory grounded in qualitative data to be built. Much of the current research regards change as something that leadership had to deal with, adapt to, manage, control, or predict. The problem of interest was whether change, specifically a punctuated equilibrium model of change, was 
the catalyst for leadership emergence. There was little evidence of a direct link between this phenomenon other than the early studies of Romanelli and Tushman (1985). They discovered that executive leadership had a significant role in mediating punctuated change; however, they did not posit that punctuated change stimulated leadership emergence in executives. Although no literature has been found that described the mechanics of how sudden change, in a defining incident, triggered leadership success or failure, Bennis (2004), a leadership scholar, came close to recognizing this unique connection. The author's perspective on authentic leadership, described as crucibles of leadership, is the unexpected events that trigger a "heroic journey" rather than defeat ( $\mathrm{p}$. 334).

\section{Purpose Statement}

Several theorists are reviving punctuated equilibrium as a critical factor in understanding leadership and organizational change. Robinson (2007) stated that "this area is understudied, but could provide insight . . . as the PET could serve to integrate models of change in individual decision making" (p. 148). This investigation explored the relationship between punctuated equilibrium and leadership emergence. NDM was the broader frame that explains the relationship between punctuated equilibrium and leadership emergence. Any identifiable link among these qualitative variables may have existed only in one's imagination until this research illuminated the causal association between punctuated equilibrium and leadership emergence. Defining and comparing behaviors arising out of the observation of qualitative variables determined the order in which one variable influenced the other. In other words, directionality is established if 
motivating factors occur before observable indicators of leadership emergence. That is the reason why grounded theory was the best approach to the questions that are articulated in the Nature of the Study section.

Grounded theory research is an iterative process that is built on data collection, drawing comparisons, flip-flopping concepts, and analysis (Corbin \& Strauss, 1990). The idea behind this particular research project was to "generate a leadership theory rather than to test theory" (Parry, 1998, p. 85). With that stated, three major concepts live at the core of this research. Both punctuated equilibrium and NDM have single workable definitions; however, leadership emergence does not. To operationalize leadership emergence a variety of traits that may include creativity, courage, and compassion, manifest in the individual. A working definition can be carved out of a collection of characteristics that quickly assemble in an individual for the purpose of service to the common good of others (Bennis, 2007; Sternberg, 2007). Although not excluded from consideration, other potential leadership emergence indicators, such as commitment, communication, charisma, and developing followership, may take longer than a punctuated event timeframe allows to develop and observe. The timeframe under investigation in this study was limited to a brief period lasting from seconds to hours.

A qualitative study using three data collection methods was appropriate for this study because one of the goals of the study was to build a new way of thinking about the directionality of leadership emergence. Interviews, observations, and a survey were used as qualitative data collection methods. The survey, in the form of a multiple-choice questionnaire was used as a qualitative tool to collect data on the decision process 
(Singleton \& Straits, 2005) and behavioral indicators. Although questionnaires and interviews are forms of the survey technique, questionnaires are not commonly used in qualitative research (Trochim, 2001). However, they were used in this study to compare and relate variables. According to Singleton and Straits, “Anticipated relationships are implicit in the researcher's disciplinary focus" (p. 51). To that end, these three data collection methods were chosen to discover relationships and behavioral indicators arising out of simulated punctuated equilibrium and leadership emergence.

Grounded theory was a practical and imaginative way to build theory about a convergence of concepts (Corbin \& Strauss, 1990). Data triangulation between three qualitative methods in a grounded theory study was a significant aspect of this design (Kan \& Parry, 2004). The core purpose of this study was to discover a relationship between punctuated equilibrium and leadership emergence without a preconception of any relationship at all.

Data were collected from three separate populations. The survey vignette in the form of a multiple-choice questionnaire was given to members of the Wilderness Education Association (WEA). There were 430 WEA members accessible through the organization's Website including former students, faculty, and undergraduate students.

The interviews were conducted with professionals who work with critical incident situations. These professionals included critical incident specialists who are also trainers, wilderness leadership faculty, wilderness medical workers, and forest rangers. Interviews were the primary means of data collection with specialists, 5 of whom have observed 
leadership decision making during a major disaster. The critical incident specialists and the wilderness faculty are from the northeastern region of the United States.

The third population, which was accessed through participant observation, includes adults from a variety of backgrounds who participated in a wilderness experience. All individuals in the group, ranging in age from 33 to 76 , were unknown to me at the beginning of the study. Participants had varied wilderness experience and traveled from locations in the northeastern United States and Canada.

\section{Significance of Study}

Every researcher must hope for a significant and resounding effect on the science he or she studies, but the prudent researcher is likely to focus on the most direct effect. The most direct effect or significance of this study was to discover how leadership emergence and sudden, unexpected change were tangibly related in real time. It produced evidence that leadership flows from change rather than supporting the common perception that change is an aberration in the leadership process. In other words, change was typically studied in terms of an event that leaders had to adapt to or manage and it was assumed leadership was already in place to manage change as in the case of trainers, guides, corporate officers, and political leaders. Documenting the evidence, or lack of evidence, that change is a mechanism of leadership emergence, was a critical addition to the research.

\section{Closing the Gap}

"Leadership is easy to identify in situ; however, it is difficult to define precisely" (Antonakis et al., 2004, p. 5). Many leadership studies have preceded this one but none 
has settled on one holistic definition that considers leadership and change as one phenomenon. This study was needed to close the gap in organizational leadership and organizational change literature, providing insight into an individual's leadership ability. The gap, which is metaphorically wedged open with thousands of random ideas, had much to do with the motivation for this study. Random unrelated theories may eventually be replaced with a mechanism to close the gap as researchers begin to see sudden change and leadership emergence as one phenomenon rather than two. Hence, this study fills a gap in the research in two ways. First, the research will enable a new theory to be built to explain a causal relationship between sudden change and leadership that explains how leadership emergence is triggered by sudden change. Second, and as a potential byproduct of the research, leadership and management might finally be defined as two distinctive and unrelated phenomena.

Complexity science models often transcend domains, and this study contributed to the idea that punctuated change and leadership emergence are one interconnected process rather than two. This contribution to the existing body of literature may change the directionality of future investigations, from the popular idea that leaders adapt to events of punctuated change after periods of incremental change, to the new idea that the punctuated change, as a sudden and unpredictable event, rapidly ignites leadership emergence in an individual. The individuals identified here as emerging leaders may hold an official position of leadership or may be individuals who have had no previous experience in an official leadership capacity. 


\section{Contributions to Social Change}

The research conducted may be a significant contribution to the perception that every individual can respond as a leader at any given moment. It may elevate an individual's sense of responsibility to others. Contributing to humanity was a consistent theme in new leadership paradigms that grew out of complexity science, and was expressed as a theme throughout my prior research.

The idea is similar to Wheatley's interpretation of self-organizing systems as a way to understand how everyday people respond in a disaster situation (2006). Her short essay, Leadership Lessons from the Real World, provided some evidence that society is composed of individuals who maintain equilibrium and manage incremental changes until a point in which a crisis stimulates a self-organizing process. The idea that humans can self-organize and help one another under critical decision-making conditions may provide evidence that positive social change can grow out of this proposal. (Moerschell, 2008, p. 42)

The potential for continual positive social change might be found in understanding the phenomenon of emergent leadership because what we learn can be taught to others. Lessons can come from individuals who are committed to the needs of the many rather than of themselves. Those who prioritize compassion, courage, and creativity as primary drivers in decision-making, bring to that process a sense of the interconnected nature of every decision. An individual who accepts a leadership position brings with them the potential to fail to act during a time of emergent need. The most profound implication for social change that this research might provide is a pathway of intolerance for mediocre, marginally responsive leadership as the relationship between leadership and change has the potential to be redefined. Although results of this study can be broadly applied to organizational, political, and group leadership studies, the truest 
significance is that profound leadership ability can be found in the ordinary individual. Their extraordinary actions, as triggered by the conditions of PE, may open a new line of inquiry that unites the disciplines of leadership theory and complexity science.

Nature of Study

Grounded theory is about exploring relationships and continually comparing elements in the data. This qualitative study using grounded theory has been shaped by the methodology as described by Glaser and Strauss (1967), Corbin and Strauss (1991), and Glaser (1978). Techniques of data collection and analysis are described as an iterative process in which the researcher toggles back and forth between idea generation, data collection from the field, and categorizing data in several stages, each advancing in sophistication. This type of methodology was well suited for discovering relationships among several variables that previously seemed unrelated and it requires some imagination from the researcher. Hence, the process of building a theory from comparing data and developing the idea that there is a relationship yet to be defined was an appropriate approach for this study. Grounded theory was a good fit to investigate the relationship between punctuated equilibrium as a sudden change event and rapid leadership emergence because it examined the "interactive nature of events" (Corbin \& Strauss, p. 159).

The choice of grounded theory as a way to investigate this phenomenon was supported in the work of Parry $(1998,2004)$, who not only conducted a grounded theory study of leadership but also detailed why grounded theory was an effective way to investigate the dimensions of leadership. His leadership study will be referenced in more 
detail in chapter 3. Parry's work provided evidence that this qualitative method was a creative way to build a theory while grounding that theory in the data-it could be argued that it as much of an art as a science. The freedom to move backward and forward in the research rather than adhering to a strict linear path, as in an experimental method for example, was well suited to my problem solving style and this study.

It may not be enough, however, to build a theory with only the qualitative method of "proposing relationships among concepts" (Corbin \& Strauss, 1990, p. 23). To guide abstract ideas into a tangible frame, a survey instrument was distributed to wilderness education students. These data were coded as their own set and then later combined with the themes that emerged from the interviews and observations. This will be discussed in detail in chapter 3.

There were challenges in designing a qualitative survey vignette for the wilderness leadership students that attempts to define emerging individual characteristics. To clarify, the data were categorized and coded in a grounded theory methodology rather than a statistical analysis.

A sense of urgency in an individual may be a significant factor in identifying whether the intersection of punctuated equilibrium and leadership results in immediate success or failure. The survey investigated that aspect because the vignette was designed to stimulate the subjects' thinking about a what if scenario. Even though decision-making is implicit in this model, creativity, compassion, and courage represents broad characteristics that shape questions that assess leadership emergence and decision making. Although the grounded theory method of recording and coding data specifies 
that the researcher should not have preconceived ideas, without these targets the goals of the research may be lost.

Corbin and Strauss (1990) and Glaser (1978) discussed how it is advantageous for the researcher to have personal experience with the phenomenon being studied. Experience combined with imagination, prior knowledge from the literature, and creativity are components of theoretical sensitivity. A grounded theory method that required a combination of experience with the population being studied, extensive prior research, and creativity are descriptors of theoretical sensitivity. This described my position with the study and was a personal advantage in the data collection process, especially in observations and in interviews.

Detail and sample instruments used in the study are presented in chapter 3 of this dissertation. Personal observations of students in an outdoor adventure challenge represented a piece of the qualitative part of this study. Qualitative data collection also included interview questions and conversations with critical incident specialists and wilderness leadership educators. A semistructured interview format was used to capture and record their perceptions of leadership emergence during a critical incident, based on their specialized field knowledge and prior experience. Ten wilderness education leaders and faculty and 5 critical incident specialists, who were identified by their primary profession and not by name, were asked to recall events with which they had been involved. The questions explored the subjects' memories and perceptions of leadership behaviors and interactions with actual leadership within the first 24 hours of the critical incident. 


\section{Research Question}

The research problem in this dissertation is stated as follows: How does leadership emergence intersect with punctuated equilibrium, a sudden and unexpected change event, within a naturalistic decision making framework? The subordinate question is; can leadership emergence be observed and identified in these conditions, and if so, what characteristics identify this process of emergence?

This study is driven by an intuitive sense that sudden change and leadership emergence are linked in a measurable way. The study is driven by the desire to close a gap in the literature that has not yet linked these concepts by looking at change as the driver for leadership. Keeping in mind that this is a grounded theory study and the researcher should not have preconceived ideas about leadership emergence, some parameters had to be set to support the investigation process.

\section{Conceptual or Theoretical Framework}

There are four major areas of research behind the development of this dissertation, including punctuated equilibrium theory, complexity science, recent leadership emergence models, and naturalistic decision making. These touchstones have had tremendous influence on the formation of ideas that stimulated the research question. They will be revealed in detail chapter 2 by exposing the most influential theories and models in these categories. They represent a collage of ideas that are stimulating and unique, and that in many ways advocate for a continuance of research that parallels the direction of this dissertation. 
To view one aspect of the organizational process through a complexity science lens holds the potential to see the scope of interaction between sudden change and leadership emergence. The punctuated equilibrium model of change is a sophisticated model from which to view this interconnected process. Gould (2007), Robinson (2007), and Drazin, Glynn, and Kazanjian (2005) are authors whose theories on punctuated equilibrium will be explored. The revolutionary and controversial idea of punctuated equilibrium was introduced by Gould from the domain of evolutionary biology (Mayer, 2007). Gould recaptured evidence of this discovery in Chapter 9 of The Structure of Evolutionary Theory (2002). This particular chapter was recently reprinted as a standalone publication entitled Punctuated Equilibrium (2007). This document will support the origin of the idea from which the diversity of applications for punctuated equilibrium arose.

The diversity of PET adds to its attractiveness for this particular study. According to Gersick (1991), “The most important implications of the punctuated equilibrium paradigm are suggested by the very diversity of the fields that have been affected by it" (p. 33). The variations and intricacies of this theory from several perspectives will be featured in chapter 2. For instance, Robinson's (2007) study of punctuated equilibrium and decision making will be reviewed as a study that intersects concepts. He wrote, "Punctuated equilibrium theory could serve to integrate models of change in individual decision making" (p. 148). The most interesting feature about punctuated equilibrium is that it introduces the concept of urgency and crisis in organizational decision making. According to Drazin et al. (2004), "What is most inviting about punctuated equilibrium 
models is that they formally introduce the concept of crisis into models of change" (p. 176). This statement reinforces its role in this study and opens the door to expand the empirical research of this mechanism. Chapter 2 will reveal original theories, gaps in the theories, and previous studies that have utilized punctuated equilibrium in the study of decision making, change, and leadership.

Complexity science is the second area of investigation that will set up a fundamental and overarching way of thinking. Complexity scientists believe that there is order beneath chaos and that there is not one definitive idea to explain how things work, but rather "a range of theories and models that can be applied to understanding change" (Poole \& Van de Ven, 2005, p. 374). The theorists whose work will be reviewed in this section include Poole and Van de Ven, Schneider and Sommers (2006), and Dooley (2004, whose work will reveal complexity ideas about change and leadership. The literature review will reveal that complexity science theories have had a long-standing application to leadership emergence and change studies (Schneider \& Somers).

Complexity scientists have a lot to say about time. Time is a central issue in the study of change but is often ignored (Poole, 2004), and change theories often regard time as a mere backdrop in the formation of theory. This study, unlike many others, regards urgency as an important factor. Urgent time is implicit in a critical decision making event as an individual's sense of time or, as Poole described it, "the temporal predispositions of people" (p. 23). An individual's sense of time urgency is a component that cannot be ignored in the complex nature of decision-making, leadership, and change. This study 
will not investigate time or urgency, but it is important to recognize that it is inherent in the phenomenon being studied.

The third theoretical touchstone of this study is a very brief review of recent leadership theories that relate directly to the phenomenon being investigated. It is beyond the scope of this dissertation to uncover all relevant leadership theories; however, an attempt to establish how a leader emerges from a punctuated change circumstance is a critical component to this study. To do that, chapter 2 will reveal work within the past three years that investigated the rapid activation of leadership traits, particularly in terms of a critical incident context. Theories that link leadership emergence to problem solving ability, creativity, courage, and compassion are of particular interest. The launching pad for leadership theories as they exist today will include the work of Bennis $(2004 ; 2007)$, Guastello (2007), Sternberg (2007), Zaccaro (2007), and the research team of Byrne et al. (2007). These theorists have set the stage for future research that may reveal the mystery of how, exactly, a leader appears. Bennis, who has studied the triggers of leadership emergence, described instances of unlikely people emerging as leaders in a short span of time triggered by a critical incident. According to Bennis, "We found that something magical happens in the crucible-an alchemy whereby fear and suffering are transformed into something glorious and redemptive" (p. 333).

It is not magic. In describing how leaders emerge in a time of natural disasters, Wheatley (2006) suggested that a sudden, tragic, and unexpected event could change everything. The author wrote that "change always involves a dark night when everything falls apart" (p. 16). The focus of this section of the literature review will support this 
study by identifying gaps in the leadership research that are consistent with the questions in this study. Society's changing values and a higher risk of terror and the unexpected is a call for a new type of leader that may be defined in this research. There is little research concerning the problem-solving abilities that emerge in a critical incident. According to Antonakis et al. (2005), "Interest in understanding practical problem solving abilities of leaders is growing" (p. 10). Recent literature that described leadership emergence with limiters of punctuated equilibrium, decision making, and problem solving in a compressed timeframe and the rapid emergence of traits that include creativity, courage, and compassion were considered for the literature review in the next chapter.

A fourth relevant component to the framework of this study is a relatively new theoretical area. NDM is a model of decision-making that describes a circumstance in which an individual has to make a decision under extreme conditions characterized by a sudden, complex, and often dangerous situation (Carroll, Klein, \& Lipshitz, 2006). Literature on NDM is relatively recent and sparse. Unlike organizational decision making, NDM was introduced to the literature in 1989 by Klein at a conference of decision-making researchers. Literature surrounding this newly discovered area of research signifies not only the essence of the phenomenon being studied but provides a justification for utilizing a critical incident and outdoor leadership challenges as the appropriate way to study the intersection of leadership and change. Recent theories and case studies of Klein and colleagues will be reviewed to support a distinction between decision making that occurs over a longer time span and decision making as an immediate and urgent process. 
Another setting in which the NDM process will be investigated is Galloway's study of decision making in a wilderness medical situation (2007). He looked at decision making factors in wilderness leaders and concluded that more investigation is needed to understand the decision-making process "in the context of a naturalistic decision making" (p. 114).

Very few studies have been found that described an intersection of leadership emergence and punctuated equilibrium as a model for change. In fact, a search of the literature has yet to reveal that much is understood about this intersection. That is why four separate areas of science were investigated in the literature review. Combining pieces from four theoretical frames, a new theory is expected to emerge. With punctuated equilibrium as the core concept driving a study that brings together complexity science thinking, naturalistic decision making, and leadership emergence, this new theory might make a significant contribution to society.

\section{Definition of Terms}

Concepts arising out of complexity science may be considered jargon unique to that field. Several terms associated with complexity science are core concepts of this study. Common terms are clarified in this section so that one meaning is understood and ambiguity about multiple meanings is eliminated. Terms unique to the broad theoretical frameworks mentioned earlier and that are likely to appear in sections of this dissertation are defined. 
Compassion: An empathetic attitude toward other living things that includes elements of emotional connectedness and sensitivity that often influences critical decision making (adapted from Lengbeyer, 2005; Wheatley, 2006).

Complexity science: The study of the interrelationships and interconnectedness among microcosmic or macrocosmic parts. A way of seeing, similar to a kaleidoscope lens, that brings into focus elements that were not visible before. Complexity science illuminates order beneath chaos and complexity that integrates ideas that "transcends the physical, biological, and social sciences" (Schneider \& Sommers, 2006, p. 351) that has recently entered into the study of change, innovation, and leadership behavior (adapted from Poole \& Van de Ven, 2005).

Courage: Individual's spiritual and cognitive strength to pursue a course of action that he/she believes is the best course of action for the benefit of the many, even though the individual faces uncertainty, difficulty, and risk of harm to themselves (adapted from Lengbeyer, 2005).

Creativity: The ability to take disparate things and turn them into something new and useful (Bennis, 2004, p. 334).

Critical incident: An unplanned or unexpected event that triggers a breakdown, or radical and immediate change, in systems and/or individuals. In this study, a critical incident will simulate the punctuated change event that stimulates an individual to respond. It will be used in two contexts: that of an outdoor adventure challenge and a disaster situation (adapted from Caverly, 2006; Drazin et al., 2004, p. 118). 
Leadership: A confluence of skills, motives, behaviors, and characteristics that quickly assemble in an individual for the purpose of service to the common good of others, and not themselves, often triggered by a crucible experience (Bennis, 2007; Sternberg, 2007).

Naturalistic decision making: The study of individual decision-making process that occurs in a situation that is unexpected, sudden, and often dangerous that is associated with a high cost of failure or success (adapted from Carroll et al., 2006).

Outdoor adventure challenge: An unexpected situation faced by wilderness education students, in both academia and professional leadership training that simulates conditions of ambiguity and danger that leads to individual decision making.

Punctuated equilibrium: In organizations: A model of organization evolution defined by extended periods of incremental change, or convergence, punctuated by reorientations or dramatic change that transforms the organization's deep structure (Romanelli \& Tushman, 1985). A simpler definition is, “Organizational change is best characterized as long periods of equilibrium punctuated by brief periods of major change and transformation" (Drazin et al., 2004, p. 173).

Punctuated equilibrium: In physical science: Evolutionary change is not gradual as Darwin implied, but rather, change is quick and sporadic, after long periods when nothing changes. This can be proven in fossil records as proven by Eldredge and Gould in 1972. This was the model for subsequent punctuated equilibrium theories (adapted from Drazin et al., 2004; Gersick, 1991; Gould, 2002). 


\section{Assumptions}

Even though data were collected from three unrelated subject populations, it is assumed that the theory to emerge from the data had significance for organizational leadership studies. The study of leadership through outdoor adventure experiences and critical incident events is not new. Evidence of leadership in these settings was documented in the work of Hahn, the founder of the Outward Bound program in the early 1970s research from the Center for Creative Leadership (Martin, 2007); and numerous other organizations that include Wilderness Medical Associates, the Wilderness Education Association, and finally, several executive training programs that place executives in challenge situations. The recent book by former New York City Mayor Giuliani, Leadership (2002), discussed his own metamorphosis on September 11, 2001. Hence, the rationale behind this approach is that both the outdoor adventure experience and data collected from critical incident specialists inferred that change sparks the emergence of leadership by the very nature of the punctuated incident.

Facts that are assumed true in this study are the following: First, that a critical incident or outdoor challenge provided an opportunity to witness a punctuated equilibrium change event. This concept is critical to this investigation. To review, the PET of change is a sudden and unexpected change event that occurs after long periods of equilibrium or stasis. Since it is not possible to replicate an unexpected event, the researcher must find instances in which this can be simulated. An outdoor adventure challenge is one of the venues in which a sudden change event is likely to occur. An example might be that a sudden and unexpected torrential downpour occurs just hours 
before a group of outdoor leadership students are to cross a normally calm river. Since they are leadership students, the trained faculty guide may choose not to intervene in their decision-making process. It should not be assumed that there are only two solutions, go forward or go back. The outcome of an event that could change circumstances dramatically and increase or decrease the level of risk and harm, might replicate an event in which leadership emergence can be observed during a critical incident.

Next, it is assumed that there will be timely access to the populations under investigation for interviews, observations, and survey distribution. Finally, it was assumed that these are the most appropriate populations from which to gather data and build theory. This exercise will discover and test the leadership potential that may lie in the individual in such a way to complement Wheatley’s (1999) organizational leadership theories and expand upon prior punctuated equilibrium theories.

There are multiple perspectives on leadership emergence and effectiveness and there are many ideas about change, but this study attempted to trap the intersection of change and leadership emergence. It was assumed and anticipated that the study of decision making, particularly NDM, PET, leadership emergence, within a complexity science frame would provide the desired outcome. Robinson, who studied punctuated equilibrium and decision making together, wrote that "punctuated equilibrium theory provides a way out of the theoretical logjam between incremental and nonincremental decision theories" (2007, p. 148). It is assumed that the research will connect decision making, punctuated equilibrium, and leadership emergence as a clustered event. 


\section{Scope, Limitations, and Delimitations}

Research into grounded theory in organizational studies has often been longitudinal occurring over a period of years (Kan \& Parry, 2004). This study, however, was not a study of one organization or industry, but rather three separate populations that, based on their unique experiences within a span of a few months, could build ideas about leadership and change. It was hoped that this study would broaden organizational leadership perspectives. It was critical to clarify that this was not an investigation into crisis leadership, nor was it an exploration of how to make leaders into better crisis managers. Although creativity, courage, and compassion operationalized leadership in this research, it was not a study of creative leadership or leadership traits. It stood apart from creative leadership or one particular style of leadership, such as situational, contingency, transformational leadership, because this study looked for specific cognitive behaviors that provided evidence of a rapid emergence. Urgent time was a limiter to leadership behaviors and for this reason separated it from other leadership models. Additionally, decision models represented a separate and distinct area of study, and even though decision-making was an inherent part of the process under observation, this study did not attempt to form conclusions that challenged current decision models.

The uniqueness of this study is its revival of punctuated equilibrium, particularly in leadership studies. Punctuated equilibrium as a model for change has been investigated in the past in several settings that will be delineated in chapter 2 . The research in this paper did not try to tie all of the punctuated equilibrium models together, but rather contributed one more piece of substantive evidence that punctuated equilibrium is the 
stimulus for leadership emergence. Leadership research has yet to describe the real time mechanism of leadership emergence. The research and work in this dissertation will investigate, in real time, what leadership descriptors ignited during a punctuated equilibrium event.

\section{Chapter Summary}

Chapter 1 has built the framework for the dissertation research. This chapter has proposed how a grounded theory study was to be launched to investigate the relationship between sudden change and leadership emergence. As stated earlier in this chapter, investigating this relationship may require a different kind of thinking-thinking that parallels complexity science theories of change and leadership. This chapter has described the background and framework from which the idea for this study evolved. The following chapters are presented in the spirit of complexity scientists like Wheatley (2006) who stated, "We need to consider carefully what we are learning about leadership in these disaster-laden times. I hope we learn that we can rely on human caring, creativity and compassion (p. 20).

A brief summary of the most relevant points from this chapter begins with the premise that change does not always follow leadership, but rather that punctuated change might precede or cause leadership emergence. To investigate these phenomena prior theories of NDM, punctuated equilibrium, leadership emergence, and complexity science were selected for review in chapter 2. Complexity science is a lens that gives clarity to the interconnected nature of events, domains, and ideas. 
This chapter described a qualitative design from which to research the convergence of punctuated change and leadership emergence within a NDM frame. Leadership emergence was operationalized through evidence of cognitive traits of creativity, courage, and compassion. To address the research questions, data were collected from wilderness education faculty, trainers, and critical incident specialists. Each group's specialized knowledge and unique experiences of leadership emergence in high risk, often tragic circumstances will add breadth to the understanding of individual behavior. This dissertation poses some challenging questions that were investigated; the findings are reported in chapter 4 of this dissertation. Specifics about the research methods used to answer these questions will be presented in chapter 3 .

The next chapter, chapter 2, will present the theoretical cornerstones from which a new theory can be built. These touchstones are from four distinctive fields of study: PET, complexity science, NDM, and leadership emergence. The selection of literature to be reviewed will be limited to theories, models, and ideas that are directly linked to the relationship between leadership emergence and punctuated change. Profound ideas from peer reviewed journals, dissertations, and book chapters, will be organized in terms of the four fields of study. The remaining chapters will present a research plan and describe the process and analysis. The last two chapters in this document will offer the reader a new theory to consider that was grounded in the research landscape. 


\section{CHAPTER 2: LITERATURE REVIEW}

The first chapter of this dissertation revealed that the phenomenon under investigation is the intersection of rapid and unexpected change and leadership emergence. The study of this convergence was described in terms of a punctuated equilibrium model that represents the change event, and a critical incident that will simulate the decision-making opportunity within the change event. Rapid emergent leadership was the expected outcome of matching an individual with the punctuated event. Initial indicators of emergent leadership were identified as creativity, courage, and compassion. The following literature review will provide proof of a gap in the literature that reorients the direction of thinking about change and leadership. This literature review will support the notion that change is not always the product of leadership emergence, but rather, rapid and unexpected change is the stimulus for leadership emergence.

The literature to be reviewed comes from four distinctive areas: punctuated equilibrium theory, selected recent studies in leadership emergence, naturalistic decision making, and an enveloping framework of complexity science, specifically the selforganizing model of change. The complexity science frame will deepen the understanding of time and interconnectedness and most importantly, entice the reader into a divergent way of thinking. Although up to five authors will be referenced, the work of Gould and Robinson will offer two perspectives on PET. Gould and Eldredge, a paleontologist and an evolutionary biologist, challenged Darwin's idea of gradual evolution of species with the proof that species appeared suddenly and unexpectedly in terms of geological time (Gould, 2002; 2007). Robinson, writing on policy theory in the 
Handbook of Decision Making (Morcöl, 2007), put punctuated equilibrium together with organizational decision making in a new model for policy-making. Other important theorists will be mentioned as a point of reference; however, two of the most important punctuated equilibrium theories that connect to organizational change and leadership are from 1985 and 1991. Although dated and frequently referenced in PET literature, the premier work of Romanelli and Tushman (1985) and Gersick (1991) have been integral in the formation of this study and are worth mention.

\section{Overview of Process and Research}

The research path leading to this has been a 2-year journey. As many connections were made between concepts and gaps were realized, specifically concerning how, why, and in whom leadership emerges. The State University of New York library system supports many academic databases and has an extensive interlibrary loan system for books, journal articles, and dissertations. The process of finding relevant literature required developing astute record keeping on searches, results, and dates. Searches for literature ranged from multiple key word searches in multiple databases to accessing materials listed in the references lists of relevant authors and articles. Staying on point was challenging because punctuated equilibrium crossed into many domains. What was not discovered in the search of the literature was a solid connection between leadership emergence and punctuated change.

Recent perspectives on leadership emergence were easier to locate than punctuated equilibrium; however, finding the most suitable mix of theories from which to launch a new theory was challenging. The selection of theorists in four journal articles 
was made based on three criteria: their connection to complexity thinking; second, their support for creativity, compassion, and courage as traits in leadership emergence; and the growing perspective that a new kind of leader is needed for our society, one who emerges because of crisis or sudden unexpected change. Bennis (2004), a professor and author in leadership and change was the closest in identifying the stimulus for leadership that is investigated in this dissertation. Wheatley (2006), who rose to popularity in organizational thinking and leadership in the 1990s, revisited leadership in real world settings in a complexity science frame. A recently published study by Byrne et al. (2007) that examined how leaders think about crisis in real world settings will be critical to this review. A grounding review of Zaccaro's (2007) trait based perspectives of leadership with reference to previous studies helped to build the complete framework for the research to be conducted. A brief summary of the theories of Lengbeyer (2005) and Sternberg (2008) will be included to further the understanding of leadership traits that may include creativity, courage, or compassion as evidence of leadership emergence.

Although the discovery of NDM came late in the building of this literature review, it was not long before it was discovered that NDM was implicit in theory generation about change and leadership in critical situations. A relatively new and enlightening area of study, investigating decision making in critical situations is evidenced through the work of Beare and Lynch (2005) and one of the original theorists, Klein (2000), whose work on analyzing an individual's awareness during critical incidents will be reviewed. Klein has published studies that were more recent indeed, but this essay in particular correlates with the beginning of NDM thinking. Additionally, 
Galloway, a wilderness medical educator, investigated decision-making expertise in a wilderness medical context. Each of these studies will have a direct link to the two areas under investigation in this dissertation, the outdoor wilderness population and the critical incident specialists.

Complexity science provided the context in which a study of leadership emergence, punctuated equilibrium, and NDM could come together. There was a great deal of support for studying leadership emergence and change within this frame.

Complexity science is not old news; rather it has become embedded as a new way of thinking about change (Poole \& Van de Ven, 2004). The appropriateness of studying leadership in a complexity science context is discussed by Schneider and Somers (2006) and Poole and Van de Ven and will justify the unique perspective to be pursued in this study. To be sure, punctuated equilibrium as explained in the self-organizing model of change is only one of several complexity science theories of change. Dooley, a management professor at Arizona State University, wrote a useful meta-analysis of the complexity models of change that was influential in this research path.

\section{Punctuated Equilibrium Theory}

Punctuated equilibrium theory (PET) is a concept that arose out of evolutionary theory, gravitated into complexity science (Drazin et al., 2004), and is the most apt place to begin this literature review. Punctuated equilibrium continues to exist within a matrix of ideas and disciplines including evolutionary biology, paleontology, quantum physics, organizational theory, the social sciences, and group behavior (Drazin et al.; Gersick, 1991; Gould, 2002). It was introduced into organization studies in 1985 with the work of 
Romanelli and Tushman which is now considered the accepted view of organizational change (Drazin et al.). Most of the initial literature found for this review referenced the Romanelli and Tushman studies from 1985 and 1994. There were two problems with this; first, too many studies might have been launched solely from Romanelli and Tushman's interpretation of PET in organizational process. Second, their research in the microchip industry to apply the PET theory is no longer relevant because the microchip industry is gone (Emery, Lewin, \& Weigelt, 2004).

The launching point for this dissertation research was triggered by Romanelli and Tushman's incomplete discussion of how leadership relates to punctuated equilibrium. The previously mentioned study sparked the interest in punctuated equilibrium as a novel way to understand how things change. Simply put, it challenged the common belief that change is a gradual and incremental process that occurs over a long period. PET regards change as a sudden and radical event that upsets the core of the system and settles down in an entirely altered state. This brief period of radical change can be represented as a spike or anomaly sandwiched between long periods of stability. It is often unexpected and alters the fundamental system. In organizational theory, it is referred to as a revolutionary period (Tushman \& Romenelli, 1985). In physics, it is referred to as chaos (Gersick, 1991). In evolutionary biology, it is referred to as punctuations (Gersick; Gould, 2002; 2007).

In this research study, punctuated equilibrium will be referenced in terms of a critical incident. The best way to understand punctuated equilibrium is to return to the original concept within evolutionary biology that, in the mid 1970s, challenged the 
Darwinian view of change. It caused shock and protest in much of the research community (Myers, 2007).

Punctuated Equilibrium in Evolutionary Theory

The work of Gould $(2002 ; 2007)$ has been quoted, interpreted, and linked to punctuated equilibrium in many of the documents investigated in this research. Proof of punctuated equilibrium surfaced in the mid 1970s; however, in 2002 the paleontologist, Gould, published The Structure of Evolutionary Theory that expounded on the work. Chapter 9 of this 1,400 page book is dedicated to PET. With its impact and relevance to evolution and the dynamics of change in multiple domains, Gould's chapter 9 has recently been published as a stand-alone book entitled Punctuated Equilibrium (Myers, 2007).

In evolutionary biology, punctuated equilibrium presented a theory of change that was introduced as an alternative, anti-Darwinian explanation for the evolution of life on the planet earth. Gould and Eldredge discovered, through fossil records, that species arose through a catastrophic, unpredictable, and sudden event. This event would radically alter the course of events to follow. The theory signified that the origins of life had a definitive beginning and ending and suggested that humans are in the middle of a punctuation (Gould, 2002; Myers, 2007). After these relatively short bursts of major activity, life would settle down and continue in a relatively uneventful manner until the next punctuated event.

The Eldredge and Gould research method was pure empirical science. Through a study of fossil records, they proved that there were long periods of inactivity, or stasis, 
punctuated by a sudden appearance of a species. This idea of stasis was slow to catch on with their colleagues in the scientific community, which was a point of frustration to Eldredge and Gould for over a quarter century (Gould, 2002). Eldredge and Gould determined that the species appeared very quickly in terms of geological time (Gould, 2007). In Gould's words, "Punctuated equilibrium addresses the origin and deployment of species in geological time" (2002, p. 765) whose sudden appearance accounted for less than $1 \%$ of their entire existence (Gould). The long held notion of slow evolution was broken and now an accepted theory, punctuated equilibrium, accounted for the "evolutionary transitions in which species become extinct and are replaced by new species" (Drazin et al., 2004, p. 173). This theory of rapid and radical transformations was to become a critical aspect in the worldview of change and integral to a complexity science framework.

The work of Eldredge and Gould may seem to be a very long way away from organizational change theories, but in fact, Gould (2002) recognized the diversity of applications of PET. This surprising aspect of Gould's writing in the text Evolutionary Theory (Gould) was his awareness and prediction of PET as a view of change that could find a home in several domains. Citing metaphors of punctuated equilibrium in the development of art, social structures, group behavior, and technological change, he seemed particularly interested in the work of Gersick. Gersick (1991), who compared six different domains in the punctuated equilibrium paradigm, referred to this type of change as having revolutionary outcomes (Gersick; Gould). The author's extensive study that categorized and compared the work of task teams and five other paradigms represented a 
major body of work. They included Prigogine and Stengers's self-organizing systems dubbed as the Grand Theory, Gould's biological evolution, Kuhn's hard science, Romanelli and Tushman's application to organizations, and Levinson's individuals (Gersick). The purpose of her study was to explore revolutionary change theories and broaden "its general applicability and its special potential to contribute to the study of organizations" (p. 11). The point to be made here is to prove the history, the foundation, and versatility in applying punctuated equilibrium to other domains including leadership.

The domains in which PET as a change paradigm found a permanent home was not limited to the above-mentioned applications. "Punctuated equilibrium represents . . a a broader punctuational [sic] paradigm about the nature of change-a world view that may, among scholars of the new millennium, be judged as a distinctive and important movement” (Gould, 2002, p. 970). Gould was particularly proud that this idea was being developed by scholars in other domains as more than a "vague metaphor" (p. 970). He documented quite extensively, the long reach of this concept into other domains and opportunities. Recently, in 2007, PET has mediated and contributed to the understanding of organizational decision making and policy formation (Robinson, 2007).

Punctuated Equilibrium's Emerging Connections

Executive leadership as mediator of punctuated change was a critical aspect of Romanelli and Tushman's (1985) study, but there are not many new ideas coming out of that study today. Punctuated equilibrium's connection to leadership rarely surfaces to the top of the discussion and it appears that opportunities for research are scattered throughout the literature. Cognizant that many concepts about leadership and change are 
complex and concurrent, complexity scientists continued to explore applications for punctuated equilibrium and its mechanism. A strong indication of this appears in a comparative study of structural change that built on the concept of logics conducted Drazin et al. (2004). Drazin et al. took the position that logics represented the underlying "glue" that held the organization together included the meaning, purpose, and values that were embedded in its core (p. 65). The study presented how change and innovation occur within an organization by identifying its deep core structure or underlying logic that is "embedded in the structure at the time of its construction" (Poole \& Van de Ven, 2004, p. xv). An extensive review of complexity literature led Drazin et al. into an innovative view of change in various complexity models.

In their punctuated equilibrium model, change was described in terms of Eldredge and Gould's concept that there were long periods of equilibrium punctuated by bursts or transformations. They drew upon Gersick's work to articulate two distinctions with this model from other theories of change. First, that change is not gradual, and second, that it does not take a path of "predictable progress" (Drazin et al., 2004, p. 173). Although they claimed that the punctuated equilibrium model has never been fully tested, they made a compelling claim that punctuated equilibrium presents a "powerful new metaphor for change into our organizational lexicon" (p. 174). However, they identified the gap between punctuated equilibrium and the role of crisis in organizational transformation. They proposed that crisis has a bigger role in transformation than researchers have yet to discover. 
Punctuated equilibrium formally introduced the "concept of crisis" into a change model (Drazin et al., 2004, p. 176). They argued that crises could represent "exogenous jolts" to the underlying organizational logic (p. 176). Their article did not explain how this has happened, but rather, how it could happen. They referenced the work of researchers who have studied the "sociopsychological [sic] effects" of critical change on members of an organization. They referred to the dramatic change event as critical incidents or "organizational breakdowns" (p. 181). This is the point at which the organization would come apart before it could reassemble. It is the point that disrupted the deep logic, or its deep structure (Drazin et al.; Romanelli \& Tushman, 1985; Gersick; 1991).

How crisis and leadership interact in a punctuated equilibrium frame has yet to be understood; however, this is one of the only studies to hint at a connection waiting to be discovered. There is no dispute to be made when, at the end of their discussion, Drazin et al. claimed, "that crisis shifts structures of power and meaning" (2004, p. 182). This implied a punctuated change or a large unexpected disruption does not cause the entity to settle back into the same place it was before the critical incident which, is a truism throughout the study of punctuated equilibrium. Their final point, however, that these events are "reversible and temporary" (p. 182) does not seem to be consistent with PET. A punctuated change on the level of crisis or organizational breakdown does not flow back to its previous existence. A punctuated change event creates a new level of existence. 


\section{Robinson's Ideas About Organizational Decision Making}

The research path in terms of discovering punctuated equilibrium was much like the decision to buy a new car. I wanted to take it for a ride, kick the tires, and scratch the paint before I decided to own it. Robinson's (2007) contribution of PET to organization decision making helped me to own another piece of the concept. His analysis is important to the upcoming research and theory building for three reasons. First, it integrated the domains of policy and decision making with punctuated change as a solution to understanding the rate or speed of change. Second, he explored the application of hypothesis testing and regression analysis. Although no attempt will be made to apply a statistical analysis to the convergence of leadership and change in this dissertation, the idea that punctuated equilibrium could expand into a testable hypothesis presented another launching point for researchers to pick up the study. Finally, and most importantly, Robinson provided justification for punctuated equilibrium in the organizational decision process. At issue is the debate between incremental and nonincremental decision theories (Robinson). Written for an audience of policy makers, Robinson advocated that an understanding of punctuated equilibrium bridged the gap in decision science literature that integrates models of organizational and individual decision making. The Robinson study began to make connections into organizational domains that indirectly connected with leadership. The distinction between leadership effectiveness and the spark for leadership emergence will begin to surface in the following section of this literature review. 


\section{Recent Theories in Leadership Emergence}

A stimulus for the forthcoming research was to gravitate away from the peculiar concept that leaders can learn how to lead change. Leading change, particularly in a dynamic organizational environment, could be viewed as practical as learning how to drive a runaway bus. How the change event influences leadership emergence in the individual is a pragmatic approach with regard to punctuated equilibrium. Four pieces of the puzzle will be assembled that provide the best linkage to understanding leadership emergence in the frame that it is being studied here. Bennis (2004) and Wheatley (2006) provided scenarios and historical accounts of how leadership emerges after a critical event. Byrne et al. (2007) examined leader cognition in a real world crisis setting through a theoretical model. A brief reference to Zaccaro's (2007) trait based perspectives of leadership will ground and update theoretical history to the literature reviews. Although not reviewed in detail, supporting evidence for creativity, courage, and compassion, as manifestations of sudden leadership emergence, will be supported in this section by Lengbeyer (2005) and Sternberg (2007). These theorists have set the stage for future research that may reveal the mystery of how, exactly, a leader appears.

\section{The Crucibles of Leadership}

This section is a review of an essay written by Bennis as the concluding chapter of The Nature of Leadership (Antonakis et al., 2004). Bennis (2004) merged and elevated several ideas critical to this dissertation, leadership emergence and critical incidents. Implicit in this discussion are aspects of decision making, creativity and intelligence. Leadership theory provided a backdrop to this essay that analyzed leadership emergence 
in real life crisis settings. One well-known incident included the terrorist attacks in New York City on September 11, 2001 and the sudden emergence of leadership ability in then Mayor Rudolph Giuliani. Crisis as trigger for leadership emergence is not completely understood, however, Bennis (2004) referred to his previous research and interviews of over 50 leaders who identified a single critical and defining event, a crucible, as the point their leadership ability emerged. These life or death moments in the leaders' history characterized one type of authentic leadership ability. Bennis noted that common attributes of these leaders included optimism, intelligence, and creativity.

The emergence of authentic leadership ability in often-unlikely candidates was represented within four criteria. The essential competencies that Bennis (2004) associated with authentic leadership emergence were "adaptive capacity, the ability to engage others through shared meaning, a distinctive voice, and integrity" (p. 334). He described adaptive capacity as creative ability, specifically, the creative problem solving ability witnessed in "unprecedented problems" (p. 334). Bennis's description of authentic leadership strikes a chord that can be played in this dissertation research because he identified an area yet to be studied that examined elements of leadership emergence and decision making in an unexpected critical event.

The revealing nature of amoral, or "morally neutral" (Bennis, 2004, p. 337) and noncoalition building leadership is sharpened by contrasting historical examples of real world leaders. The prior investigations conducted by Bennis ranged from the leadership ability of Khrushchev to executives at Enron. A specific example of powerful leaders whose influence is not challenged by groups or individuals, when it should have been, 
was the first important message in Bennis's editorial on leadership. The second message that emanated from this literature was the need for further research in globalization and leadership and the effect the media has on the public's perception of leadership.

Although several compelling points were made about how society looks at authentic leadership, the inspiration derived from this article is firmly centered on the crucibles of leadership. In other words, his analysis of major critical events that trigger leadership emergence and his short journey of proof may remind leadership researchers, including this one, that unexpected critical events may be closely linked to leadership emergence. Bennis, who concluded that the most unlikely leader may emerge alongside a powerful leader, stated that " $9 / 11$ was a compelling reminder that war and other violent crises are inevitably crucibles from which leaders emerge" (2004, p. 332). The question that remains for this upcoming research to discover is how.

\section{Leadership in Real World Crisis Settings}

Bennis was not the only author interested in leadership emergence during a moment of crisis. One of complexity science themes, humanity, prevailed in a published essay of Wheatley in Leader to Leader (2006). Wheatley is the president emeriti of the Berkana Institute of Leadership, as well as an author, lecturer, and leadership consultant. Written as a response to the challenge that her theory of leadership could not work in the real world Wheatley explored how every person has the capacity to "self-organize" in times of crisis (p. 16). By way of review, Wheatley's groundbreaking approach that constructed a new science for organizational leadership in the mid to late 1990s followed on the heels of complexity scientists Capra, Prigogine, and others. This relationship- 
centered concept of organizational theory was an amalgam of ideas that came from the domains of quantum physics, systems theory, and biology (Wheatley, 1997). Selforganizing systems were a central concept of her work and the focal point of the 2006 essay. Self-organizing systems are entities with the capacity to reorganize during a threat or disruption organizational equilibrium (Dooley, 2004; Wheatley, 2006).

Crisis as a manifestation of unexpected and punctuated change and leadership emergence come together in Wheatley's interpretation of self-organizing systems. Her essay, like the essay of Bennis, used real world examples of leaders rising out of the ashes of disaster. Hurricane Katrina, the Oklahoma City bombing, and the World Trade Center attack provided evidence that spontaneous leadership emerged in individuals, who are not in official leadership positions, out of compassion for one another (Wheatley, 2006). Wheatley's assessment of the official leadership during Hurricane Katrina and Oklahoma was less than complementary. Wheatley argued that bureaucratic mires slowed down the recovery process and undermined the systems ability to self organize (Wheatley). The author identified creativity and compassion among the attributes that emerge in individuals who are suddenly faced with unexpected and large magnitude change events.

The most significant message in Wheatley's (2006) essay was that leaders are already here-that they exist among common people in society whose leadership ability can and will emerge the moment it is needed. Although there are many parallel themes in this essay that connect the theory awaiting to be built out of pieces of punctuated equilibrium, leadership emergence, and NDM, there is little more than historical 
reference to go by. This article did nothing more than apply theories from her 1992 publication to contemporary events. With that said, these contemporary events will be included in the forthcoming research interviews with critical incident specialists. The work of Byrne et al. (2007) offered a systematic and measurable approach to view leader cognition and emergence in real world settings.

In the 2007 article published in The Leadership Quarterly, Byrne et al.'s metaanalysis of leader cognition models in crisis conditions linked the concept of crisis together with change. The lack of distinction between "organizational crisis and change problems" (p. 536) created a problem in interpretation from the onset of the discussion. The central issue under investigation was "how leaders think about crisis or change events" (p. 516). In other words, they identified a significant gap in the leadership literature in terms of the cognitive variables in motion when a leader is faced with a change decision. It seemed immediately apparent that crisis was defined differently than the previous articles positioning it as a mundane everyday change event rather than an unexpected and sudden punctuation. The article later revealed in fact, that crisis was a "change from standard operating procedures, where this change has significant implications for performance and people-potentially both positive and negative consequences" (p. 521).

The initial review of Byrne et al. (2007) of the cognitive elements that emerged from prior studies were intelligence, intuition, creativity, wisdom, decision-making ability, vision, tacit, and schematic knowledge. These descriptors fell short in the search for rapidly emerging leadership characteristics in crisis; in fact, the authors admitted that 
studies that examined how a leader thinks, the cognitive manifestations, do not have a common focus. The lack of focus between concepts was evident in the process model of leader cognition. It was as difficult to understand, in my opinion, as a biochemical diagram of a thought process. To reiterate, the ambiguous distinction between crisis and change may have been why the authors struggled with building a model.

Byrne et al. (2007) claimed that "leadership makes a difference under conditions of crisis" (p. 521). One might argue that one of the studies they referenced to support this claim was faulty. They referred to the Bligh, Kohles, and Meindl's study published in 2004 that examined the change in intensity and language used in George W. Bush's speech rhetoric before and after the terrorist attack on the World Trade Center in 2001. It did not support the claim that leadership made a difference but rather it was a statement on rhetoric. It is a common notion that most politicians have speechwriters that write to reflect the mood and tone of the nation and popular culture at the time. Whether or not this was the case in these particular speeches, it is my opinion as an instructor in public speaking, that this was a distracting and controversial example to use in measuring leader cognition.

There was no doubt that the title and abstract of this article about how leaders think about crisis could lure one into further examination. Even though it fell short of building a platform of significant findings from which to launch new theory, it created a significant list of gaps to fill. Specific gaps in the research that were identified included models that addressed time pressures, continuity in situational settings, cognitive variables, and the process in which leaders actually solve problems in a crisis situation. In 
their summary, Byrne et al. (2007) opened a door for the direction of the research contained in this dissertation.

Crisis or change problems of the sort presented to leaders evidence certain unique characteristics such as complexity, ambiguity, novelty, consequences, and time pressure. Clearly studies of strategies are most likely to prove useful if they take these attributes of crisis or change problems into account. (Byrne et al., p. 538)

\section{Traits That Describe a Punctuated Equilibrium Leader}

The search for leadership traits and attributes associated with punctuated change and leadership emergence was similar to putting a puzzle together using various pieces of the literature. This section presents a collection of some of the most relevant points found in recent leadership literature that support creativity, compassion, and courage, among other traits.

The research of Bader, Kemp, and Zaccaro (2004), and Zaccaro (2007), provided an extensive history of leadership trait research beginning with Lao Tzu and Plato. The most important aspect of this historical review was that it affirmed that researchers are beginning to put ideas together in complex configurations by integrating leadership traits and circumstances (Bader et al., 2004). They rekindled attributes of higher intelligence, creativity, divergent thinking, and cognitive complexity as triggers of leadership emergence and ability. According to the authors, creativity and divergent thinking are the strongest predictors of leadership achievement (2004). Trait complexity extends into personality, motivation, and social appraisal skills that involve emotional intelligence. Specific connections to punctuated change events within this collection of attributes were 
not obvious; however, responsibility motives and tacit knowledge lending itself to problem solving skills seemed to imply a connection.

When it comes to a discussion of traits and attributes, the distinction between leadership emergence and effectiveness is fuzzy. Zaccaro (2007) raised the question of whether a study of attributes more strongly predicts emergence or effectiveness. Hence, the problem in the literature was that very few connections were made between a situational variable like a critical incident, and leadership attributes (Bader et al., 2004). Even though cognitive attributes like adaptability and risk propensity are among the characteristics associated with likely predictors of leadership emergence (Zaccaro), there are abundant research opportunities to identify the triggers. This is further proof that time and urgency, outside of the complexity science frame, has been a missing variable in leadership trait studies.

The interconnected nature of traits as part of a whole, characterize the emergence of leadership. Zaccaro (2007) and Sternberg (2007), among others, began to recognize a synthesis of cognitive abilities with creativity at the core. Creativity is a main attribute associated with critical problem solving ability in a leader (Bader et al., 2004). Creativity, often associated with intelligence, is a necessary component in understanding the behaviors for the leader who spontaneously emerges in a crisis (Bader et al., 2004; Bennis, 2004; Sternberg, 2007). Bader et al. (2004) cited studies in which creativity, also referred to as divergent thinking, has been linked to a leader's ability to negotiate complex problem solving contexts. 
Among the integration of leadership traits, (Zaccaro, 2007) creativity, compassion, and courage will characterize the rapid appearance of leadership in this study. Sternberg's (2007) model of the synthesis of creativity with wisdom and intelligence amplifies the findings of trait researchers. But the concept of integration and synthesis is relatively new to the study of leadership and binds closely inside the complexity science framework. Although volumes of creative leadership studies and the models of divergent thinking linked to leadership success make great reading, the interest here is how these three traits work together. According to Sternberg (2007) describing the synthesis of leader traits, "integration is a key means by which progress is attained in the sciences" (p. 36). New directions for theory building in the leadership research are flowing toward the integration of multiple traits (Avolio, 2007). The task of building theory of rapid leadership emergence during punctuated change will not be limited to observing the integration of these three traits, but will include situational awareness (Klein, 2000) and rapid high stakes decision making.

The behavior of Mayor Giuliani and the city's government officials during the events that followed September 11, 2001, are imprinted on the hearts and minds of most of world (Bennis, 2004; Giuliani, 2002). The disaster situation epitomized the nature of rapidly emerging leadership with strong indicators of creativity, courage, and compassion. Courage was immediately apparent, when for example, Mayor Giuliani was on the phone to the White House in a then deteriorating city hall, unaware that the sound he was hearing was a tower collapsing and debris flying rapidly toward him. An aid jumped over the desk, grabbed the mayor, and shoved him under a desk to safety 
(Giuliani). Could this action be considered a selfless act that characterizes a newly emerging leader and; can they be connected to courage and compassion? Compassion and crisis are not typically associated with one another, but a promising view of leadership may stress empathy for others is "more than relevant, it is integral" (McKee \& Massimilian, 2006, p. 48).

Courage is associated with compassion simply because acts of courage imply a heightened awareness, a situational awareness, for the well-being of others (Klein, 2000). It is among the cognitive aspects of swiftly emerging leadership that is connected to selfless behavior (Lengbeyer, 2005). Often associated with heroic leadership, courage is the ability to carry out a task with the awareness of risk to oneself and others (Lengbeyer). On the matter of decision making, courage to stand behind a decision and execute it without regard for one's self is a characteristic of leadership unmatched by many. Knowing what to do and actually doing it may explain the difference between leaders who are in name only and the type of leader who emerges successfully in a crisis (Lengbeyer).

The kind of leadership emergence, punctuated change event, and decision-making matrix that this research is attempting to reveal is that leadership ability may exist in every person. In the leadership emergence literature there is a noticeable gap in understanding the mechanism of leadership emergence and crisis situations (Bennis, 2004; Zaccaro, 2007). According to Brown, Lewis, and Scott (2004), “Several studies have shown that crisis contexts enhance perceivers' attributions of leadership ... and that crisis may unconsciously activate the leader category" (p. 143). Studies in decision 
making during a critical incident are very similar to the studies of rapid leadership emergence during a sudden and unexpected change event. The following section discusses NDM as the third major domain from which my study will be launched.

\section{Naturalistic Decision Making and Critical Incidents}

The core of this research study is to investigate what leadership behaviors emerge immediately in a punctuated equilibrium event. The mechanism that connects punctuated equilibrium to leadership emergence became known through the theory of NDM. It may provide a valuable link in the research because the uncertainty, urgency, and danger that can be present in an outdoor adventure experience simulate decision making in real world settings (Beare \& Lynch, 2005; Carroll et al., 2006). NDM as an opportunity for study came about through a discussion with the research director at the WEA who directed me to the research of Galloway. Galloway (2007) conducted a quantitative study in medical decision making and its relationship to outdoor leaders' experience. Also reviewed in this section are Klein's (2000) studies in critical incident decision making that affirms the direction of this research. Finally, the research of Beare and Lynch's (2005) outdoor leadership decision making will be reviewed.

Decision Making in the Wilderness

Galloway (2007) attempted to find a relationship between experience and decision making through a quantitative method in an attempt to "operationalize [the] experience" (p. 101). Using Factorial Decision Vignettes, a short story of a simulated critical situation that was likely to occur in an outdoor wilderness, he was able quantify a relationship. He administered 20 vignettes "randomly selected from a pool of vignettes" (p. 105) to 103 
subjects from a sample of field instructors in two separate Outward Bound schools (p. 107). Similar to the Beare and Lynch (2005) study reviewed later, Galloway's research justified the use of simulated events to investigate emerging cognitive attributes. That is important because chapter 3 of this dissertation will describe research methods that are built from some of these ideas.

The data collection activity in Galloway's (2007) research resulted in a pool of 2,060 different decisions. Using a grounded theory selective coding process combined with quantitative data analysis methods, he was able to conclude that experienced leaders tended to have more cognitive resources from which to make a decision, and were less influenced by the group. The more profound result of this study was proof that naturalistic decision making, as shown in the medical decision-making context, is a complex and "multifaceted construct" (p. 114) from which to study relationships between experience and decision making. It could be projected that leadership ability is implied, and the gap as identified by Galloway, was that more study is needed to consider the many environmental and social-psychological variables involved in the process.

Experience was a factor in Beare and Lynch's (2005) comparative study of decision-making strategies in unknown and unexpected situations. Lynch is a senior lecturer and scholar in outdoor education. Beare is an experienced mountaineer who, in 2001, studied the decision-making process of 23 expert kayakers and mountaineers. His 2001 study concluded that "experts assess situations in an active, ongoing way by seeking out typical cues and anomalies rather than passively waiting for an indication that something is not right" (Beare \& Lynch, p. 214). 
The Beare and Lynch (2005) comparative study of rational decision making and the unique qualities of natural, or intuitive, decision making integrated some themes of emerging leadership in unexpected change situations. They defined their area of research as how an individual "naturally" (p. 212) makes a decision in real world settings. These setting that NDM tended to occur are uncertain, dynamic, constrained by urgent time and "high stakes" contexts (p. 212). Reasoning, imagination, awareness, and memory are among the cognitive qualities that funnel into the problem identification and problem solution process characterized by NDM (Beare \& Lynch, 2005).

Uncertainty, a constant variable in outdoor adventure experience, creates a unique set of parameters for decision making. The brief comparative study of Beare and Lynch (2005) provided evidence that real world decision making has value in identifying which cognitive variables rapidly ignite in the individual. It introduced the possibility that imagination and intuition, which are often associated with creative thinking, may be measured in the NDM process. Awareness and appraisal of a situation are two additional elements that imply rapid emergence of the cognitive ability to identify and solve a problem. Situational awareness in particular, consumes much of the field of study in NDM (Beare \& Lynch; Klein, 2000).

\section{Situational Awareness}

Situational awareness facilitates a better understanding of what may be an essential core competency from which decisions are based. Building upon the work of Klein (2000) and others, Galloway's (2007) study is nothing short of impressive in its exploration of factors that influence the cognitive process of leaders, and those to become 
leaders, in a critical situation. The search for wider domains of critical incidents through which to investigate naturalistic decision making led to the work of Klein. The investigation into the phenomenon of situational awareness with respect to critical incidents and decision-making process, reviewed next, provided some welcome support for the direction of this dissertation.

Klein, chief scientist and chairman of Klein and Associates, was interested in the study of decision making in various domains and developed the model known as Naturalistic Decision Making (Endsley \& Garland, 2000, p. xix). His interest, which is closely related to a critical element in this dissertation research, is of decision making "under conditions of stress, time pressure, and uncertainty" (p. xx). An older version of his research on critical incidents was used because it anchored the concept of NDM in relation to punctuated equilibrium and leadership emergence. Cognitive traits and attributes that were articulated earlier in this essay were investigated under conditions of rapid change, or critical incidents.

Klein (2000) investigated the phenomenon that situational awareness was linked to decision-making performance in various critical incident events. The relevance of situational awareness was defined as the perception of elements in the environment that determine reactions to rapidly changing events (Galloway, 2007; Klein), to the study of decision making and critical incidents was broken into four items. They were that situational awareness was, a) linked to the performance of the individual, b) lack of awareness, or limitations, may lead to errors, c) that situational awareness may be related to expertise, and most importantly to my study, d) that it is the basis for making decisions 
in natural conditions (Klein). Critical incidents, according to Klein, are the best way to "the nature of this complex phenomenon" (p. 69).

The work of Klein (2000) exposed a huge field of techniques that could enable research and discovery. To investigate how an individual recognizes what to do immediately in a crisis, two types of research techniques were identified: the retrospective accounts from observers' memories during a critical incident and the process-tracing method. The latter, which is a real time activity, is the process of observing critical decision making while it is actually happening (Klein). The method of retrospective accounts was used in the interviews with critical incident specialists in this dissertation and it is described as an interview method that explores decision-making activities recalled by people at the events (Klein). Both of the methods, according to Klein, “depend on introspection because researchers ask the participants to articulate what they are seeing, noticing, inferring, and interpreting" (p. 66).

Suggestions for research methodology, the types of interview questions that need to be considered, and the methods of analysis were helpful in solidifying ideas emerging out of this literature review that will be articulated in chapter 3. The Klein perspective that was shared in Analysis of Situation Awareness from Critical Incident Reports (2000) was useful in expanding the knowledge base of future researchers with regard to framing the questions and narrowing the focus.

Complexity Science Views on Change, Time, and Leadership

The fascinating aspect about the complexity frame is that it proves that leadership and sudden change cannot be contained to one area of study. The discovery of whether a 
rapid and unexpected change can be the stimulus for leadership emergence may be found within the complexity theory frame. Complexity science and the popular phrases that emerged from its roots in chaos theory and general systems theory have been thought by some to be trendy and no longer valid in the study of organizations (Davenport, 2003). There is little doubt that the literature in complexity science is, at the very least, confusing because of the abundant metaphors that blur the clarity of concepts and processes. Nevertheless, the complexity science frame will deepen the understanding of change, time, and leadership. One does not have to look far to find authors who continue to carry the complexity science torch of understanding in multiple domains including change and leadership. Schneider and Somers (2006), and Poole and Van de Ven (2004), are among the authors who advocate for complexity science as a way of seeing and understanding.

\section{A Complexity Science View of Change}

Poole and Van de Ven's publication, Handbook of Organizational Change and Innovation (2004) is a robust collection of change perspectives in the complexity science framework. One chapter in particular, written by Dooley, a professor and author, provided clarity about the complexity science view of change. In fact, Dooley (2004) precisely articulated four distinctive models of change that arose from the empirical side of science. In doing so, Dooley was able to eliminate the multiple meanings of popular phrases like open system, complex adaptive, equilibrium, and self-organizing and put them in their proper place. 
The four "complexity science-inspired models organizational change" that Dooley (2004, p. 354) discussed are complex adaptive system models, computational models, dynamical models, and self-organizing models. Each has a distinctive process of change that is connected to either the molecular level or the organizational level. The first three models will be described briefly, but the self-organizing model is the most relevant to leadership emergence and punctuated change research.

Complex adaptive system models imply change is continuous and evolving. Agents or entities within this model learn how to adapt to that change to insure their own survival. The system is an interconnected system, like an organization, that cannot be separated into parts. The system works to guard against threats from the outside environment. The relationship of agents within the system and their ability to network and share information is familiar to many as the complexity science organizational social structure (Dooley, 2004).

Computational models of organizational change and dynamical models of organization change rely on simulations of the process. Out of the computational models, concepts like cellular automata and rugged landscape arise. With regard to change, small changes can lead to larger changes that are more significant in the system (Dooley, 2004). The rugged landscape model of change that is characterized within the computational model has introduced different ways in which agents, or people in the system, learn. Both computational models of change are represented by a computer simulation of local "interactions between the parts" (Dooley, p. 355). 
Dynamical models represent change among variables in a system in mathematical terms. Parts are in constant motion and are continually changing. Once change stops the system is "dead, quite literally" (Dooley, 2004, p. 365). The dynamical model of change has four distinctive patterns, or mathematical dimensions, in which familiar phrases emerged. They are white noise that represents "pure randomness," pink noise that represents "constrained randomness" and chaotic process that is characterized by "control and cooperation" (Dooley, p. 366).

To summarize, these three models are conceptualizations of change in systems, organizations, or individuals (Dooley, 2004). They each describe the interrelationship among parts of the system that is dynamic. Each model is "generic" and can be applied to different domains to describe the change process (p. 356). Of the four categories, the selforganizing models of change provided the closest explanation to the change phenomenon being investigated in this study. The concepts within the self-organizing model of change support the idea that change is sudden and dramatic.

The self-organizing models are characterized by "interconnections and interactions" (Dooley, 2004, p. 355) but more importantly, this model described the dissipation of energy creating a "far from equilibrium state" (p. 367). The interest in exploring leadership emergence in terms of a self-organizing system is not diminished (Guastello, 2007). In terms of the type of change that is of interest to this study, the selforganizing model described an event that triggers a rapid disorganization in the system. Goldstein's research from 1998 as cited by Dooley in the description of this process, most accurately described the potential connection between leadership emergence and 
punctuated change to be investigated. Goldstein (as cited in Dooley) described the selforganizing process as “"the spontaneous emergence of novel patterns and configurations; the amplification and incorporation of random events; the discovery of creative alternatives for functioning; and the arising of new coherence and coordination amongst the parts of the system"' (Goldstein as cited in Dooley, p. 368).

The interesting idea emerging out of this work is that crisis is the trigger for a self-organizing model of change (Dooley, 2004, p. 368). A complexity science framework is the only framework that supports a reverse direction of events and is the first hint that change might cause leadership emergence. The nonlinear, nonevolutionary conceptualizations of change captured by this model may move researchers into a divergent way of thinking. The self-organizing description of change invites the paradox that the system does not change the environment and the environment does not change the system; rather, "the environment triggers internal mechanisms that are the source for transformation" (Dooley, 2004, referencing the work of Maturana and Varela, 1992, p. 368). In other words, a crisis as an opportunity for punctuated change is the trigger from which other entities may emerge and transform.

\section{A Complexity Science View of Time}

Dooley (2004) claimed that time was the "most significant variable" in all of the above models (p. 370). Complexity science defined the tempo of time as an individual's sense of urgency in a situation. An individual's sense of time urgency is a component that cannot be ignored in the complex nature of decision making, leadership, and change. How leaders, or potential leaders, respond to "complex [and] unpredictable patterns of 
change" (Schneider and Somers, 2006, p. 354) create an image of an emerging leader as highly sensitive to time. Dooley, like Poole and Van de Ven (2004), recognized that time has been a missing element in the study of leadership and change. A combination of views that change is continual, social settings are dynamic, and that leadership's role is "revolutionary more than evolutionary" (Schneider \& Somers, p. 354), are additional justifications for considering complexity science within the framework of this study. A Complexity Science View of Leadership

The importance of complexity science to the study of leadership has not been fully realized; however, Schneider and Somers (2006) supported the view that future researchers should continue to try to understand leadership in this frame. Leaders arising out of a complexity model may not be aware of their role or the rate in which emergence opportunities appear. This type of leader, different from an incremental and compliant leader, "frequently leads without authority" and in a sudden and temporary capacity (Schneider \& Somers, p. 356).

There are yet to be identified linkages among leadership, change, and the complexity process-a relationship characterized by "complex unpredictable patterns of change" (Schneider \& Somers, 2006, p. 354). The ability to understand how change and leadership fit together in this paradigm is central to building, rather than testing theory (Schneider \& Somers). The opportunity to investigate rapid success in terms of forward momentum, or failure in terms of non action, fits well in a complexity model. Complexity science is a means to connect a new view of leadership with the underlying theme that order lies beneath chaos (Pool \& Van de Ven, 2004; Schneider \& Somers). More 
importantly, and a point that speaks to the core of this investigation, is that an emerging leader's profile is connected to selflessness, courage, and compassion. This theme was articulated by Schneider and Somers, "Some researchers have been provocative . . . in tying the sense of order under Complexity Theory to spirituality and improvement of the human condition, but are vague regarding inferences for leadership" (p. 351).

To summarize, complexity science provided the context in which a study of leadership emergence, punctuated equilibrium, and NDM can come together with factors of human spirit (Poole \& Van de Ven, 2004; Schneider \& Somers, 2006). It identifies crisis as a model of change and questions how variables might interact in a crisis, which is central to the change process. Complexity science is an appropriate launching point for theory building without being restricted by the confines of a single domain. The study of leadership and change within complexity science enables researchers to extend past the limits of disciplinary boundaries and consider "a new set of ideas that transcends" these domains (Schneider \& Somers, p. 351). Complexity science, particularly with regard to leadership, is a science that gives researchers a lens to view a "phenomenon as comprised of multiple interacting agents" (Poole \& Van de Ven, p. 394).

\section{Conclusion}

The goal of this literature review was to integrate research from various domains to build a platform for the research and theory articulated in chapters 4 and 5 . A collective analysis of the literature may not be possible; however, a foundation was established and gaps were identified. The most significant outcome of the literature review was confirmation of a gap in the relationship among punctuated equilibrium, 
leadership emergence, NDM, and complexity science. An attempt to close this gap through a carefully selected research design is the subject of chapter 3 of this dissertation. The articles in the literature review were chosen to build a theoretical foundation that pointed the direction for data collection and analysis. Theories occasionally overlapped and provided ephemeral linkages among concepts. For example, naturalistic decision making brought crisis together with leadership emergence by the nature of the process (Klein, 2000). Punctuated equilibrium theory united crisis with time and implied a rapid decision-making process (Poole \& Van de Ven, 2004; Robinson, 2007). Lasting and definitive connections have not yet been established between the four. The stimulus to rethink leadership emergence existed within the complexity of forces that describe social networks (Avolio, 2007). The overarching structure of complexity science is the place in which the concepts can unite.

\section{Summary}

Through a rigorous selection process, only the most relevant studies that had the most direct connection to two or more elements were included in this review. The literature review included the original concept and recent spin offs of PET, recent ideas about leadership emergence including trait theories, and the relatively new field of NDM. Additionally, this chapter provided justification that the frame of complexity science is the most appropriate lens through which to view a process of leadership and change intersecting.

The literature review began with the background theory of PET as articulated by Gould who, together with Eldredge, replaced Darwin's idea of gradual evolution with 
punctuated and sudden appearance of species (Gould, 2002; 2007). The concept of punctuated equilibrium has enjoyed extended applications into other domains since the mid 1970s. Included among the applications were decision making, organizational change, leadership, quantum physics, biology, and team behavior.

Recent perspectives on leadership emergence were accentuated by examples derived from the book Leadership (Giuliani, 2002) and perspectives on leadership in crisis settings. Scholars who had begun to relate these settings to triggers of leadership emergence were of most interest. Leadership in real world settings was described by Bennis (2004), Wheatley (2006), and Byrne et al. (2007). Personality traits connected to this phenomenon were revealed through the work of Bader et al. (2004), Zaccaro (2007), Lengbeyer (2005), and Sternberg (2007).

Naturalistic decision making as connected to situational analysis, critical to leadership ability, was described by Klein (2000). His work was a significant contribution to this investigation because it described an individual's awareness during critical incidents and the research associated with this discovery. Beare and Lynch (2005) posited decision making in natural situations that simulated the unique qualities of real life decision making. Similarly, Galloway (2007) investigated decision-making expertise in a wilderness medical context.

Complexity science, as stated previously, is the platform through which these concepts can integrate. It presented a divergent way of thinking about change, time, and leadership, and the possibility that complexity science holds the key to understanding these variables in relation to humanity (Poole \& Van de Ven, 2004). The appropriateness 
of studying leadership in complexity science was captured in the review of Schneider and Somers (2006), and Poole and Van de Ven. A review of Dooley's (2004) specific change models offered within the complexity science domain was necessary for clarification of terminology and process. This somewhat vast and scattered landscape of divergent concepts may prove to be a true indicator that punctuated equilibrium, leadership emergence, and NDM can converge.

The next chapter of this dissertation, chapter 3, describes a plan that was launched to investigate a convergence concepts articulated in the literature review. A grounded theory research design was selected as the most appropriate methodology. Chapter 3 includes a timeline of activity, samples of survey questions, data collection instruments, and methods for analysis. Through interviews, observations, and surveys, research questions proposed in chapter 1 are addressed, categorized, and coded for analysis (Corbin \& Strauss, 1990). The next chapter will include details of fieldwork to include a description of the subjects, my relationship to the subjects, and a description of the reliability and validity measures. 


\section{CHAPTER 3: RESEARCH METHODS}

The purpose of this investigation was to determine whether a punctuated equilibrium change event is related to rapid leadership emergence, and if so, how it is

related. As stated in chapter 1, this study was driven by experience, gaps in the literature, and the intuitive sense that sudden change and leadership emergence are linked in a measurable way. Naturalistic decision making in a critical situation is one way in which this phenomenon can be studied. The literature review in chapter 2 discussed the nature of the concepts investigated. To summarize, punctuated equilibrium as a sudden change event and rapid leadership emergence may be linked in the context of NDM.

Chapter 3 will describe the grounded theory research design, data collection methods and instruments, procedures for analysis, and measures to insure the reliability and validity of the research instruments and analysis. The first section of chapter 3 describes the plan for research that was executed. This chapter will describe how research methods align with the research questions posed in chapter 1.

\section{Research Design}

The research design chosen for this study is grounded theory. The choice was influenced by Corbin and Strauss's (1990) qualitative research methods and Kan and Parry's (2004) grounded theory study of leadership. The Kan and Parry study will be described in the following section. Their study of leadership revealed unexpected relationships between variables through the assignment of themes to data chunks in a process that is unique to grounded theory. Similarly, it is an appropriate design for this study because of its iterative nature that allows the researcher to toggle back and forth 
between idea generation, data collection, and data analysis. With each phase, idea generation will advance in sophistication. Several data collection methods, described below, are appropriate ways to discover how variables may interact. The idea of grounded theory research is exciting because it requires imagination in data analysis and it can complement prior experience of the researcher.

Much deliberation and study went into the decision to utilize a grounded theory method above other qualitative research methods. The goal of the research is to build theory. According to Corley and Shah (2006) quantitative research is not able to build theory. In the search for a nonlimiting and robust method to study leadership, some qualitative methods were instantly excluded. Case study research, bound by time and space, was not considered for this dissertation. Similarly, phenomenology, ethnography, literature review, and statistical analysis were considered and rejected for the reasons mentioned.

Appreciative inquiry, a method that created a significant detour in this investigation, was given great consideration and although initially it seemed a good fit, it turned out to be a mismatch in the study of the relationship between leadership emergence and punctuated change. Although appreciative inquiry is derived from action research, looks for relationships, and builds theory through data collection and analysis (Reed, 2007), it was designed for group process and rapid implementation within an organizational setting. The research design for this study required independence, flexibility, and creativity. 
The nature of grounded theory is evolving and exploratory, and the research questions may change during the course of the process (Creswell, 2007). Even so, a starting point must be established and the purpose broadly defined. Kan and Parry (2004) conducted a grounded theory study at a time in which it was common to use organizational case studies and quantitative methods in the study of leadership (Kan \& Parry). This study stood out because it was one of the first studies to combine grounded theory data collection and analysis with a quantitative component from which to triangulate the data. Their study investigated leadership and change resistance issues within a nursing population in a hospital in New Zealand (Kan \& Parry). Their grounded theory study paid close attention to process details put forth by grounded theory pioneers who included Corbin, Strauss, and Glaser. In fact, they adopted Glaser's (1978) coding families in their analysis. The study was a comprehensive documentation of decisions and choices involved in a grounded theory research process.

The Kan and Parry (2004) study stood out for another reason, and that was their use of the Multifactor Leadership Questionnaire (MLQ) as a quantitative tool. This quantitative addition was clearly articulated as their fourth objective in the study. They referred to the triangulation of qualitative and quantitative data as a "major innovation" of their work (p. 469). Whether or not this idea carried directly into my research, it was inspiring to see how effective grounded theory could be in leadership research. The Kan and Parry study was beneficial for three additional reasons. First, it rationalized the use of grounded theory as a methodology in organizational research; second, it described the use of specialized software, NVivo, in the coding and analysis process. Finally, it revealed 
the straight and crooked paths in data analysis and expressed those through models and charts. As stated in chapter 1, there is much evidence that this qualitative method is a creative way to build a theory while grounding it in the data. Kan and Parry's study provided evidence that the research before me should be seen as an art as much as a science.

\section{Data Collection}

Three data collection methods were implemented for this study: interviews, observations, and a survey. The choice of data collection instruments are greatly influenced by the researcher's skills, access to populations, budget, and opportunities to work with the subjects (Creswell, 2007). Hence, three data collection methods and sample sets from three populations were used in this study. Retrospective interviews were conducted with professionals who are trained in critical incident management and wilderness leadership. Unobtrusive participant observations, conducted in an actual outdoor adventure challenge, constituted a second method of data collection. The third method was the distribution of a survey to wilderness education students via a partnership with the WEA. This Web-based survey asked former and current students to read a short vignette and respond to 18 multiple-choice questions that reflect their decision making and leadership behaviors. The cover letter to the survey and interviews provided my contact information and Walden University's IRB contacts in the event participants should have any questions concerning the purpose of the research. The IRB approval number for this research entitled Leadership Emergence Study is 07-17-08-0312302. 
The choice of three data collection methods, interviews, observations, and a survey vignette, was to look for a relationship between rapid leadership emergence and a punctuated change event. The idea was not as far reaching as it seemed. To clarify, this study was not attempting to simulate leadership emergence, rather, it regards a critical incident in close proximity to a punctuated change event. As stated previously, the critical incident simulated punctuated equilibrium. To witness this relationship, interviews, the most important data collection tool in this investigation, collected information from actual events in which a critical incident and leadership came together.

Observation in a wilderness adventure setting may or may not provide an opportunity to witness a critical incident. With that said, it was an opportunity worth pursuing because of the conditions inherent in these types of adventures. The survey vignette used as a qualitative data collection method in this study assessed the decision making and cognitive process within a sample frame of wilderness leadership students and faculty. Wilderness leadership, by its very nature, positions leadership with skills necessary to manage one or more critical incidents. The relational elements of rapid leadership emergence and punctuated change may be seen within the framework of NDM in this likely population. This subject population and the subjects in the observation component may provide a true perspective from within the critical NDM framework for this study. 


\section{Interviews}

Interviews accounted for most of the data collection in this study over a 3-month period. As stated previously, individuals from several professions were the subject of the interview portion of this investigation. Ten wilderness education faculty or trainers and 5 critical incident specialists were asked to recall events in which they had been involved. The entire population of individuals whose profession is in some way connected to the management or training of critical incidents is vast. The entire population may include, but may not be limited to all CEOs, first responders, social workers, wilderness guides, rangers, civic government officials, the military, and law enforcement. The sample was chosen because of geographic considerations, access, and personal knowledge of highlevel professionals in the field who were willing and able to participate in the study. This sampling frame included professionals from wilderness medicine, critical incident stress debriefers and trainers, rangers, wilderness leadership faculty, and outdoor wilderness guides.

Fifteen individuals were chosen through purposeful sampling to provide information from their unique perspectives. It is expected that more than 15 interviews of retrospective accounts would saturate this particular method with many interesting stories but not likely with any new additional perspectives. For this study, 15 interviews seemed a reasonable starting point from which to find themes emerging from the data.

An identical semistructured interview was conducted face to face when possible and over the telephone when necessary. The questions explored the subjects' perceptions of leadership behaviors and interactions by recalling an actual critical incident. This 
probing of a professional's recollection of a past critical event is very similar to Klein's (2000) data gathering technique referred to as retrospective accounts. Referenced earlier in chapter 2, retrospective accounts is an interview technique that taps into the subject's memory to recall details of what occurred during a critical incident (Klein). The emphasis in Klein's study was situational awareness and decision making, whereas the interviews conducted for the dissertation research probed how, when, and in whom leadership traits emerged.

The interviews conducted with the wilderness education faculty and wilderness medical trainers were largely a matter of convenience and geographical access. The wilderness education faculty and trainers live and work in the northern New York region. Interview subjects from the State University of New York at Potsdam, St. Lawrence University, Wilderness Medical Associates, and the Adirondack Mountain Club were easily accessible from my location in Potsdam, New York. Five critical incident specialists, all of whom I have had personal or professional contact over the years, live in different regions of the United States. Two of the specialists have formed their own crisis intervention company. The third subject is an executive leadership trainer and a former school superintendent. These three are located in Pennsylvania and a fourth specialist is from Rhode Island. Two additional interviewees, who were invited from the International Critical Incident Stress Foundation (ICISF), live and work in Maryland in the medical and teaching professions and serve as consultants to the United Nations.

The relationship between researcher and subjects is clarified here so that there are no issues of interviewer bias. I had a brief past professional relationship with the critical 
incident specialists when I served as director of the Rural Health Training Center at SUNY Canton. They were recruited and hired by me to conduct a series of trainings to set up critical incident teams in our area. I have not had contact with two of the subjects in over 7 years. The other two became acquainted with me as frequently hired trainers in workplace violence prevention and critical incident stress debriefing for the program mentioned above. The fifth interview subject, also a leadership trainer, is someone whom I had not met prior to this research.

Some of the individuals interviewed were known to me professionally as fellow faculty. Most of the other individuals were chosen through my familiarity with the organizations with which they work. For example, the Adirondack Mountain Club, Wilderness Medical Associates, and member universities of the Wilderness Education Association (WEA) are organizations known to me through personal and professional contact. Only two of the individuals who are not faculty were known to me personally. One subject was my wilderness first aid trainer in 2001, and the other is the education coordinator at the Adirondack Mountain Club. My correspondence with the education coordinator has been limited to questions about programs and hiking trips.

A semistructured, five part face to face or phone interview format was chosen to probe this population's experiences during critical incidents. The first few questions of the interview established their experience in the field and prompted them to focus on one particular event. The next set of questions probed their relationship with individuals in an official leadership capacity during a critical incident. The next set of questions explored their perceptions of leadership emergence in individuals who were not in official 
leadership positions during the critical incident. The fourth set of questions investigated their personal leadership role in a critical incident if that is applicable. The last section asked what variables came into play during the critical incident. The questions were intended to explore the subjects' perceptions of leadership behaviors and interactions with individuals during a critical incident.

In the early stages of writing the proposal, I made initial contact with the subjects to inform them of my upcoming research and requested permission to send a letter of invitation later in the summer. Additionally, I had created a table of contact information to $\log$ all correspondence on a spreadsheet.

\section{Observation}

Unobtrusive participant observation, the second method of qualitative data collection, provided direct contact with a different group of subjects over a 3-day period. It seemed impossible to enumerate the population of adults and teenagers around the world who might participate in outdoor adventure challenges this year, therefore, the sample frame for the observation was a convenience sampling. I participated in a leave no trace educational trip with seven adults whose experience was similar to any other nonextreme adventure challenge.

As established in chapter 1 and supported in the literature review in chapter 2, a sudden and unexpected change cannot be planned. Therefore, an outdoor adventure challenge provided the opportunity for a critical incident to occur. The individuals, who became known to me only after the observation began, participated in 72 continuous hours of hiking and camping in August of 2008. During the course of those 3 days, the 
group traversed three high peaks in the Adirondack Mountains, each with elevation of over 4,000 feet.

According to Corley and Shah (2006), the goal of observation in grounded theory is "to understand how the social context influences individual behavior and how individual behavior influences the social context" (p. 1828). The course took the group up the mountains, across rivers, and through rugged wilderness and provided an opportunity for participant observation that was congruent to that goal. The course was one of many educational events provided by the Adirondack Mountain Club (ADK) of which I am a member. The trip, which was led by a licensed guide, was a rigorous test of endurance, and was not without a threat of danger. According to the information letter received by participants, the educational course was designed to teach cooperative camping skills, shared responsibility, decision making, and wilderness ethics. The ADK is a member-based organization that protects the natural resources of the Adirondack Park through education, responsible recreation, and advocacy (Adirondack Mountain Club, 2008).

As mentioned in chapter 1, Corbin and Strauss (1990) and Glaser (1978) discussed theoretical sensitivity as the researcher's advantage of personal experience with the phenomenon under investigation. This important criterion in grounded theory research was met particularly well in this particular opportunity for observation. With backpacking and hiking experience combined with wilderness medical training under my research hat, a 3-day backpacking trip in the Adirondacks was a beneficial research resource. The inherent nature of these guided trips included the risk of bear encounters, 
injuries or medical emergencies, and sudden changes in environmental conditions due to weather. This type of risk, however, was not caused by the research. The trip would have taken place with or without my presence and had risks unrelated to the research.

The opportunity to witness a NDM event was likely as a participant and covert observer. The trip leader was informed of my research prior to the trip, but my role as researcher was not mentioned to participants initially. This is because it would have been a distraction and could change their natural behaviors. It was later determined that full disclosure was appropriate. I took notes of my observations during breaks on the trip. This process of recording my observations and impressions is what Corbin and Strauss (1990) referred to as memoing. Memoing or taking field notes is a process of recording personal impressions of what is being observed (Corbin \& Strauss; Singleton \& Straits, 2005).

My expectation was that the strongest leadership themes related to creativity, courage, and compassion, would emerge in the field notes. The data recorded on this trip was limited to my impressions as researcher and participant. As suggested by Corley and Shah, observations help the researcher understand participant behaviors in social situations (2006). Nevertheless, the nature of grounded theory research does not guarantee that the data collected is what the researcher expected. That is why multiple methods of data collection were used in assessing whether or not there was a relationship between leadership emergence and extreme change events. The third component to the research, the survey, was a means to explore relationships between and among variables and increased the opportunity to see what is happening more clearly. 


\section{The Survey Vignette}

The survey is a multiple-choice questionnaire that asks participants to respond to a short essay describing a critical incident. The questions were designed to draw upon their decision-making process, attitudes and behaviors that would most likely to occur. The entire population of members represented the sampling frame for the survey that included all of the former and current students that were members through affiliated universities of the WEA. The respondents to the survey were completely random within that population. The opportunity to survey the membership in the WEA was granted with the approval of a written application. The application, which was similar to an IRB application, was submitted to the research committee within the organization prior to the actual research. As a faculty member of one of the member universities, SUNY Potsdam, access to this organization was available.

Through a preliminary telephone inquiry with the research chairperson of the WEA, I was informed that permission was often granted to researchers to access its small national student population through the association's Website. The director of research revealed that the organization would likely assume the role of partner in the distribution of the survey and subsequently signed a community partner agreement as indicated on Walden's IRB instructions.

The survey design format, as guided by WEA standards, consisted of a vignette and 18 multiple-choice questions. The vignette was a story about a critical and unexpected change event during a strenuous day hike with six others. The story was based on an actual experience I had as trip leader on an Adirondack hike in 2005. The 
students were asked to respond as if they were one of three experienced hikers on the trip. The questions were intended to explore the students' perceptions of leadership emergence, decision making, and leadership attributes including creativity, courage, and compassion.

Respondents signed a consent form with the survey that verified that they were at least 18 years of age. The survey instrument was released via a link to the WEA Website through July and August of 2008. Of the 430 members, 22 surveys were returned composing the sample set. Data were categorized and coded according to the aforementioned leadership themes. Although surveys are not a common instrument for data collection in grounded theory, the information collected in these surveys reflected the students' association of an actual experience they might have had in wilderness leadership.

\section{Testing Instruments for Validity}

Interviews are the primary data collection tool in grounded theory research (Corbin \& Strauss, 1990; Creswell, 2007). But interviews by themselves may not be enough to build a robust theory that investigates relationships from several perspectives. Although the interviews collected a unique assortment of experiences and perceptions of leadership emergence during a critical incident, combining observation and survey with interviews strengthened the research.

A survey vignette in the form of a multiple choice questionnaire was chosen because it is the most appropriate way access current and former students in the Wilderness Education program who were trained and exposed to outdoor adventure 
challenges intended to build leadership skills. The survey designed for these particular students was be pretested on a small class of students at SUNY Potsdam to check whether the instrument tested what it intended to test. This process and the discussion with faculty members in the program helped me to determine whether the survey addressed leadership emergence, change, and decision making in a complex outdoor challenge. The first version did not and two consecutive revisions were made before it was launched on the WEA website.

To test the validity of the interview instrument, the interview questions were subjected to peer review from a wilderness leadership field trainer and faculty colleague. His frank and insightful perspective was useful as a critical testing path for this instrument. The work session with this person, who fit the profile of an interview subject, assisted me greatly in focusing the questions to the intent of the research. Peer review is a valuable technique used to troubleshoot weaknesses in a survey instrument and in determining whether the questions are measuring what they are supposed to be measuring. This process; however, is limited by personality and the personal relationship the researcher has with the peer reviewer. In this case, the person invited to test this instrument was barely an acquaintance; however, his reputation among fellow trainers, students, and colleagues as someone who is experienced, honest, and intelligent, made him the right choice. This particular test of validity is also limited by his willingness to participate. He was not only willing and able; he played the role of "devil's advocate" for review of the interview questions (Creswell, 2007, p. 208). However, his advanced 
understanding of the study, after the work session, excluded him from being an interview subject.

The participant observations were not subjected to pretests; however, the reliability of the data was captured in a rigorous note taking process while participating in the trip. I recorded my own process as well as the observations of my companions, who were strangers, and the trip leader's behaviors. Observations allow the researcher to experience the phenomenon and observe it. Data collection and data analysis in grounded theory is an iterative and flexible process that works with a combination of data collection methods (Corbin \& Strauss, 1990; Corley \& Shah, 2006).

\section{Grounded Theory Data Analysis}

Data were coded in several steps in accordance with Glaser, Corbin, and Strauss's methods referenced earlier in this chapter. Qualitative data derived from observations, interviews, and the survey was analyzed using the process that assigned symbols, diagrams, or themes to data bits (Singleton \& Straits, 2005). A matrix was assembled on a Microsoft Excel ${ }^{\circledR}$ worksheet as a tool to sort data. The spreadsheets had sufficient tools to assist in coding, categorizing, thinking, imagining, and building theory grounded in the data. It was a process of comparing elements and looking for relationships, first generally and later more specifically, until the categories and themes are exhausted.

Creswell (2007) referred to a grounded theory study in which a huge poster board with bits of notes and labels were used to move data around. Utilizing a paper method and computer method in the thought process, the coding process advanced in sophistication as themes were discovered. Theme selectivity and complexity was 
achieved by breaking data bits apart and putting them back together in new ways (Corbin \& Strauss, 1990). This stage of analysis is about category building, discovering relationships, and comparing elements. Without knowing what categories were to emerge, it was difficult if not impossible to anticipate the families or groupings. Late in the process, I discovered a reflective coding matrix and concept identification chart as aids to coding (Goulding, 2002; Wilson-Smith, 2008). The nature of grounded theory calls upon the researcher to remain flexible to learn and adjust according to the data they are collecting (Corbin \& Strauss; Kan \& Parry, 2004). The additional coding techniques mentioned above were helpful for that purpose.

The purchase of a digital audio recorder with a USB port was a time saving tool because it downloaded audio files from interviews. The device allowed me to adjust speeds to transcribe interviews while listening to the audio on my computer. Microsoft Excel spreadsheets were sufficient tools to code, categorize, think, imagine, and build theory grounded in the data. Several iterations of coding spreadsheets were created. All data collected in this investigation is stored in a locked file cabinet and will remain there for a period of 5 years.

Procedures to Address the Research Questions

By way of a brief internal summary, specific procedures to address the primary research question were conducted through the interview data collection and analysis process. Interviews were the primary means to explore whether punctuated equilibrium, as an unexpected change event, was related to leadership emergence within a NDM frame. Survey data was collected in an attempt to support the interview findings. Both of 
these methods, together with observations, were intended to define the mechanics of how leadership can be observed in the individual. Initially, it was expected that a limited set of characteristics would appear when leadership and change intersected that would include creativity, compassion, and courage.

The multiple data collection methods took place simultaneously. Data analysis, particularly the coding and categorizing of information, began when at least two interviews were completed. Data were coded separately for each data collection method at first and later, after all of the data were collected, broken down and reassembled into one big picture. This process, referred to as axial coding, occurred after the open coding process and before the selective coding process (Corbin \& Strauss, 1990; Glaser \& Strauss, 1967). The process of grounded theory was justified because of its emphasis on looking for relationships in the data by constant comparisons (Glaser 1978; Glaser \& Strauss).

\section{Triangulation}

Triangulation of data is not necessarily limited to combining qualitative analysis with quantitative analysis (Creswell, 2005). The process of triangulation, using different data collection methods to minimize the deficits of each, can enhance the rigor of data analysis (Singleton \& Straits, 2005). This seems quite intuitive, for example, drawing conclusions from evidence obtained from one data source is similar to making a hasty generalization on an idea or an issue. According to Creswell, triangulation is a validation process whereas Trochim (2001) refers to triangulation of a process of minimizing errors to get a better interpretation of reality through analyzing different perspectives. 
The forthcoming investigation into leadership emergence and punctuated equilibrium required a complex approach to collection and analysis; hence, three data collection methods were chosen to increase validity in this research. Grounded theory data methods work well with triangulation because relationships between variables are likely to be similar in all three methods. Through triangulation, similarities in data may look like differences and lead to the discovery of causal conditions that were not expected to appear. According to Singleton and Straits (2007), the similarities that appear by using different data collection methods that converge in one point adds confidence to the findings. Triangulation is one way, but not the only way, to become reasonable assured that the internal validity of the research will hold.

\section{Validity and Reliability in Data Analysis}

The primary test of validity in grounded theory was through data analysis, constant comparisons, and the storage of data records. The process of comprehensive note taking and maintaining a process journal increased the validity of the research (Kan, 1998). Core categories emerged and were consistent enough to build a theoretical model of the phenomenon. Internal validity was addressed in the grounded theory coding process itself. Although grounded theory is difficult to replicate, the actual process can meet a transferability criteria (Corely \& Shah, 2006). In this study, the qualitative survey vignette, although normally used as a quantitative method, was analyzed qualitatively. A variety of data sources and running a Cronbach's Alpha determined the degree of reliability in the data. The results of the Cronbach's Alpha are presented with the findings and analysis in chapter 4 . 
The data collected from observations were recorded in a field notebook with time reference every time an entry is made. Interviews were kept confidential, recorded, transcribed, and safely stored in both paper and electronic files. The survey data that were received through the SurveyMonkey service from anonymous respondents from the WEA membership were within the sampling frame. According to Singleton and Straits (2007), a 50 to $60 \%$ return on the surveys are needed to insure reliability. They survey, as will be discussed in the Findings section of chapter 4, yielded a mere 5\% response return.

\section{Conclusion}

This chapter has provided concise details of how the phenomenon of punctuated equilibrium intersecting with leadership emergence within a NDM frame was studied. Quite noticeably, there has been no mention of punctuated equilibrium anywhere in this chapter, but the concept of punctuated equilibrium lies at the heart of this study. The research design choices were made to capture, as closely as possible, the simulation of a punctuated change event. The interviews drew upon past actual critical events that affected significant changes. The observation put me in close proximity to an opportunity to witness a punctuated event, and at the very least, document leadership behaviors. Finally, the surveys probed leadership thinking of members within the WEA for their expected behaviors in a simulated event that probed leadership, change, and decision making. 


\section{Summary}

Chapter 3 revealed the research plan that was executed during the last two quarters of the 2008 calendar year. It described how the research design and the research questions aligned. The contents focused on how a grounded theory study investigated, explored, and compared elements. Relationships necessary to this process were formed while the initial proposal was being carved out. Pretest populations and subject populations were identified, and the administration and distribution of data collection instruments were determined months in advance of the actual data collection. Data collection and analysis was an iterative process that was consistent with grounded theory methodology. Many of the methods proposed here grew out of prior research discussed in the literature review.

Within the timeframe mentioned above, 15 interviewees sharing 45 retrospective accounts (Klein, 2000) were gathered through interviews. A survey was distributed to wilderness education students, and I participated in a 3-day outdoor adventure challenge for data collection through observation. As expected, categorizing, coding, thinking, and analyzing data was an ongoing process as suggested by Corbin \& Strauss (1990). Transcripts of interviews were made within 24 hours after the interview took place. Records are stored safely and the confidentially of participants will be protected. The research began immediately after Walden University approved my IRB application.

The upcoming chapter will report the findings from the research. The data collection process accurately reflects problems and discoveries in the process. This written account illustrates that the path of evidence and process were significant. The 
upcoming chapter communicates outcomes, patterns, and conclusions, not only text, but also in figures and tables when appropriate. 


\section{CHAPTER 4: FINDINGS}

The core purpose of this study was to discover a relationship between punctuated equilibrium and leadership emergence without a preconception of a relationship between the two concepts. The research process was perpetuated by a deficient representation in the literature that brought real time events into the process of change and leadership emergence. The model of change represented in this study was limited to a sudden and unexpected event that was simulated through the investigation of critical incidents. Similar to punctuated equilibrium, critical incidents are unplanned or unexpected events that trigger a breakdown, or radical and immediate change, in systems and or individuals (Caverly, 2006).

The behaviors of an individual during a critical incident were investigated from the point of view of critical incident intervention experts, wilderness and executive leadership trainers, and first responder/paramilitary personnel. Each of these subjects engaged in the decision-making process during an unexpected and rapidly emerging change event also known as naturalistic decision making (Carroll et al., 2006). Hence, NDM was the logical frame through which to explore the individual's emerging behaviors, particularly behaviors associated with leadership. Leadership emergence behaviors described by the subjects, occurred within the seconds, minutes, and hours following a critical incident. Their descriptions of events, or retrospective accounts, create the best vantage point to see an intersection of forces. 
There were three objectives in this investigation. The first of which was to discover the relationship between sudden change and leadership emergence within a limited span of time. The second goal was to identify the mechanisms of leadership emergence. The third objective was to discover what characteristics signaled leadership emergence and whether creativity, courage, and compassion were among those traits.

The first goal of the grounded theory investigation and process was to explore whether there was a causal relationship between punctuated equilibrium, represented as an unexpected change event, and leadership emergence. The secondary objective was met through 40 stories of critical incidents from 15 interview subjects that occurred within the context of a NDM framework. These interviews revealed the motivating factors and observable indicators of leadership emergence. It was anticipated that the research would identify creativity, courage, and compassion as quickly observable leadership emergence indicators. This objective was met, but not as expected. This chapter will detail how these questions were investigated to include the process of data collection and the findings, the grounded theory process of analysis, and conclusions.

The Process

\section{Interviews}

The primary data collection method was conducted through 15 semistructured interviews with individuals who had been involved with a critical incident. Twelve interviews were face to face, and three interviews were conducted via a professional conference phone, all of which took place between July 8 and August 18, 2008. The duration of each interview was between 45 minutes and 75 minutes. The interview 
participants were selected based on the likelihood they would have encountered a critical incident in their line of work. Further, since the population of individuals who might have encountered a critical incident is a very large population, the selection of these individuals was based on access, availability, and prior knowledge of their work. Identification and contact was made through organizations with which the subjects were affiliated.

The interviewees were grouped into three categories that generally described their professions. Five of the individuals interviewed worked in the field of critical incident intervention or mitigation. Six individuals worked as wilderness leadership trainers, guides, or faculty. Four of the subjects were first responders or forest rangers who represented a classification of highly trained emergency medical personnel and paramilitary. Most of the interviewees had experience or training in one or more areas of work involving critical incidents. Three face to face interviews occurred in eastern Pennsylvania while the other nine took place in northern New York in the towns of Watertown, Lake Placid, Raybrook, Potsdam, and Canton. Three phone interviews were conducted with critical incident specialists, one from Rhode Island and two from Maryland. The interviewees are referenced in this document by pseudonyms and their real names and identities were kept confidential.

The semistructured interviews were each conducted in four distinctive parts. The first section prompted the interviewee to recall stories involving their personal interactions with official leadership during a specific critical incident. The second set of questions explored observations that they could recall of an unofficial leader, or unlikely 
individual, rising into a leadership position. The third part of the semistructured interview explored the interviewees' role as leader in a critical incident. The fourth part of the interview requested that the interviewee offer his/her perception of how several different concepts were related to leadership emergence. Each interviewee had stories, or retrospective accounts, for one or more of the sections, and some used the same critical incident story for more than one section. Except for the retrospective accounts of official leadership, most of the stories of leadership emergence were of individuals who did not have prior leadership experience. This was especially true in retrospective accounts of unofficial leadership emergence, arguably the most descriptive portion of the interview responses. Some interviewees did not have an experience for all three sections. Excerpts from the interviews are revealed in the Findings section of this chapter. Actual critical incidents discussed in the interviews are categorized in the chart below.

The stories that described triggers for leadership emergence could be categorized into five broad themes. Thirty-three stories involved an immediate threat of physical or psychological harm to individuals, 12 stories recalled situations following a critical incident that stimulated a need to help others, six incidents described a void in leadership, 11 were connected to a crisis in a community or organization, and four were staged leadership training incidents. Seven retrospective accounts gave different perspectives of leadership using the same critical incident. These stories fit into multiple categories, and some were repeated in one or more of the three sections of retrospective accounts of leadership. 
Interviewees were asked to view leadership from three separate retrospective accounts. The first section investigated their recollection of a critical incident in which they interacted with official leadership. Official leadership was defined for them as a mayor, a police chief, or Federal Emergency Management Agency (FEMA), or anyone who served in a position above their rank during a critical incident. Nine of the interviewees had stories for this and six did not because they were serving at the top leadership position during the incident. Critical incidents described in this section by the other nine interviewees included the TWA Flight 800 crash, Hurricane Wilma, a tuberculosis case, a meningitis case, the Bridgeport building collapse, a head injury, the 1998 ice storm, and two cases of a student lost in the wilderness. One incident describing interactions with official leadership emergence was typified in a description of the TWA Flight 800 crash in Long Island in 1995.

The FBI was called in because there was some indication it was a terrorist act-a criminal act. I was the FBI's team leader. . . at the time [and] we became part of the command operation. The assistant director of our office. . . was the overall commander. He brought out a mobile command post to set up on site, [my] team reported directly to his command. We were in a position to observe the command structure and how it impacted [our team].

[The assistant director] delegated responsibility. He had so many people reporting to him and had so much responsibility interfacing with so many different agencies and components of his own agency he had to delegate assignments to other people. ... He had a reputation for being a good manager prior to this incident. I worked in a field office with him and saw him operate on a daily basis and he brought all the skills out to the field with him. His efficiency in the field was remarkable. (Colin)

Table 1 that follows provides a listing of critical incidents described in each section of the interview grouped by general descriptive category. 
Table 1: Critical Incidents Grouped by Category

\begin{tabular}{|c|c|c|c|c|c|}
\hline \multicolumn{6}{|l|}{ Critical Incidents Described in the Interviews } \\
\hline & $\begin{array}{c}\text { Threat of } \\
\text { Harm }\end{array}$ & $\begin{array}{l}\text { Response } \\
\text { to a Need }\end{array}$ & $\begin{array}{c}\text { A Void in } \\
\text { Leadership }\end{array}$ & $\begin{array}{c}\text { Organiz- } \\
\text { ational or } \\
\text { Community } \\
\text { Crisis }\end{array}$ & $\begin{array}{c}\text { Staged } \\
\text { Leadership } \\
\text { Event }\end{array}$ \\
\hline \multicolumn{6}{|l|}{ Interactions with Official Leadership } \\
\hline Student lost in the wilderness & $\mathbf{x}$ & & & & \\
\hline Student lost in the wilderness & $\mathbf{x}$ & & & & \\
\hline Northeast Ice Storm of 1998 & $\mathbf{x}$ & $\mathbf{x}$ & $\mathbf{x}$ & & \\
\hline Serious head injury in a guided hike & $\mathbf{x}$ & & & & \\
\hline The Bridgeport building collapse & $\mathbf{x}$ & & & $\mathbf{x}$ & \\
\hline A tuberculosis case in a school district & $\mathbf{x}$ & & & $\mathbf{x}$ & \\
\hline 1995 crash of TWA Flight 800 in Long Island & $\mathbf{x}$ & $\mathbf{x}$ & & $\mathbf{x}$ & \\
\hline Hurricane Wilma relief effort & & $x$ & $\mathbf{x}$ & & \\
\hline Outbreak of meningitis within a school district & $\mathbf{x}$ & & & $\mathbf{x}$ & \\
\hline \multicolumn{6}{|l|}{ Observations of Unofficial Leadership Emergence } \\
\hline Guides involved in white water rafting accident & & $\mathbf{x}$ & & & $\mathbf{x}$ \\
\hline Group of students lost in the mountains & & & $\mathbf{X}$ & & $\mathbf{X}$ \\
\hline Evacuation of injured victim in swamp & & & & & $\mathbf{x}$ \\
\hline Disabled boy leads rescue from mountain & $\mathbf{x}$ & $\mathbf{x}$ & & & \\
\hline Serious head injury in a guided hike & $\mathbf{x}$ & & & & \\
\hline Two students drowned on college campus & $\mathbf{x}$ & $\mathbf{x}$ & & & \\
\hline 1986 Earthquake in El Salvador & $\mathbf{x}$ & $\mathbf{x}$ & $\mathbf{X}$ & & \\
\hline Mountain biking accident & $\mathbf{x}$ & & & & \\
\hline School bus hit by a speeding car & $\mathbf{x}$ & & & $\mathbf{x}$ & \\
\hline Young boy falls through river ice and drowns & $\mathbf{X}$ & $\mathbf{x}$ & & & \\
\hline Hurricane Wilma relief effort & & $\mathbf{x}$ & $\mathbf{x}$ & & \\
\hline Rhode Island Station night club fire & $\mathbf{x}$ & $\mathbf{x}$ & & & \\
\hline White water rescue & & & & & $\mathbf{x}$ \\
\hline Severe storm destroys student camp structures & $\mathbf{X}$ & & & & \\
\hline \multicolumn{6}{|l|}{ Descriptions of Self Emerging as Leader } \\
\hline Rock climbing injury and evacuation & $\mathbf{x}$ & & & & \\
\hline Man falls 35 feet in a training exercise & $\mathbf{x}$ & & $\mathbf{X}$ & & \\
\hline Motor vehicle accident - multiple fatalities & $\mathbf{x}$ & & & & \\
\hline Rescue of a lost person & $\mathbf{x}$ & & & & \\
\hline Serious hand injury while hiking & $\mathbf{x}$ & & & & \\
\hline Motor vehicle accident - one fatality & $\mathbf{x}$ & & & & \\
\hline Hurricane Andrew 1992 & $\mathbf{x}$ & & & $\mathbf{x}$ & \\
\hline Individual has grand maul seizure during a canot & $\mathbf{x}$ & & & & \\
\hline Hospital closing - workers displaced & $\mathbf{X}$ & & & $\mathbf{x}$ & \\
\hline Teacher killed in motor vehicle accident & $\mathbf{x}$ & & & $\mathbf{x}$ & \\
\hline Officer was stabbed to death in the line of duty & $\mathbf{x}$ & & & $\mathbf{x}$ & \\
\hline Hurricane Wilma relief effort & $\mathbf{x}$ & & & $\mathbf{x}$ & \\
\hline Rhode Island Station night club fire & $\mathbf{x}$ & & & $\mathbf{x}$ & \\
\hline Mountain skiing accident - injured victim & $\mathbf{x}$ & & & & \\
\hline \multicolumn{6}{|c|}{ Other incidents used in response to the relationship and interpretation of concepts } \\
\hline Individual injured while kayaking & $\mathbf{x}$ & $\mathbf{x}$ & & & \\
\hline Serious injury while mountain hiking & $\mathbf{x}$ & $\mathbf{x}$ & & & \\
\hline Total incidents by category & 33 & 12 & 6 & 11 & 4 \\
\hline
\end{tabular}


The second set of interview questions investigated the interviewees' perceptions of leadership emergence in an unofficial or unlikely individual. The behaviors of these individuals, clarified as a student, bystander, or lower ranking worker, were identified in the context of the same critical incident they described earlier, or a separate incident. Fourteen interviewees had stories of unofficial leadership emergence, and one did not. Critical incidents ranged from a young boy with a learning disability who emerged as a leader in a rescue, to a shift in leadership during the 1986 El Salvador earthquake relief effort. The range of leadership stories ran the gamut from subtle leadership emergence to profound and significant transformations in individuals. An excerpt from an interviewee describing an unexpected event triggering leadership emergence in an individual follows:

A bus driver [from our district] was transporting students and a car ran through an intersection and hit the bus at high speed. It went right under the bus and sheered off the roof of the car. The bus driver on the bus rose up as the leader during that incident. No kids were hurt. . . . He jumped into action and did not think of himself but to protect the children's safety. He jumped out of the bus and triaged everyone. (Mark)

The third part of the interview investigated the interviewees' perceptions of self in a leadership role. Almost half of the respondents in this section were highly regarded as leaders in their field. All 15 of the respondents had stories for this category. A summary of critical incidents described in this section included circumstances related to wilderness medical rescues, motor vehicle fatalities, personal injury cases, a lost person, a line of duty death, hurricane relief efforts, a catastrophic night club fire, and a hospital closing. All of the incidents described were grouped into leadership emergence as triggered by an immediate threat of physical or psychological harm to others. Although there are no 
typical examples in this grouping, an excerpt describing a type of an incident triggering leadership emergence is presented below.

I remember I decided to take this really long hike maybe 13 or 14 miles round trip, and I was about as far in as you could get and I passed this group of people and I just knew something was out of place. . . They asked if I saw a woman running. I said no and they said she was supposed to be ahead of them. Now the bells were going off that [something was wrong]. I realized that the missing woman did not speak English and she was trying to trail run for the first time.

She could not read the signs and interpreted the arrows on the signs in the opposite way so she ran deeper and deeper into the woods. I looked for her footprints. . . . About 9 miles in I found a woman huddled down in a mud bog and she was terrified when she saw me. I tried to remember the few words of Spanish I knew . . . and finally convinced her to follow me back to her family. She followed me about 20 yards behind for the 9 miles out. (Ian)

The interview questions for each of the first three sections were very similar and were designed to stimulate the interviewee to think about leadership from three separate perspectives. These open-ended questions prompted the interviewee to reflect on the individual in the critical incident and describe their most prominent characteristic and their weakest characteristic, how they were able to identify the individual was emerging as a leader, perceptions of their decision making style, and their attitude toward the individuals at risk. Questions prompted the interviewees to identify a time in terms of seconds, minutes, or hours, that they perceived the leadership indicators to become obvious. This process of questioning created a path for common themes to emerge. The analysis process and themes will be detailed later in this chapter.

The fourth section asked the interviewees to interpret the relationship among particular concepts and leadership emergence. Four specific questions directed them to describe their perceptions surrounding the relationship among a critical incident as a 
sudden and unexpected change event, leadership emergence, and the decision-making process. The last three questions in this section asked the interviewees to comment on whether they perceived a relationship between creativity and leadership emergence, compassion and leadership emergence, and courage and leadership emergence. The last question posed to the interviewees was whether they had any final thoughts they wanted to express. Eight out of the fifteen interviewed offered substantial comments at the end.

\section{The Survey Vignette}

A survey vignette was created on SurveyMonkey (refer to Appendix A) that included 18 questions concerning how one would respond to the critical incident described in the vignette. The survey was created with the cooperation of the Wilderness Education Association (WEA), who agreed to set up a link to the survey on their website for their members. The point of contact, the office manager at WEA located at Indiana University, became a helpful partner. She utilized the WEA member newsletter that frequently promoted the survey's presence in addition to the creation of a link to the survey on the homepage of the WEA website (www.weainfo.org). This partnership provided access to a group of responders who were likely to have encountered a critical incident in their work.

The survey was available to all 430 WEA members from August 6 to September 16, 2008 when they visited the website. Twenty-two completed surveys were collected and analyzed, which represented a 5\% response return. The purchase of a SurveyMonkey membership for the duration of the survey included a percentage breakdown of each response per question. The survey had an overall low reliability score, 1.96 , after a 
Cronbach's Alpha test was run. Twelve out of the 18 questions were then divided into two groups, observable indicators and motivation to act, and the test was rerun for each group with an Alpha of .263 and .409 respectively. Comment sections that were added into the survey instrument for two questions further indicated that the survey questions might have had multiple interpretations; hence, a quantitative analysis based on the survey instrument was not used in the analysis of this research.

\section{Observation}

As put forth in the proposal, a 3-day backpacking journey into the Adirondack high peaks with six other individuals provided an opportunity to observe leadership emergence in a critical incident. Although I participated as a hiker and researcher for that trip, a critical incident did not occur. The observational research was not intended to be a primary data collection method, but I did not want to exclude it as an opportunity. With that said, a memo journal was maintained and an analysis of how leadership mitigated the risk of a critical incident during this trip was stored for future study. The backpacking trip held implications for group behavior and group cohesion observed in challenging conditions and the ability to self-organize and adapt. Although the experience may have relevance for future studies, including studies on group behavior and critical incident mitigation, the data collection through observation does not have relevance to the immediate research question posed in this dissertation.

\section{Processing and Record Keeping}

The process of record keeping was rigorous. The written transcripts and the actual Windows Media Audio files (.WMA files) were stored on my personal computer's hard 
drive during analysis in addition to a back up on an external hard drive. An interview master sheet recorded when, with whom, and how each interview was conducted. The table created in a Word document included the interviewees' real names and code names, or pseudonyms, to protect the identity and confidences of each interviewee. A separate file kept track of contact information and the dates of every contact with the interviewee. In addition, a master activity log kept records of the research process and milestones. Memos were recorded throughout the process, first on a Word document, and later, handwritten on a yellow pad for increased access and quickness in recording ideas. All records were kept on my personal, nonnetworked computer in my home office and data were not transferred to other individuals for transcribing or analysis.

The analysis phase began concurrently with data collection and advanced in sophistication as data were collected. The first step was to transcribe data within a day or two of the actual interview from the interview guide (refer to Appendix B).

Transcriptions of the 15 interviews were reassembled on a master interview guide that arranged all responses by interview question. This second step of the process took place as selected excerpts from each question were transferred into one 49-page document. Selected excerpt is clarified here as interview transcription passages that eliminated extraneous banter. One of the most difficult aspects of this stage was eliminating the "ums", repeated words and phrases, and detailed background explanations that were unnecessary to the interpretation of the data. A frequent habit of almost every interviewee was to begin to answer questions directly but wander into subjects that were often contained in upcoming questions. Since I wanted to maintain a semistructured question- 
by-question format, I would take that data and transfer it into the appropriate question heading for analysis. Hence, I did not interrupt the interviewee and skipped asking the question directly during the interview.

The records from data collected on the survey were sorted by the survey host website. SurveyMonkey provided all responses and a tally of response percentages question by question. Although the paid service and resources of SurveyMonkey was able to provide a variety of reports and data, I created a concept identification chart similar to the process used in the sorting of interview findings. Data obtained from the survey was coded separately from the interview with respect to the interview data as the primary source.

Documents, other than the activity log and memos, that were created during the analysis stages included a conditional relationship guide (Wilson-Scott, 2008) used for open coding that identified emerging themes. Also created were a concept identification chart (Goulding, 2002), a concept map containing direct quotes from the interviewees, a reflective coding chart (Wilson-Scott) to identify core themes and supporting themes, and diagrams (refer to Appendix C). Each of these files were protected on my personal computer and backed up to an external hard drive that was kept in a separate location in addition to paper copies bound in a 3-ring binder.

A significant volume of data were collected in the research process and many discoveries were realized that were relevant to the research question. Although the process of managing and interpreting the data was overwhelming at times, a methodical and organized approach was used to record the findings. The next section reveals the 
findings sorted first by frequency of response, and second, by the sequence in which the behavior occurred, and third, by relevance to the research question.

\section{The Findings}

The initial realization that occurred early in the sorting process, and that guided the remainder of analysis and interpretation, was that data findings had to be sorted in a real time frame, or what could be referred to as an event continuum perspective. It made little sense to look at concepts or themes without looking at their relationship to other concepts on a time continuum. Hence, the findings of the interview process are presented here as they appeared in the Concept Identification and Grouping Chart. This enabled the data to be viewed in terms of a sequence of events arranged in approximate real time.

Prior to beginning analysis, I had to find a way to sort the data that made sense in terms of viewing the intersection of sudden, unexpected change and leadership emergence. The interview respondents indicated a sequence of events, that one event most often followed another in a real time sequence, to explain the leadership emergence process surrounding the sudden change event. In other words, every time a decision was made, the path split in two and consequences of that decision led to another event. The simple diagram that follows is a representation of a sequence of events from which the raw data were perceived and grouped in a logical way. This stage does not represent an analysis of information, but rather, it is a method to group frequently occurring concepts from the interviews. 


\section{The Representation of Events}

Individuals who participated in the interviews were asked to recall events that triggered a series of behaviors related to leadership emergence. In the retrospective accounts, the individuals did not create the change event, but rather, the change event occurred first and created the conditions in which the individuals responded to in various ways. In all cases, the sudden and excepted change event was represented as a critical incident that created rapidly developing decision-making conditions that also represented a call to action. The stories of each interviewee described their involvement in terms of retrospective accounts in a real time, real life situation. Individuals offered a robust and detailed description of events from their unique vantage point during a critical incident that described how change stimulated behaviors. All of the participants interviewed chose to react, or to do something, when confronted with an unexpected and sudden change event. The do something category is interchangeable with leadership emergence. Even so, several interviewees speculated as to why or how an individual could do nothing.

It's hard for me to imagine but I've been on incidents where people walk by and say it's not my problem to deal with. They just don't have the same level of ideals or base morality. (Ian)

One interviewee described the difference between an individual that does

something to one that does nothing in the following way.

People with training, with experience would all react in a similar way. . . . Some people are going to react and go help people and others are going to be shut down and not do anything. . . or worry about what's going on. I think training helps but that boils down to the person's personality whether they are going to do it or not. . . Some people are trained for war who are heroes and are great and some people [who] you never thought would be a hero is the most competent person there and the so-called hero could be cowering in the trenches. (Ren) 
Some interviewees differentiated between individuals who would not or could not arise as leader, from individuals who were willing and able to emerge as a leader. The distinction between the do-somethings and the do-nothings represented the first decision in the naturalistic framework of a critical incident. Even though interviewees described reasons why an individual might choose to do nothing, no one seemed to understand fully that type of individual. Moreover, although the type of individual who would do nothing was recognized as a possible alternative to leadership emergence, many did not recall ever witnessing this behavior. All of the interviewees who made this distinction agreed that every individual had the potential to rise as a leader but some chose not to out of fear, lack of experience, or lack of compassion. One of the interviewees, Zach, described it like this.

Everybody has the ability to do that even though they may not want tothe ability to step up and be leader. A lot of them choose not to out of fear of screwing up or getting hurt. ... I think there is a correlation between the sudden stress when the hormones get released. . . . We either panic or just do what we need to do. Everybody has the ability but some people choose not to use it. (Zach)

Their interpretation for inactivity, which is relevant to the research question, was described as an individual freezing or becoming paralyzed when confronted with a critical incident. Other reasons for individuals to do nothing, which was drawn from conjecture rather than individual experience, was a fear of failure, not having prior experience, or the lack of desire to step up. This response, that some related to the physiological response of flight or fight, seemed to be a rare occurrence in the retrospective accounts. 
I really believe many people have a fight or flight mechanism. . .they freeze, or panic or back away. Or they say something needs to be done so let's help. I don't know where that comes from.... I think that some folks might not necessarily be the leader type-whatever characterizes that-in their every day life-but if something happens they're gonna step up. (Dan)

You see some people who have a prescribed leadership position who freeze-they are paralyzed-you see some people thinking way outside the box. (Eiji)

The behavior of individuals who do something in response to a sudden change event, known here as the do-somethings, are the central subject of the research. Rapidly and prominently displayed characteristics were identified in individuals involved in a sudden change event. These indicators were linked to the ability to solve problems and make decisions in a quick and efficient manner, hence, leading to an unfolding of leadership success outcomes. The terminology used to describe an individual's choice to do something was frequently referred to by the interviewees as stepping up. In the event continuum perspective referred to earlier, motivation to so something or do nothing came first, how that choice was observed and identified came second, decision making and problem solving growing out of prominent characteristics came third, and success or failure in individuals who responded to a sudden change event followed. The diagram below is a pictorial representation of the event continuum perspective. 


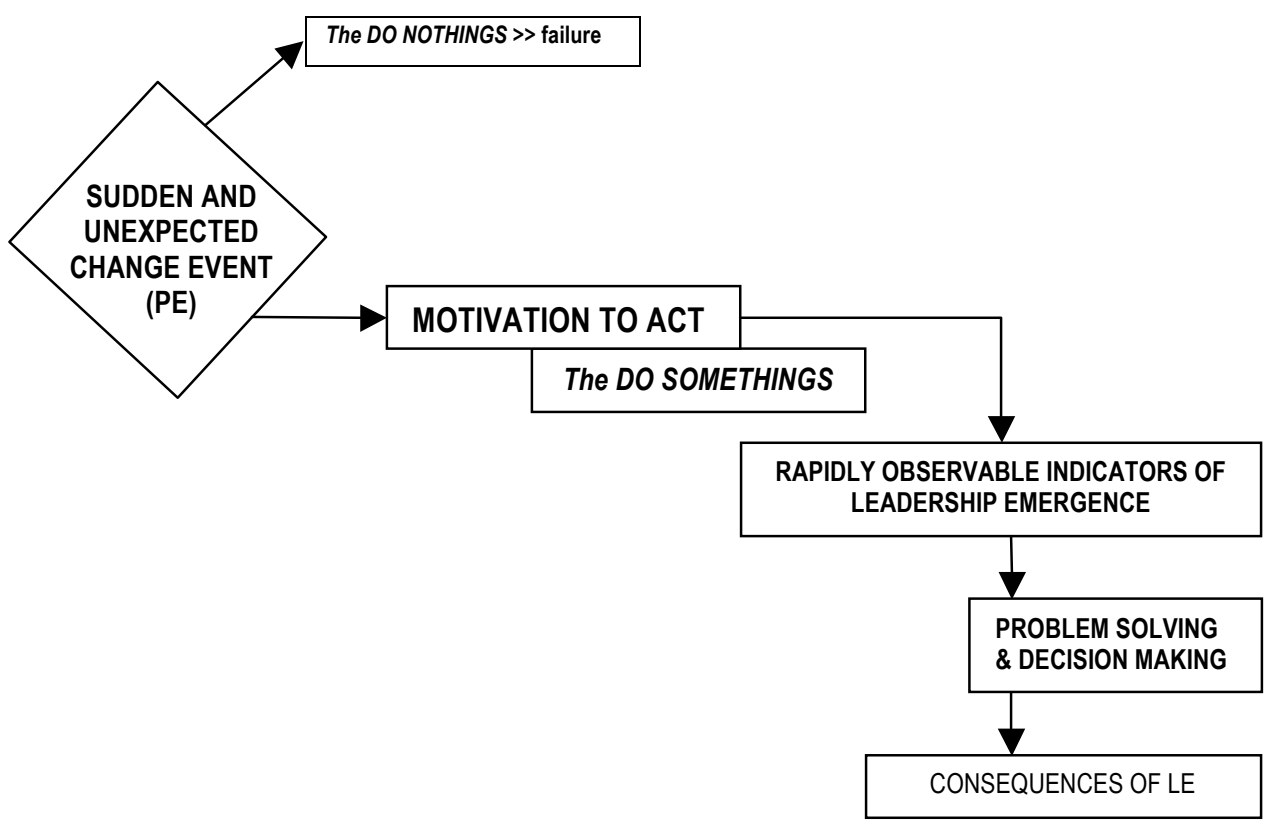

Figure 1: The Event Continuum Perspective Indicating a Sequence of Events

Motivation to Step Up and Lead

The data from interviews identified eight reasons why individuals were motivated to step up into a leadership role but three occurred frequently (see Appendix C). These frequently occurring drivers that characterized the spark for leadership emergence were instinct, compassion, and responsibility to others. They appeared in responses compiled from three perspectives of leadership: interactions with official leadership, unofficial leadership emergence, and self as leader. The most frequently cited motivation for individuals to do something was compassion, concern and caring for others, which was mentioned 24 times. Instincts arising from experience or training presented at least nine times. There were at least eight instances of individuals, often without a conscious thought process, who reacted to a perceived need. A deep sense of responsibility stood out as the third significant motivator of leadership emergence and had several descriptors. 
Motivating factors that appeared one or more times in the interviews included commitment to humanity, the desire to help, the pressure of the situation, and frequently heard was, it was just the right thing to do. Ian discusses the rise of unofficial leadership emergence below.

Something had to be done and he responded ... when people are faced with adverse circumstances their overall compassion for others drives a lot of their ability to do things they would not normally do. (Ian)

In every case, the rate of leadership emergence in an individual was described as rapid, immediate, almost immediate, instant, or within minutes. Once it was established that there was a motivation for an individual to emerge as a leader, the next questions probed deeper into how it could be observed. The findings that describe what leadership emergence looked liked in terms of individual behaviors are described below.

\section{Prominent Characteristics of the Do-Somethings}

The interviewees were asked to describe how they were able to identify that leadership was emerging. Responses from two questions, one that asked interviewees to identify the most prominent leadership characteristics in themselves and second, observable indicators of leadership emergence in others, were combined for this section of findings. These questions were intended to draw out what interviewees observed in others and interpreted in themselves, as the excerpts below will illustrate. As was established earlier, motivation was the ignition to respond, but the mechanism or observable indicators of leadership emergence appeared in distinct ways. Three frequently occurring behavior categories stood out above the rest. A sense of calm, a quick assessment and analysis of the situation, and a rapid physical reaction without 
regard to self, were the most frequently cited indicators when all responses were tallied. These descriptors, which can be generally grouped as emotional, cognitive, and physical, link the change event to the mechanism of leadership and define what the individual was processing at the critical decision-making moment. These responses described the mechanism that ignited the decision-making process that carried throughout the sequence of behaviors.

An individual's emotional indicator, a sense of calm and the perception of calmness in others, was a frequently observed characteristic in leadership emergence. A sense of calm was described in 15 responses by the interviewees describing themselves or others. Related themes and subordinate themes to the characteristic of calmness were the ability to focus, to gain clarity, and the ability to step back and listen. Other interview responses that supported a sense of calm as a predominant characteristic included a reference to a second sense as the ability of knowing what would happen next. An intuitive sense, knowing that something was out of place or not right, grew out of the condition described as a sense of calm. A sense of calm is described as emotional control, a pragmatic indicator, in the following excerpt.

You have to remain totally calm. You have to. As soon as you get miserable information in any crisis, you step back and you just sit down and listen and take it all in-and don't react to it immediately. In other words, sit and think, take a moment, don't take immediate action until you know what's going on. (Mark)

A cognitive indicator, the ability to quickly assess and analyze the incident appeared frequently as a prominent and observable leadership emergence characteristic. Figuring in as the second most prominent theme in leadership emergence, the ability to 
assess the situation was related to responses that included critical thinking, in depth knowledge, intelligence, and experience. Experience, lending itself to leadership emergence, was mentioned more frequently by the first responder/paramilitary as a product of their training.

I was able to assess really quickly what we needed and get the right resources coming. Quick and accurate assessments are my strengths. (Jing)

Other findings that fit here include the ability to see the end point, or in other words, the big picture, which was a skill related to the ability to anticipate next steps. Related to that was the innate ability to know what to do, take control and stay in control of the situation. Awareness of others, learning quickly, and organizing resources may be among characteristics that could also fit in the cognitive response category.

I can see the big picture very quickly and I can make quick and strong decisions once I have the big picture in mind. I am very decisive. When I decide something is or is not going to be done-it is or is not done. I make those decisions very quickly. I am generally pretty clear in what I am doing and when I am not, I usually back off and ask for advice. (Mick) Knowledge, intelligence, and experience indicated that the individual knew exactly what to do immediately. At least two out of the three concepts were grouped together as one descriptor in 27 responses with intelligence being the least mentioned indicator. Some respondents claimed that prior knowledge was closely related to intuition. Communication ability was mentioned as a prominent indicator five times.

The other thing that is really strong [in me] is that I ...bring everyone together and debrief keeping the communication open at all times, so that everyone knows what's going on. (Amadi) 
The third frequently cited observable indicator to leadership emergence was a rapid physical response without regard to the risk to one's self. This category is complex and for now, is presented not as an attempt to analyze responses, but rather to preserve the rich detail of responses for analysis later. During the interviews, I had frequent opportunities to listen as participants recalled that they did not think about their actions, or the risk to themselves during a critical incident, but reacted impulsively. Retrospective accounts from all three leadership perspectives, official leadership, unofficial leadership, and self as leader, were rife with phrases such as; "jumping into action", "did not think of myself", "tremendously energized", "positive attitude". Interviewees indicated that their desire to help and/or their concern and compassion for others compelled them to put the well-being of others first and detach from their own well-being. Some referred to this as going on "autopilot" or getting into the emergency medical technician (EMT) mode.

In a split decision rescue scenario I would say my impulsivity is appropriate-in terms of sorting out the risk and making a decision in terms of risk benefit analysis to myself and to the patient. (Ren)

These findings in the data indicated a strong leadership emergence behavior as the willingness to take a risk and step forward with the welfare of others as central. Without suggesting a premature analysis, there was early evidence that the more highly trained and experienced the interviewee was, no matter what their profession, the more likely they were to put themselves at risk for others. This idea will be revisited in the analysis section.

Many responses did not fit neatly into emotional, cognitive, or physical themes. Other characteristics that described the emergence of leadership included the ability to 
communicate ideas, decisiveness, and the willingness of a leader to work as an equal with subordinates and assume the same risks. There was significant overlap in the concepts previously mentioned to spiritual indictors and to leadership emergence processes that interviewees could not fully explain. Some very significant comments related to spiritual motives and indicators of leadership are difficult to categorize simply and clearly. For example, one interviewee captured this theme in the following comment.

He could magically draw people to him.... [He had] a special quality where you know that 'this guy has your back'. I've never been able to quite define it. (Colin)

\section{Character Faults in the Emerging Leader}

Weakest characteristics were described by the do-somethings not as a failure but rather; an ability or characteristic that could be made stronger in the future. Six respondents could not identify a weak characteristic in retrospective accounts of emerging leadership. Three respondents cited insufficient empathy and compassion for others while in a leadership role. Other responses to weakest characteristics included the inability to assess accurately the situation and the inability to see the full scope of the change event. Others cited lack of follow through, reacting too quickly, and becoming easily overwhelmed, as weakness that were detected immediately after leadership emerged.

Being too critical-and a lack of empathy toward management. ... I was just appalled at the lack of good leadership-it made me furious at times. (Caitlin)

[I was] too focused on the victim and not enough focused on the group. [I] lost sight of the safety of the group [and I] probably did not have enough empathy or sympathy for the victim. (Sam) 
These were minor and correctable traits and included the inability of the emerging leaders to take care of themselves as the sudden change event unfolded. This weakness had the most bearing on the duration of leadership. Even though a rapid physical response without regarding risk to one's self was considered an indicator of leadership emergence, it was also cited as a weakness. The inability of a leader to protect their physical and emotional well-being affected decision-making ability in official leadership and self as leader. It resulted in a break down, within days, of the individual's ability to think, focus, make a decision, and communicate that decision. It hindered the emerging leader's ability to sustain.

The inability to see the big picture was cited as another weakness. Descriptors of emerging leaders came with it a hyper-focus on the situation at hand. This finite focus on the immediate tasks, a single aspect focus, was cited four times when describing self as leader.

It was a long while into it before I saw the whole big picture. I think I hyper focused on what I was doing at the moment and didn't take enough time to step back out of it. (Barb)

\section{Preliminary Findings Linking Sudden Change with Leadership Emergence}

The responses to questions concerning the relationship among concepts, particularly investigating the linkage if any, among leadership emergence, sudden change, and decision making, struck at the heart of the research. The first task was to determine whether there was a linkage and in fact, the data showed a strong link. However, the primary question in the research is; how are the concepts linked? The responses can only be regarded as a collection of opinion and not proof of a relationship. 
The data collected found that out of 15 interviewees, 14 had very strong opinions about the linkage and their responses were given without hesitation. One interviewee had not given it much thought. Twelve interviewees described the relationship in terms of a sudden change event as a transition of individuals into leaders and that it was a personal choice to step up or back down. This is consistent with those who thought a critical incident was a critical indicator or testing ground for leadership emergence.

Findings support the premise that a sudden and unexpected change event triggers leadership emergence in individuals. The data indicated, at least from the perspective of individuals with some level of professional involvement in critical incidents, that there was a cause and effect relationship. One of the individuals related an experience of a group spontaneously self-organizing as an example of the two concepts coming together. Two interviewees thought leadership could emerge only with prior experience. This theme will be explored later in more depth in the analysis section as will the responses. Initial findings indicated that interviewees established a strong to very strong linkage with the concepts.

I think that [a critical incident] is where all leadership comes out of. ...It is where the core comes out of. The incident is essential. (Wade)

Eiji, a critical incident intervention specialist, thought that the linkage was overwhelming obvious.

That's like asking if there is a relationship between sun and light. (Eiji)

\section{Survey Findings}

The findings from the multiple-choice survey were generally grouped in three categories: decision making, motivation to act, and observable indictors. The findings 
below are related to the fictional critical incident scenario given in the survey. The rate and style of decision making was not impulsive, rather, the majority of respondents indicated that they would make a decision after a few minutes of either personal deliberation or with consultation with the group. Half of the respondents would make an instinctive decision based on their training or experience and would take action immediately to evacuate the individuals at risk. Almost all of the remaining respondents had a broader sense of responsibility to protect the individuals who were in the physical proximity of the leader and those who were not. An authoritarian decision- making style was chosen by almost half, while just over half of the respondents chose a consultative style. A summary of survey results can be found in Appendix D.

A significant majority of respondents indicated that they would assume a leadership position immediately based on their experience. The motivating factor behind the rapid actions taken by the leader was the safety of those immediately at risk. Here it is implied that the leader could affect the outcome based on the decision making. Decision making was associated with the anticipated outcome that everyone would be safely out of harms way. All respondents indicated that they were motivated by compassion, but the survey did not probe responsibility and instinct as alternative motivating factors. The overwhelming majority though that their ability to assess the situation was their strongest leadership indicator, while a quarter of the group were driven by compassion.

As the situation advanced from no danger to extreme danger, the emotions of the leaders evolved from cooperative, to anxious, to responsible. The strongest self-perceived emotion indicated at the moment of the crisis was empathy toward the individuals at risk. 
Putting one's self at risk for the well-being of others was divided between those who would not hesitate to do so, those who would not, and those who did not know what they would do. Those who would not put themselves at risk for others weighed slightly in the majority.

Findings from the survey did not fit so neatly into the response categories that formed in the interviews. Out of 18 questions, there was a significant degree of consistency within each response but few of the responses either supported or contradicted interview findings. Answers to the multiple-choice survey questions did not reveal a definitive link, but rather an implied link in the relationship between a critical incident and leadership emergence. The majority of respondents perceived that a critical incident had the potential to change someone or something forever, which affirms the premise of this study.

\section{Preliminary Findings for Creativity, Courage, and Compassion}

Each interviewee was given a question that probed the relationship among various concepts and leadership emergence. Creativity, courage, and compassion did not appear as observable indicators or characteristics of leadership emergence in the opinions gathered from almost all of the interviewees. But most interviewees related one or more concepts as a critical aspect at some point in the leadership emergence process. Creativity, courage, and compassion appeared at one or more points on the real time event continuum perspective. Creativity in particular, was often related to effectiveness and appeared later in the sequence. The data from the interviews rarely indicated that creativity, courage, or compassion were observable indicators at the moment of 
leadership emergence, but rather, as something that was deeply embedded in the individual beforehand or materialized later on in the process. Only one multiple-choice survey question addressed the indicators that were listed among adaptability and motivation. Out of the five self-descriptors, adaptability ranked higher than motivation, and creativity, courage, and compassion, were not indicated at all.

Findings revealed that interviewees consistently indicated that creativity was a process that enabled leadership to find alternative solutions to emerging problems. It was described as breaking from protocol, making due with resources that are available, and thinking outside the box. Two interviewees cited creativity as the ability that distinguishes effective leadership from ineffective leadership. One interviewee stood out by relating creativity as the fuel in organizational growth and change.

The whole idea is that people inside the organization and the leader have to constantly grow. In order to do that you have to be creative because you have to constantly change the way you think about things. If you don't the organization will never grow. You have to be creative enough [and] feel comfortable enough with creativity so that you can constantly look at new ways to make the organization grow so that it can reach its potential. (Mark)

Creativity was found to be a tool of leadership and an enhancement to leadership effectiveness. Although all of the interviewees responded that creativity had a significant role, particularly in later stages of leadership emergence, none felt it was an observable indicator of leadership emergence. In other words, creativity in terms of thinking out of the box and breaking from protocol was connected to problem solving ability. Interviewees described creativity as the ability to utilize resources, see things differently, develop a new set of options, and show innovation. 
The concept of courage was most often related to the act of standing by one's decision no matter what the consequences may bear. Several interviewees described courage as the ability of an individual to get past their fear.

I think the biggest thing is the courage to act . . . and not be afraid to do something. I think that is what paralyzes a lot of people. (Dan)

Another interviewee captured a frequently occurring perception of courage in the following way:

They [emerging leaders] have to be [courageous] in order to step up and take the fall in case they are wrong. (Jing)

But interpretations of courage varied greatly. Some interviewees suggested that informed decision making characterized courage and commitment to action without informed decision making was reckless rather than courageous.

There are people who respond who I would say are more stupid than courageous. It is not courageous to jump into a hydraulic to save their friend. There is a difference. There are people who are trained who go into burning building all the time but they understand fire, how it works, its relationship to material, where it moves in the air. ... So it's a calculated risk. (Ren)

Courage was most often found at the end of the leadership emergence continuum as the quality in an individual to stand by their decision at the end of the process. This will be explored in more detail in the analysis section.

I think that there is [a connection] whether it be through an emotional connection or a social connection or spiritual connection. . . . [Courage is] your sum total of base values. (Ian)

Data collected from interviews revealed that compassion was a complex phenomenon that occurred at various times during the leadership emergence process. At least two interviewees indicated that compassion has absolutely no relationship to 
leadership emergence during a critical incident, while the other 13 interviewees perceived it as a core component in those who rise as leader. The difference among those comments was when compassion surfaced. One of the interviewees from the field of critical incident intervention stated:

If you don't have it [compassion] you shouldn't be a leader... it only takes a little compassion to change the whole scheme of things. (Colin)

As many regarded compassion as a critical aspect of leadership, almost everyone interviewed referred to compassion as an emotion that had to be cut off. This idea of disengagement from compassion was captured in the following statement.

Compassion. . . is extremely important but it has to be balanced. . . . You have to [be] caring enough that you want to help but you do not want to sabotage your ability to help by being so distraught that you are ineffective. (Cait)

Leadership may be triggered by your compassion for others-your desire to help them. (Jacob)

The idea that compassion had a separation point was mentioned eight times. Compassion in terms of empathy toward those in need was cited as a primary driver for leadership emergence six times.

\section{Grounded Theory Analysis}

The data collected revealed a complex and dynamic phenomenon that described leadership emergence during a sudden and unexpected change event. The link between sudden change and leadership emergence was immediately apparent but not so obviously revealed was why and how leadership emerged. This process, beginning immediately at the change incident and continuing through the next minutes, hours, and days, is the subject of the following analysis. The problem of interest was how the mechanics of 
punctuated equilibrium as depicted by a sudden change event, triggered leadership emergence or failure to emerge. The framework of NDM, as expressed through retrospective accounts of critical incidents, was a good way to study the roll out of the leadership emergence phenomenon because it examined individual behavior and decision making in rapidly emerging situations.

The theory to arise out of this analysis will include the indicators of leadership emergence and the role that creativity, compassion, and courage have in the process. Since this was and is a complex phenomenon that considered many intervening variables, it is likely that this new theory is only one of many possible explanations of the process. To build such a theory, interview responses were coded and categorized until core themes were found. Survey responses were grouped into themes that were similar to the coding matrix used in the interviews and then analyzed for additional emerging themes. The survey data supported only a few aspects of the interview. Survey findings were siphoned through a reflective coding matrix similar to the matrix used in the interview; however, data did not align well. Although there was little parallel support uncovered in the survey in relation to interview data, none of the data contradicted the interview findings. Survey data was included in the overall analysis as an adjunct to the interview analysis.

All coding themes were emic, arising directly out of the interviewees' perceptions and words. The research analysis was filtered by two main themes each with three sub themes. As hard as I tried, it was difficult to compress each element into little boxes inside charts with cleanly and clearly defined lines. If it were easy to do this, the analysis process would be contrary to a complexity science perspective. As indicated much earlier 
in this dissertation, complexity science presents a lens from which to view a dynamic process that considers many evolving relationships among variables (Poole \& Van de Ven, 2004). The figure below shows how dominant themes begin to take shape in relationship to the event continuum perspective.

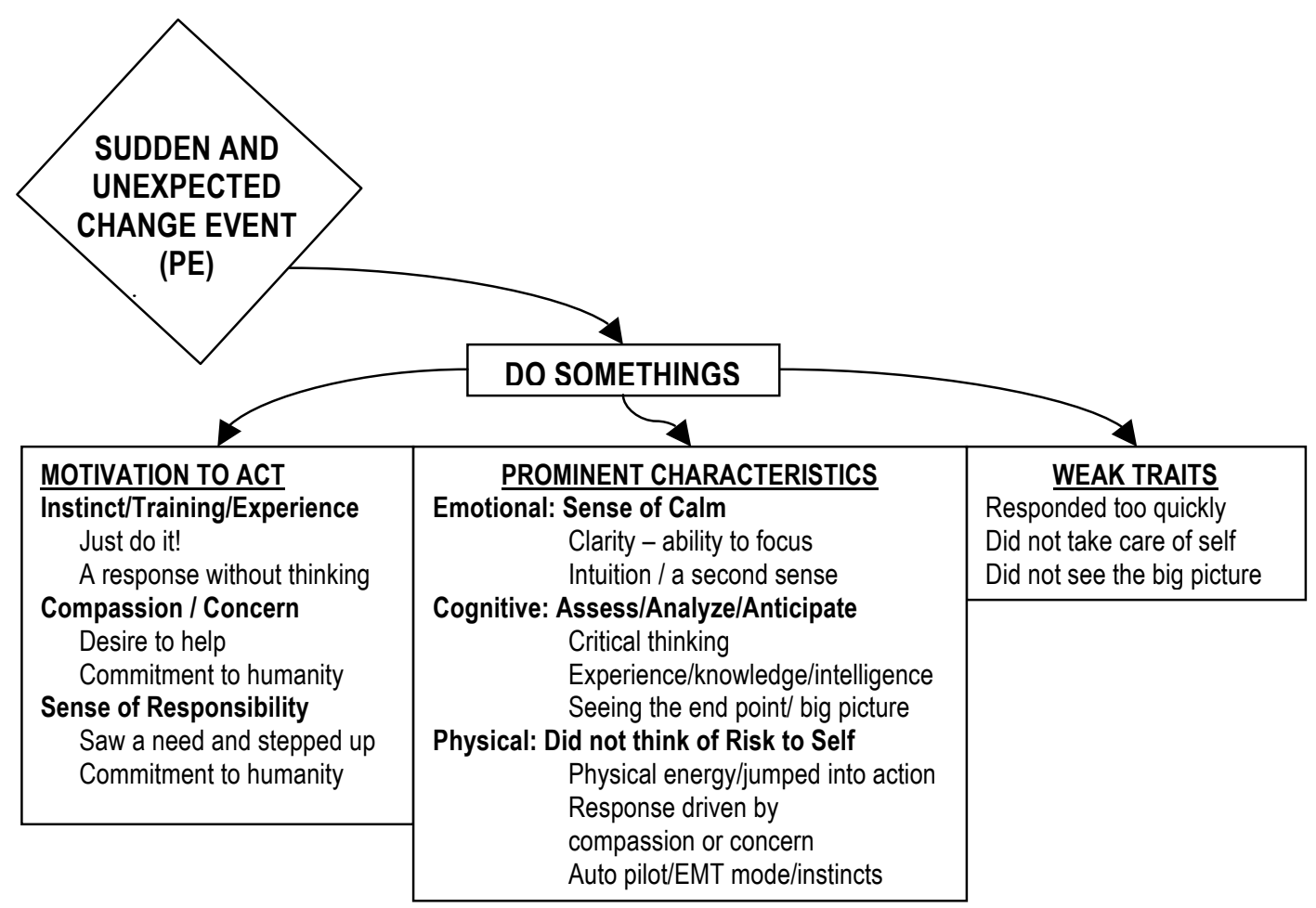

Figure 2: The Event Continuum Perspective Illuminating Core Themes

Core categories, arising out of the evidence, were arranged in a coding method that established relationships between concepts. Although well defined, they may not permanently settle in the position that they seem to fit. The use of a reflective coding matrix, inspired by the work of Wilson-Scott (2008), for both the interview and survey data, was a very helpful analysis aid. The reflective coding matrix and other coding steps legitimized one of the most distinguishable markers in the formation of grounded theory -that themes rise from the data and cannot be forced. The subsequent evidence and 
theory is "grounded in the voices, actions, and experiences of those studied" (Goulding, 2002, p. 106).

\section{The Motivation to Act}

Even though six interviewees speculated as to why individuals would fail to respond when a critical incident occurred, few of them could imagine that type of scenario, and fewer had ever witnessed an individual failing to respond. One of the interviewees in describing his experience as a wilderness leader referring to a critical incident on white water rapids shared the following incident.

[The students] were overly anxious to help. Overly willing-they would have done anything including putting themselves in harms way. ...they weren't concerned about themselves. Most of them just wanted to get that raft down the rapids [and] they didn't care how. These incidents that they talk about in NYC-people dropping dead on a sidewalk and nobody helping. ... I've never had an experience like that. Its always. . . people are just diving on the person who is injured and they want to help. (Sam)

In spite of comments like that one, there were also sufficient references to individuals who would do nothing. Those who failed to respond split the initial decision path immediately following a critical change event. Hence, the real time event continuum is as follows: A critical incident simulates a sudden and unexpected change event.

Although every individual has the potential to emerge as leader, some choose not to act. Therefore, an initial distinction is made between these two types of individuals taking two separate decision paths. The initial event is the critical incident; the second event is the choice to do something or do nothing that separates individuals.

For those who do something, three significant and frequently occurring drivers were identified. The core drivers that motivate individuals are; a) instinct, training, or 
experience, b) compassion, concern, and the desire to help, and c) a strong sense of responsibility to others.

Instinct, training, or experience is characterized by the behavior of instantaneously responding without consciously thinking about it. The motivating force draws from past experiences of the individual whether it is actual experience, training, or having visualized a response scenario in the past. The type of individual motivated by instinct, training, or experience has chosen a career path that is likely to put them in a response situation. Those individuals may be search and rescue specialists, fire fighters, emergency medical technicians, or other types of first responders. The evidence collected from the survey vignette questions that probed the rate of evacuation during a critical incident indicated that $45 \%$ to $75 \%$ of the respondents made decisions without hesitation. This is consistent with the interview data since all respondents in the survey had some level of training, certification, or experience.

The individuals interviewed who fit this description tended to attribute something in their core personality, or make up, that motivated them to help others. These types of individuals affect the outcome of the change event by quick intervention and problem solving through creativity. Another characteristic of this group was to make a decision and stand by the consequences of that decision whether it led to success or failure in mitigating the change event.

The second distinct and separate motivational category included those with compassion, concern, and the desire to help. Over half of the survey respondents felt compassion or empathy toward individuals at risk. The interviewees who supported this 
theme came from all fields including critical incident intervention specialists, executive or wilderness leadership trainers, emergency medical personnel, and paramilitary. These individuals responded to a perceived need or the imminent peril of others. They were willing to take a personal risk to engage in a response to the person in need. Out of the three categories of retrospective accounts, interactions with official leadership, perceptions of the rise of unofficial leadership, and leadership emergence in self, the unofficial, unexpected leaders were most likely to respond as a result of compassion and the desire to help.

Additionally, individuals that were motivated to act were compelled out of fear, facing the consequences of doing nothing, or by their talent for creating organization out of chaos. The context that motivated an individual out of compassion and the desire to help is the unplanned situation that created a series of rapidly changing conditions. Response rates triggered by a sudden change event ranged from seconds to days, depending on the gravity and danger of the situation. The more dangerous and emergent the situation, the quicker the individual would respond. These individuals never considered doing nothing and were compelled to do something by engaging in situational analysis to determine their most effective course of action.

The third driver that motivated individuals to emerge as leader was a strong sense of responsibility toward others. Four interviewees responded that they, or others they observed, reacted because it was "just the right thing to do". Interview responses that supported a sense of responsibility toward others included the story of a leader who did not differentiate his responsibility from that of his subordinates. There was evidence in 
the findings of decision-making styles that emerging leaders were cooperative and consultative, yet in control of the situation. Situational factors, particularly with regard to the degree of danger, had a significant impact on the decision-making style that was connected to the motive of responsibility. A strong sense of responsibility lingered in the individual after decisions are made and the consequences of the change event unfold.

One interviewee described a sense of responsibility as a motivational driver in the following way.

As far as leadership emergence, I think it really has everything to do with the feeling of responsibility no matter what the level [of training]. (Ian)

A sense of responsibility toward others was evidenced in those who stepped up to fill a void in leadership, and when there was an emergent threat to others. One interviewee phrased it as having a "commitment to humanity" (Barb). Individuals in this grouping functioned in a sequence of decision choices and continual problem solving. Weighing the consequences of their choice to step up as a leader, or to support an emergent leader, was not often considered in their decision to do something. Table 2 shown below is a reflective coding matrix for analysis based on the Wilson-Scott (2008) model. 
Table 2: Reflective Coding Matrix for Motivation to Act

\begin{tabular}{|c|c|c|c|}
\hline Core Categories & \multicolumn{3}{|c|}{ MOTIVATION TO ACT } \\
\hline $\begin{array}{l}\text { Processes: Why } \\
\text { Leadership } \\
\text { Emerges }\end{array}$ & $\begin{array}{l}\text { INSTINCT/ TRAINING } \\
\text { OR EXPERIENCE }\end{array}$ & $\begin{array}{c}\text { COMPASSION/ } \\
\text { CONCERN AND DESIRE } \\
\text { TO HELP }\end{array}$ & $\begin{array}{c}\text { A STRONG SENSE OF } \\
\text { RESPONSIBILITY TO } \\
\text { OTHERS }\end{array}$ \\
\hline $\begin{array}{l}\text { Properties } \\
\text { (characteristics of } \\
\text { category) }\end{array}$ & $\begin{array}{l}\text { Instantaneously } \\
\text { responded without } \\
\text { thinking about it }\end{array}$ & $\begin{array}{l}\text { Responded to a } \\
\text { perceived need or peril } \\
\text { of others }\end{array}$ & $\begin{array}{l}\text { Responded because it } \\
\text { was the right thing to do }\end{array}$ \\
\hline $\begin{array}{l}\text { Dimensions } \\
\text { (property location on } \\
\text { continuum) }\end{array}$ & $\begin{array}{l}\text { Drew from past } \\
\text { experience } \\
\text { Core personality of } \\
\text { responder }\end{array}$ & $\begin{array}{l}\text { Compelled by fear } \\
\text { willing to take risk } \\
\text { identified a need and } \\
\text { responded }\end{array}$ & $\begin{array}{l}\text { Fill a void in } \\
\text { leaderships } \\
\text { emergent threat of } \\
\text { harm to others }\end{array}$ \\
\hline Context & $\begin{array}{l}\text { Effect outcome of } \\
\text { unexpected change } \\
\text { event }\end{array}$ & $\begin{array}{l}\text { Unplanned situation of } \\
\text { rapidly changing } \\
\text { conditions requiring } \\
\text { immediate response }\end{array}$ & $\begin{array}{l}\text { Decision making } \\
\text { sequence requiring } \\
\text { continual problem } \\
\text { solving }\end{array}$ \\
\hline $\begin{array}{l}\text { Mode for } \\
\text { understanding the } \\
\text { consequences } \\
\text { (process outcomes) }\end{array}$ & $\begin{array}{l}\text { Ran down the path to } \\
\text { do something courage } \\
\text { to live with failure or } \\
\text { unpopular decision }\end{array}$ & $\begin{array}{l}\text { Chose to respond to } \\
\text { others in spite of the } \\
\text { risk and danger to self }\end{array}$ & $\begin{array}{l}\text { Chose to respond to } \\
\text { others in spite of the } \\
\text { risk and danger to self }\end{array}$ \\
\hline
\end{tabular}

\section{Observable Indicators}

The motivation to respond to a sudden change event was the first stage of

leadership emergence and the second was how that decision took shape. In other words, there were indicators that signaled the sudden rise in leadership that fell neatly into emotional, cognitive, and physical manifestations. Specifically, the emotional indicator was an immediate sense of calm. The cognitive indicator was the rapid ability to analyze and accurately assess a situation. The physical indicator was the emerging leaders' 
tendency to not consider their own well-being and put their selves at risk. These three indicators do not correlate with specific categories of motivation, but grow out of the broad theme that characterizes motivation to act.

The observable indicators capture what the individual was feeling and thinking at the critical moment and is directly linked to the decision-making process that begins immediately and continues throughout the change event. On the real time continuum, each of these indicators occurred immediately preceding decision making. The three indicators of leadership emergence, an immediate sense of calm, the ability to analyze and assess, and not thinking of the risk of harm to self, strongly dominated all other characteristics that could be observed through retrospective accounts. Other characteristics found in the official leadership, unofficial leadership, and self as leader categories included communication ability, confidence, and decisiveness. These traits were not observed as frequently nor were they linked directly to decision making.

Data that supported evidence of an immediate sense of calm as an emotional manifestation of leadership emergence were well defined. They included clarity, the ability to focus, intuition, a second sense, and heightened awareness of everything around the individual. Although response was immediate in the real time event continuum, many interviewees described their perception of surrounding events as slowing down. Two interviewees who described an overwhelming sense of calm in a critical incident described the emotion in the following ways.

Everything slows down for me. (Amadi) 
I have a 10 second delay before I react ... I'm the guy that's sitting in the chair for 10 seconds and but by the time I get up and get there I have everything figured out in my head. (Ian)

The sense of calm occurred at the first awareness of a critical change situation that typically involved risk of harm to others. This indicator of leadership appeared to be directly linked to decision making because it afforded the individual clarity and the ability to sit back and listen. Decisions made out of this emotional indicator are wellinformed and based on evidence quickly gathered through observation. Additionally, the process of maintaining calm for a few seconds before reacting enabled the responder to gather resources and prepare for rapid decision making and problem solving.

A sense of calm might be connected to the ability to assess and analyze the situation, the second observable indicator of leadership emergence. Although defined with a separate path of evidence the interconnectedness of leadership emergence indicators cannot be underestimated. The observable indicators may not be mutually exclusive and may occur with, adapt to, or transform into another, as is the case in this unofficial leader unexpectedly emerging.

His strongest thing was that he was calm enough to think about the end result before he committed people to action. He would try to see the big picture every time somebody would put a question to him. And because he had that calmness of thought I think people noticed that he had their safety in mind. They started to pay more and more attention to his acting and thinking in a safe manner. His ability to stay under control and think to the end point was the strongest thing he had going for him. (Mick)

The ability to analyze and assess the situation, grouped into a cognitive heading, stimulates the individual's sensory abilities and includes heightened powers of observation and a heightened awareness of others. Situational awareness, a related 
concept to situational assessment and analysis, was cited by three-quarters of the survey respondents as their most prominent characteristic. Individuals in this group matched what they observed to prior experience and knowledge from similar situations. Some interviewees characterized in-depth knowledge as related to an intuitive sense, or a sense of just knowing what was going to happen next. One of the interviewees described his own leadership emergence as drawing from experience and deep knowledge in a particular situation.

Experience probably served me very well because I had . . . a little bit of 'what's gonna happen next' which they didn't have. That was valuable. (Colin)

The indicator of analysis and assessment of the emergent situation is characterized by interviewees as critical thinking, vision, and intelligence. An individual's process that seemed to occur with this indicator was his/her ability to see the big picture or end point, that determined the path and consequences of decision making. Describing the ability to see the entire event with clarity and the ability to anticipate the direction that the change event would take was a consistent theme in describing leadership emergence characteristics in the interviews. Interviewees expressed that the ability to see the big picture was a significant and easily identifiable marker in leadership emergence. This omnipotent quality radiated a sense of calm, control, and confidence in their subordinates.

The third observable indicator in leadership emergence was described in all three types of retrospective accounts of leadership. The indicator that described individuals who did not consider the risk to themselves when choosing to take action in a critical 
incident repeated throughout the interviews. This idea is closely related to an oversight rather than an inability or conscious choice by the individual. Leadership emergence and the responsibility that followed consumed the individual who fit this type, and was characterized by physical energy and forward momentum. The individuals who did not think of the risk to themselves, or have witnessed leadership behaving in this way, described it as blocking of their primary physiological needs. They were often motivated by a sense of responsibility or concern for others that stemmed from the intensity of the situation. One of the interviewees, a critical incident stress debriefer during a catastrophic fire in a Rhode Island nightclub, described it in the following way:

I forgot about that [myself] completely, and that's the truth. Sleep was not even a concern until I was at the point I couldn't even function. (Barb)

In another instance, not considering risk to oneself collapsed existing leadership during a critical situation that unfolded over days. Mick, an interviewee working in an earthquake relief effort, witnessed the collapse of leadership for this reason.

What happened during that [earthquake relief] like many leaders, he didn't take care of his own self and he went from a decisive leader who pointed his finger at my nose... who in three days or four days later, without any sleep...responded with "Uh, Uh, Uh...Uh...” (Mick)

Later in the interview, Mick spoke of the unofficial leader who rose to fill the void in leadership.

[He did not take] time for himself. He had a tendency to try to do the same things the leader was originally accused of doing which was keep going, keep going, keep going. So ultimately, in the very final day of the thing, he was extremely sick. (Mick)

Table 3 shown below is a reflective coding matrix for observable indicators based on the Wilson-Scott (2008) model. 
Table 3: Reflective Coding Matrix for Observable Indicators

Core Categories OBSERVABLE INDICATORS

\begin{tabular}{|c|c|c|c|}
\hline $\begin{array}{l}\text { Processes: } \\
\text { How Leadership } \\
\text { Emerges }\end{array}$ & $\begin{array}{c}\text { EMOTIONAL: } \\
\text { IMMEDIATE SENSE OF } \\
\text { CALM }\end{array}$ & $\begin{array}{c}\text { COGNITIVE: ANALYZE } \\
\text { AND ASSESS THE } \\
\text { SITUATION }\end{array}$ & $\begin{array}{c}\text { PHYSICAL: DID NOT } \\
\text { THINK OF RISK TO } \\
\text { SELF }\end{array}$ \\
\hline $\begin{array}{l}\text { Properties } \\
\text { (characteristics of } \\
\text { category) }\end{array}$ & $\begin{array}{l}\text { Clarity and ability to } \\
\text { focus } \\
\text { Intuition second sense - } \\
\text { confidence }\end{array}$ & $\begin{array}{l}\text { In depth knowledge - } \\
\text { intelligence, critical } \\
\text { thinking - awareness of } \\
\text { others }\end{array}$ & $\begin{array}{l}\text { Physical energy - } \\
\text { Jumped right into } \\
\text { situation } \\
\text { Positive attitude }\end{array}$ \\
\hline $\begin{array}{l}\text { Dimensions } \\
\text { (property location on } \\
\text { continuum) }\end{array}$ & $\begin{array}{l}\text { Immediate response - } \\
\text { situation slows down }\end{array}$ & $\begin{array}{l}\text { Slightly delayed } \\
\text { response - ability to get } \\
\text { and keep control }\end{array}$ & $\begin{array}{l}\text { Willing to take risk - } \\
\text { Immediate response } \\
\text { driven by compassion } \\
\text { and concern }\end{array}$ \\
\hline Context & $\begin{array}{l}\text { At first awareness of } \\
\text { critical change situation } \\
\text { usually involving risk of } \\
\text { harm to others }\end{array}$ & $\begin{array}{l}\text { Knew what would } \\
\text { happen next Anticipated } \\
\text { process that was likely } \\
\text { to unfold }\end{array}$ & $\begin{array}{l}\text { At first awareness of } \\
\text { critical change situation } \\
\text { usually involving risk of } \\
\text { harm to others }\end{array}$ \\
\hline $\begin{array}{l}\text { Mode for } \\
\text { understanding the } \\
\text { consequences } \\
\text { (process outcomes) }\end{array}$ & $\begin{array}{l}\text { Stepped back to listen - } \\
\text { ability to make the most } \\
\text { informed decision and } \\
\text { gather tools to solve } \\
\text { problems }\end{array}$ & $\begin{array}{l}\text { Decisions based on } \\
\text { ability to see the big } \\
\text { picture/the end point }\end{array}$ & $\begin{array}{l}\text { Risk of rapid breakdown } \\
\text { in ability or } \\
\text { instantaneous success } \\
\text { Create a void in } \\
\text { leadership }\end{array}$ \\
\hline
\end{tabular}

Not considering the risk to oneself is an indicator that can be observed within minutes, hours, or days following a change event. These individuals are not only willing to take a risk to help, they do not prioritize their own safety and stamina. This had both a good side and a not so good side. The benefit is the instantaneous ability and success in mitigating a change event. It may often involve actions that save a life. There was evidence gathered from the interviews that the highly trained first responders are aware that the collapse of their ability 
puts everyone in the situation at risk. They tend to balance the risk to themselves with the benefit of others. Nevertheless, some individuals who rise in leadership positions do not. The disadvantage to this indicator of leadership emergence is that it comes with the risk of rapid breakdown in physical ability, clarity in thinking, and the ability to make decisions.

\section{The Role of Compassion}

Compassion might have been the most difficult concept to capture when the findings were reviewed and sorted. One thing that everyone interviewed seemed to agree upon was that the presence of compassion must be balanced with absence of compassion in a critical incident. Several interviewees implied that there was a time line or chronological order, for compassion to emerge with leadership. The data revealed that compassion is an essential component in a leader and that it may be a trigger for leadership emergence. However, in order for the emerging leader to remain operational, compassion must be buried under performance and task. With it present, the leader may become distracted and dysfunctional. Without it, the leader does not have the core from which to operate.

Several references were made to this phenomenon including Ian who described this cut off in the following way:

You have to be compassionate enough to put your life on the line or in some form of jeopardy. . . but you also have to be dispassionate [enough] not to step over that line. . . to function. (Ian)

Within the framework of decision making and response, compassion is interference. Another interviewee was very articulate in explaining this phenomenon. 
I think compassion needs to be there but in the midst of an incident I'm not too sure you can let that compassion take over. I think you have to be more operational. I think that compassion comes before. Compassion is why you do training, take more classes, why you learn more, and how you look at yourself so that you can provide compassion but not let compassion take you over. (Barb)

The truthful intent of the research was to investigate compassion solely in terms of whether compassion was an observable indicator of leadership emergence. What was discovered is that the investigation did not scratch the surface of the complex nature of compassion's relationship to leadership. One of the interviewees, a first responder, who most clearly articulated an ability to cut off compassion during a critical incident, offered the most compelling story of compassion in describing her own leadership emergence.

We had once incident [rescuing an injured victim who broke his leg and] the head of his femur was broken [and we were] about six miles into the woods. That night was 20 below [zero] and 40 below with wind chill and we spent the night with him on the side of the mountain. We couldn't fly him off and we felt it was too dangerous to move him. . . [the man was in so much pain] you could not get him to stop screaming unless you talked to him. I didn't have drugs to help him with pain and he was in excruciating pain. ... I sat next to him the entire night and [the only way I] got him to stop screaming was to talk. We discussed anything and everything about both of our lives for hours and hours. ... That was definitely compassion. I totally understood and I felt horrible [that I could not give him anything for the pain due to backcountry protocols]. (Jing)

Even though stories such as Jing's were threaded throughout the retrospective accounts, compassion found its place embedded in leadership. On the continuum of leadership emergence, its existence could be identified prior to the critical incident, or punctuated change event, and after the event was resolved. Compassion was found to be a necessity in leadership but was most often suppressed in the individual, or cut off, during the change event and the leadership emergence process. Each characteristic of leadership, 
creativity, courage, and compassion lie on different places in the real time event continuum but none intersect at the critical moment of leadership emergence.

The Fit for Creativity and Courage

Creativity and courage were not observable indicators of leadership emergence rather; a phenomenon directly linked to the problem solving and decision-making behaviors. On the time continuum of leadership emergence, creativity appeared after other indicators were observed. Creativity in particular was regarded by many as a devise to solve problems and enabled a new way of seeing. Hence, creativity is the ability to find physical and emotional solutions to problems quickly without resources. Creativity in leadership is a pathway that breaks from the typical method of doing things or protocol, and presents a new set of options. It is characterized by a particular way of thinking that most interviewees referred to as out of the box.

Creativity was linked to leadership effectiveness rather than leadership emergence and occurred after the leadership emergence phenomenon occurred. Although considered a vital tool in leadership, creativity is neither a motive for leadership emergence nor an immediately observable indicator. This is summarized in the comments of several interviewees. One interviewee who worked as a first responder framed creativity in the following way:

I think in leadership [and] dealing with CI's is that you don't have everything you want, you never do, so you have to improvise, adapt, and overcome. I think that protocols and rules are for people who can't think on their feet. Life is $99 \%$ gray and only $1 \%$ black and white. Protocols fit into that $1 \%$. (Zach) 
Courage weaved in and out of the leadership emergence process but was most noticeable at the end of the event continuum. It did not appear to be a consistently observable indicator of leadership emergence. Courage was described as sum total or a moral core of the individual who will not back down. It is where those who emerge as a leader stand in the end. It is characterized by their ability to hold their ground after they commit to a decision.

Courage was linked to the consequences of decision making when outside forces second guess leadership after the fact. One of the interviewees, a critical incident specialist, might have captured this theme better than others in this statement:

I think the courage to stand up and hold your position when everybody else is going a different way is very important in leadership. ... So if you don't have courage you don't want to be taking a lead position. (Mick)

Courage seemed to be embedded under the motivation to act early in the process but became a fully recognizable and ongoing entity of leadership late in the process.

Creativity and courage are strongly associated with leadership as the ability to find solutions to problems when no resources appear to be available, and the capacity to remain committed to decisions and beliefs even though they may be unpopular or failed. Creativity and courage were neither a driver for leadership emergence, nor an indicator; however, their position in the continuum of events of the leadership process during a critical change event was strongly indicated in the data.

The Meaning Is in the Words

Analysis of interview data revealed a rich and textured representation of leadership emergence during a sudden change event. The rich texture was revealed through stories 
and examples rather than simple one or two word answers. There was an inconsistency in the retrospective accounts with regard to time. Critical change scenarios ranged from immediate response, within seconds, to change events that played out over days and weeks. Speaking in broad strokes, most of the responses to questions were within a narrow range of time and appeared to be consistent. The extended period of time compared to immediate response time did not seem to alter findings in leadership emergence behaviors.

Explanations, examples, extensive background information, and anecdotes were part of the composition of almost every interview response. This may have inadvertently created an inconsistency in interpretation and groupings in the categories of motivation to act and observable indicators. Out of the many stories of retrospective accounts, I tried to piece together elements that would support frequently occurring concepts. For example, a sense of calm was linked with clarity, competence, and heightened focus prior to decision making. Since the meaning subjectively extends beyond words, there may have been a wider span of interpretation than documented.

As for actual content, the similarities that arose out of the sample population in the multiple-choice survey from those who had first hand experience in some sort of critical incident were significant. There were, however, inconsistencies in the survey data in relation to the interview data. Those inconsistencies in data analysis included the inability to support findings with interpretations of survey responses and the call for conjecture in analyzing survey responses. This misalignment of data collected from the survey compared to the interview hindered the consistent inclusion of the survey 
responses in the analysis process. Interpretation of another researcher combing through the raw data might differ from the analysis presented here. Two popular perspectives that were not addressed in the analysis and theory formation were followership and group behavior.

Group Versus Individual Behavior

The analysis of the data was solely focused on the behaviors, motivations, and indicators of an individual. The interpretation of the data was limited to the process that occurred in the mind and heart of the individuals who emerged as leader during a sudden change event. The interpretation did not address references to self-organizing groups and the role of followership because there was not enough evidence to suggest that either of these concepts could contribute to emerging themes. With that said two alternative explanations to data points will be offered here for future researchers as a launching pad for further study.

Neither the concept of followership nor self-organizing systems are new to leadership studies. Leadership is often thought to be nonexistent without followership. This research took a different approach to this old paradigm, but an alternative approach was evidenced in some of the data collected. In fact, some of the critical incident experts in the field defined leadership in terms of followership. For example, one interviewee described how he was able to identify leadership emergence in an unlikely leader.

Others began to follow and listen as this persons voice came out. It was a strong voice. (Wade)

An alternative interpretation of the data concerns followership connected to communication skills. Although communication was mentioned in several responses, 
communication in leadership is less of a quick observable indicator and more of a science in and of itself and beyond the scope of the research question. The core purpose of this study was to discover a relationship between punctuated equilibrium and leadership emergence, but followership may have presented an alternative approach as evidenced by the comment made by one of the interviewees referencing the literature.

The only way that you know there is leadership is if somebody follows. It is that simple. (Eiji)

Self-organizing systems, a phrase familiar to those who study leadership and complexity science, particularly the work of Wheatley (2006), characterized group behavior in an emergent situation. Even though this concept appeared infrequently in the data, it opened the door to an alternative approach to thinking about leadership emergence during a sudden and unexpected change situation. In a description of emerging leadership in unofficial leaders, one interviewee thought of a story in which the phenomenon described the intersection of a critical incident with leadership emergence.

A woman tips over [in her kayak] and dislocates her shoulder. I was in the sweep boat so I was last. But by the time I got there the whole group had formed functional roles and took charge of the situation. There was not an official leader and even though I had the most experience, they had formed a cohesive group and they self organized. They had it worked out to help her. (Ian)

Another instance of groups self-organizing was prompted by a critical incident but exacerbated by dysfunctional leadership. Recalling work in a hurricane relief effort during an interview on August 13, 2008, Cait described a group of 30 volunteers organizing tasks and functions to create a quick and efficient response. She described how the need was identified and that it was not being addressed by the existing 
leadership. Again, in a description of unofficial leadership emerging, the group self organized and became one functional and efficient unit.

The theme appeared in the retrospective accounts in this research but not often enough to be recognized as a core theme. It is regrettable because the concept of groups as self-organizing systems rising to meet a humanitarian need is a popular concept in today's world. It is worthy of additional empirical studies to pick up where others left off. On the eight anniversary of the September 11, 2001 terrorist attacks of the World Trade Center, the popular media exemplified the emergence of groups of individuals who came together and self organized to help others. The concept of interconnectedness and selforganizing systems brings this study full circle into concepts from complexity science that attempt to explain the phenomenon of leadership emergence triggered by a punctuated event.

\section{Summary}

Chapter 4 began with a summary of findings from interviews and surveys. The interview data were the primary source of emerging themes. The survey data did not yield supporting evidence to integrate with themes arising from the interviews. The data were organized in an event continuum perspective and from that sequence, a series of themes began to emerge. It resulted in an organizational pattern from which the data could be fragmented, reorganized, and understood (Glaser, 1992; Goulding, 2002).

The grounded theory process broke themed data into a powerful, sequential process from which theory could emerge. The data analysis uncovered an individual's behaviors that emerged within the seconds, minutes, and hours following a critical 
incident. The data revealed there were three identifiable motivational forces behind the individuals who chose to do something and emerge as leader. Those drivers were instinct and training, caring and compassion, and a deep sense of responsibility for others. The individuals who were motivated to do something were identified by one or more of three prominent and observable behaviors. These indicators of leadership emergence were grouped into emotional, cognitive, and physical reactions. These behaviors were identified as sense of calm, a quick assessment and analysis of the situation, and the choice to act and continue to lead in spite of a physiological risk of harm to themselves.

This chapter described the goal of the research and exposed the purpose of this grounded theory investigation, which was successfully accomplished. That goal was to explore whether punctuated equilibrium, represented as an unexpected change event, was related to leadership emergence. Hence, the theory that arose from the data was that punctuated equilibrium stimulates leadership emergence in individuals. Those individuals are motivated by instinct, compassion, and responsibility. The individuals who emerge as leader are identified within minutes of the change event by one or more of the following indicators: a sense of calm, quick situational assessment, and not being aware of the risk to themselves.

The secondary objective sought to define the role of creativity, courage, and compassion and whether these traits were indicators of leadership emergence. It was revealed through retrospective accounts and examples from 15 interview subjects that creativity, courage, and compassion, were not observable indicators of leadership 
emergence but each had a significant role in the continuum of events. The Summary

Theory table below is a graphical description that compartmentalizes the theories.

Table 4: A Summary of Theories

\begin{tabular}{|c|c|}
\hline $\begin{array}{l}\text { THE RESEARCH } \\
\text { PROBLEM }\end{array}$ & $\begin{array}{l}\text { How does leadership emergence intersect with punctuated } \\
\text { equilibrium, a sudden and unexpected change event, within a } \\
\text { naturalistic decision making framework? }\end{array}$ \\
\hline $\begin{array}{l}\text { THE } \\
\text { SUBORDINATE } \\
\text { QUESTION }\end{array}$ & $\begin{array}{l}\text { Can leadership emergence be observed and identified in these } \\
\text { conditions, and if so, what characteristics identify this process } \\
\text { of emergence? }\end{array}$ \\
\hline $\begin{array}{l}\text { PRIMARY } \\
\text { THEORY }\end{array}$ & $\begin{array}{l}\text { Punctuated equilibrium stimulates leadership emergence in individuals. } \\
\text { Those individuals are motivated by instinct, compassion, and } \\
\text { responsibility. } \\
\text { The individuals who emerge as leader are identified within minutes or } \\
\text { hours of the change event. } \\
\text { One or more of the following indicators are observed: } \\
\text { a sense of calm, quick situational assessment, and not being aware of } \\
\text { the risk to themselves. }\end{array}$ \\
\hline $\begin{array}{l}\text { PRIMARY } \\
\text { THEORY } \\
\text { SIMPLIFIED }\end{array}$ & Sudden and unexpected change causes leadership. \\
\hline $\begin{array}{l}\text { COLLATERAL } \\
\text { THEORY \#1 }\end{array}$ & $\begin{array}{l}\text { Compassion is an underlying force in leadership emergence that is present } \\
\text { before a change event and after the change event but is cut off during the } \\
\text { actual change event. }\end{array}$ \\
\hline $\begin{array}{c}\text { SUBORDINATE } \\
\text { THEORY } \# 1\end{array}$ & $\begin{array}{l}\text { Creativity is a problem-solving device that becomes apparent within } \\
\text { minutes, hours, or days, and is more closely linked to leadership } \\
\text { effectiveness than emergence. }\end{array}$ \\
\hline $\begin{array}{c}\text { SUBORDINATE } \\
\text { THEORY \#2 }\end{array}$ & $\begin{array}{l}\text { Courage exists at the tail end of the leadership emergence continuum and } \\
\text { represents an ability to stand by the initial decisions made in the process } \\
\text { of leadership emergence no matter what the consequences may be. }\end{array}$ \\
\hline
\end{tabular}

The secondary theory that places these three variables in the continuum is stated in the following way: Compassion is an underlying force in leadership emergence that is present before a change event and after the change event but is cut off during the actual change event. Creativity is a problem-solving device that becomes apparent within minutes, hours, or days, and is more closely linked to leadership effectiveness than 
emergence. Courage exists at the tail end of the leadership emergence continuum and represents an ability to stand by the initial decisions made in the process of leadership emergence no matter what the consequences may be.

The following chapter will investigate the significance of this newly formed theory in terms of organizational and social leadership behaviors. Research results will be discussed in relation to previous theories of leadership emergence and punctuated equilibrium and its implications for leadership studies. The message of social change that came out of this research will be articulated and recommendations for future research will be identified.

\section{Conclusion}

Leadership emergence is a complex phenomenon that can be seen through the focused lens of a sudden and unexpected change event. A compressed frame of seconds, minutes, or hours, created the limiters for the emergence phenomenon to be defined. Leadership emergence is far from a linear and exact process. It is a precondition that floats in space until it intersects with another random condition, a punctuated event, which ignites a sequence of events. In fact, the only way to observe this crossing of paths is to simulate the conditions through a critical incident. The sudden and unexpected event represented by a critical incident creates the conditions for rapid decision making. Each decision made represents a division of paths, that once they are committed to, changes initial conditions forever. Hence, punctuated equilibrium's role in leadership emergence is profound 


\section{CHAPTER 5: RESULTS AND RECOMMENDATIONS}

The research and dissertation contained in this document began with an idea. That idea was to discover if there was an intersection of leadership emergence and punctuated equilibrium. If a connection was present, what were the mechanics of that interaction and how could it be recognized? Punctuated equilibrium theory, as the reader may recall from the early pages of this dissertation, is defined in the physical sciences as a quick and sporadic change after long periods of time when nothing changes (Drazin et al., 2004; Gersick, 1991; Gould, 2002). In the organization sciences, it is a model of organization evolution defined by extended periods of incremental change, or convergence, punctuated by reorientations or dramatic changes that transform the organization's deep structure (Romanelli \& Tushman, 1985). At the beginning of this grounded theory investigation, the connection between PET and leadership emergence had not yet been formulated. By the end of the research process, a link was found and subsequently, a theory established.

\section{Review and Results}

\section{Overview of the Process}

The first chapter of this dissertation explained how the research question would be investigated and why the phenomenon was important to leadership and organizational change scholars. The choice of grounded theory was described as the most appropriate research design. The conceptual framework in the first chapter explained what theories laid the foundation for this research.

The second chapter dove into a literature review, rich with detail and dimensions that defined the parameters of the study. The four theoretical touchstones were PET, 
complexity science, recent leadership emergence models, and NDM. Chapter 3 followed with a detailed plan of research that defined the sample populations to be surveyed and those who would offer retrospective accounts of their involvement in critical incidents. Chapter 3 also described how records would be treated and how the individuals would be contacted, accessed, and protected with regard to confidentiality.

All transactions were carefully documented and the research process, after the fact, is described in the next chapter. Chapter 4 of the dissertation presented the findings of the research with regard to the actual data collected in 15 interviews and 22 surveys. Analysis of the data leading up to the formation of the theory, a significant contribution of this research, is documented in this chapter. The final chapter ties the entire investigation together and explores the contributions to social change and the field of leadership research.

\section{The Results and Theory}

Analysis of the data resulted in a greater understanding of the mechanics of leadership emergence. The results exposed fresh leadership themes within the context of a narrow time frame, or what was referred to earlier as the event continuum perspective, which described the behaviors of individuals that occurred seconds, minutes, and hours within a sudden and unexpected change event. The core of the research was the investigation of a critical incident, as a causal event, that led to observable leadership behaviors. The critical incident, sharing a similar definition to a punctuated equilibrium event, was a close simulation from which to view the intersection of events. By the end of the research and analysis, the primary theory that a sudden and unexpected change event, 
punctuated equilibrium, does in fact cause leadership to emerge in individuals. According to Parry (1998), "Change incidents can be the basis of investigation of the leadership process" (p. 86). In this case, Parry's early prediction was correct-that the change incident was the trigger for defining leadership emergence.

The grounded theory investigation conducted here took the leadership emergence process several steps further and identified the paths leading to motivation and the identification of observable indicators. In fact, the critical incident representing sudden and unexpected change, ignited leadership emergence behaviors and further, it was a phenomenon that could be captured in time. Hence, the culmination of this research revealed that punctuated equilibrium stimulates leadership emergence in individuals. Those individuals are motivated by instinct, compassion, and responsibility. The individuals who emerge as leader are identified within minutes or hours of the change event by one or more of the following indicators: a sense of calm, quick situational assessment, and not being aware of the risk to themselves. This research helped the reader imagine that every time a decision is made in an emergent circumstance that the path traveled by the individual splits. Most individuals choose the path to do something rather than do nothing. The choice to do something leads to additional steps, or decision paths, in the individual's ability to affect positive outcomes. As stated previously, leadership emergence is not a linear process but a precondition that floats in space until it intersects with another random condition, a punctuated event, which ignites a sequence of events. 
In terms of an organization model, leadership emergence that occurred after extended periods of incremental change and is recognized at the moment of a punctuated change, suggests a new way of thinking about leadership. The consequences from the sequence of decision-making events arising from the rapidly emerging behaviors that once committed to, determine the future, and speak directly to the reorientations that transform the organization's deep structure.

Revisiting the Literature Review

The literature review was a semi continuous process throughout the data collection and analysis. There were very few new studies found using the same keyword search parameters used in the original search. Three additional pieces of literature were considered: Emergence, How Change Happens (Frieze \& Wheatley, 2008), Evolutionary Origins of Leadership and Followership (Van Vugt, 2006), and Patterns and Variable Approaches in Leadership Emergence and Effectiveness (Foti \& Hauenstein, 2007). None of these three studies changed or influenced the direction of the research or analysis and their contributions, although significant to leadership research, were not significant to this study.

Research studies selected and reviewed in chapter 2, drawn from four major theoretical foundations, framed this study. They were PET, complexity science's theories on change and time, leadership emergence studies, and NDM. This mixture of theories made it possible to view the intersection of sudden change and leadership emergence and gently guided the tone and substance of the research. 
The most prominent jumping point for this research came from the work of Bennis (2004) and Wheatley $(1999,2006)$, two authors who inspired and elevated the cadence of leadership research. Their work represented a collage of ideas that were stimulating, unique, and paralleled the direction of this dissertation. To review, Bennis studied the triggers of leadership emergence. He described instances of unlikely people emerging as leaders in a short span of time triggered by a critical incident. According to Bennis, "We found that something magical happens in the crucible-an alchemy whereby fear and suffering are transformed into something glorious and redemptive” (p. 333).

The research in this dissertation targeted that moment of transformation and it was discovered not to be magic, but rather, a process in which every individual was capable. The discoveries made in this research align with ideas presented in Wheatley's work. Reviewed earlier in chapter 2, Wheatley (2006) described how leaders emerged during natural disasters and suggested that a sudden, tragic, and unexpected event could change everything.

The theoretical framework formed out of literature from complexity science, punctuated equilibrium, leadership emergence theories, and NDM was steadfast throughout the research and flowed seamlessly into the formation of a new theory. The idea that complexity scientists believe that there is not one definitive idea to explain how things work, but rather "a range of theories and models that can be applied to understanding change" (Poole \& Van de Ven, 2004, p. 374) is reflected in this research. Punctuated equilibrium theory arising out of complexity science gave great diversity for understanding this study. According to Gersick (1991), “The most important implications 
of the punctuated equilibrium paradigm are suggested by the very diversity of the fields that have been affected by it (p. 33). Leadership and organizational change are two of the fields suggested by Gersick's comment. A review of literature early in the investigation revealed, "What is most inviting about punctuated equilibrium models is that they formally introduce the concept of crisis into models of change" (Drazin et al., 2004, p. 176). The grounded theory research conducted for this dissertation was able to accomplish some of what was suggested by these scholars by continuing to look for ways to understand change as a force connected to leadership.

Complexity science and the framework of naturalistic decision making addressed that an individual's sense of urgency is a component that cannot be ignored in the complex nature of decision making, leadership, and change. Previous studies in NDM, although sparse, established the credibility of studying leadership emergence in critical incidents. Individual decisions made in extreme and urgent conditions characterized the 40 retrospective accounts in 15 interviews and 22 survey responses that took place within the span of the research contained in this document.

\section{Implication for Leadership and Change Theories}

The implication for leadership theory is that there is a new way of thinking about those who are appointed to, elected to, or rise in official leadership positions. Although there was no direct proof, many eyewitness accounts and opinions of experts interviewed for this research implied no correlation between individuals in leadership positions and the likelihood that they will respond for the good of the majority in a critical change situation. In fact, some data suggested that in the face of unexpected and emergent 
change, official leadership failed and unofficial leadership stepped up. A prominent critical incident specialist who has interacted during critical change events with a significant number of official leaders offered the following.

I have seen unexpected leadership rise to the top. I've seen people who are in low ranks in an organization suddenly take over. . . but the leadership under pressure can bring out the best in people [and] it can also bring out the worst. I've seen people who were expected to be leaders just pretty much abandon the ship and failed in their leadership role in the midst of some of the worst things that were happening, [they] almost walked away. (Mick)

The implication that official and organizational leaders may not have leadership ability when tested, paves the path for unofficial leadership to emerge. Unofficial leaders who emerge are the leaders described in this research and are those who step up to make a difference as characterized by this comment, "The leader shoved himself into the background and we ran it" (Cait).

The research suggested that two views of change, an incremental continual change and a punctuated change, differentiates between management and leadership. Management is associated with continual and incremental change whereas leadership arises out of punctuated change. As suggested early in this dissertation, managing change is like trying to drive a runaway bus. It is difficult to control but persistence and preparation may make an individual better at it. A sudden and unexpected change event makes a resounding distinction between management and leadership and implies that leadership is a spontaneous response to a need. This is significant because the idea of managing change is an obsolete concept, and that leadership and management are two distinctive and unrelated phenomena. In the organizational setting, the punctuated view 
of change has systemic implications for how much weight leadership training and leadership assessment tests may have in the future.

Other Significant Findings

The overarching significance to this research was that a causal relationship between sudden change and leadership was identified that explains how leadership emergence is triggered by sudden change in real time. It produced evidence that leadership flowed from change rather than supporting the common perception, that change flows from leadership.

The contribution of this research is respectfully submitted into the archives of change, leadership, and decision theories. Although leadership emergence was defined in terms of motivating factors and observable indicators, there was little to suggest that leadership emergence could be predicted. The possible exception was in individuals with training and experience that were able, because of their training and experience, to dissolve barriers between instinct and action.

\section{Social Change}

\section{Contributions to Social Change}

The research, analysis, and theory formation made a significant contribution to the perception that every individual has the ability to step up as a leader at any given moment. It focused on a collective sense of responsibility to one another, the instinct to help one another even at the risk of harm to themselves. The potential for continual positive social change might be found in the spirit of the individuals who prioritize compassion, responsibility, and their core nature as primary drivers to take action, or to 
do something of significance in the face of rapid and unexpected change. It is suggested by leadership scholars that leadership remains a little understood phenomenon, and this research suggests it will remain that way. The emergence of leadership is as unpredictable as change, yet both exist in a space defined by complexity science.

Leadership emergence is more spontaneous than it is learned. Collectively, every individual has the potential to contribute positively to that change which takes our tolerance of mediocre, do-nothing leadership to task. Societies around the world face a high risk of the unexpected every day. The risk of terrorism, natural and manmade disasters, unexpected shifts in the economy and governing systems, or the coordinating of rescue efforts of a little boy who fell through the ice after an argument with his mom, call for a new type of leader that was defined in this research.

\section{Limitations of the Study}

The research conducted did not occur in an organizational setting or critical events that occurred within an organization. Even though it is implied from the data analysis that leadership emergence in an individual is relevant to organizational leadership, a specific correlation was not made. Responses from an organizational perspective made by interviewees were sporadic and were not a significant contribution to the research.

The circumference of this research did not include references to crisis leadership or creative leadership. This was not an investigation into the training or effectiveness of crisis leadership, nor was it an exploration of how to make leaders into better crisis 
managers. A critical incident that stood in for a punctuated equilibrium event, did not address preparation, planning, but rather, the spontaneous emergence of leadership.

Creative leadership, although a significant field of study, was not addressed in this research. Creativity, however, was investigated as a possible indicator of leadership emergence. It was discovered in this study that creativity was not an indicator of leadership emergence, but rather, a problem solving devise used in the context of leadership emergence to enable leadership effectiveness. In terms of this research, creativity was limited to a few moments in the event perspective continuum. The discussion of creativity was suppressed because it did not appear as an observable indicator of leadership emergence. The complex nature of creativity and the study of creative leadership are left for other researchers to pursue.

The models of decision making and naturalistic decision making were useful devises to frame the phenomenon under investigation; however, this study did not attempt to form conclusions that challenged current decision models. Although there was sporadic overlap, the science of decision making represented a significant and separate area of study not addressed in this research.

Recommendations for Future Research

Two areas of study that were not pursued, but arose out of the data related to group behavior, were self-organizing systems and followership. A complementary research design might be a qualitative case study within an organization that is in touch with critical incidents regularly, such as a search and rescue team or critical incident 
stress debreifers. A longitudinal study focusing on one population might reveal more about leadership emergence with regard to group behavior and self-organizing systems.

The spark that Wheatley $(1999,2006)$ ignited and this research touched upon, was self-organizing systems related to group behavior. It is a robust area of study worthy of additional empirical studies. This study was limited to individual behaviors, but there is great potential to study the motivation to act and the observable indicators defined here in a broader group context. It presents an opportunity for leadership researchers to jump from individual leadership emergence behaviors radiating from a sudden change event into a self-organizing group context.

Followership has been connected to leadership studies with great frequency by scholars. Followership tends to be the other half of leadership-for one to be present, the other has to be present, like two halves of a whole (Antonakis et al., 2004; Van Vugt, 2006). The research conducted in this essay hinted that leadership might exist without followership. The new type of leader who emerges because of a punctuated change event might be less connected with followership and more strongly connected with heroism and enlightenment. Hence, the second recommendation for future study is to break the old leader-follower paradigm and continue to build new definitions of leadership.

Two leadership emergence byproducts, creativity as a problem solving devise and courage as defined by the ability to stand by a decision no matter what the consequences, are rich with opportunity for future researchers. Creativity and courage were found toward the end of the event continuum in this research but may have a much larger role as change evolves. It was suggested in the research that creativity may have emotional 
and physical dimensions, but this was not pursued. Similarly, courage was found to have more dimensions than what was articulated in this research. Each concept represents its own unique area of study. This might include a fresh quantitative survey/questionnaire similar to the MLQ.

The research revealed many dimensions of compassion and its connection to leadership. Compassion with regard to the intersection of leadership emergence and punctuated equilibrium was a phenomenon that was cut off, or ceased to exist, in the seconds and minutes on either side of the intersection. However, compassion, the word and the idea, appeared frequently in the data and may have a more profound place in leadership emergence than indicated here. Compassionate leadership is often packaged with empathy and emotion, but the research for this dissertation exposed compassion as a more powerful force than previously considered. More work is needed to contribute to the cognitive and spiritual process of compassion in leadership emergence and effectiveness.

One of the changes I would make in future studies concerns the survey. It has a place in the research but not as a secondary quantitative data-gathering instrument, rather, it should have been positioned as an iterative instrument that launched from the themes that emerged from the interview data. This process may have furthered the understanding of motivating factors to act and observable leadership indicators. Themes that emerged from the interviews were significant and exciting; however, the survey instrument that was administered in this research was misaligned with the interview findings. A redesigned quantitative study is needed to launch from the findings in the spirit of a 
Delphi survey instrument. There may be a way to quantify the qualitative data extracted from the interviews to further empirical research.

Summary

\section{Reflections on the Process}

My experience with the research ranged from feeling empty, frustrated, and confused, to elation when themes began to emerge from the data. It can truly be characterized as a process described by previous grounded theorists as cyclical, fragmented, and filled with disorder (Goulding, 2002). Having a visual imagination served me well in the conceptualization of the data. Losing sleep, obsessing with new ideas, and visualizing a model of the process have been my preoccupation over the summer and fall. I referred frequently to grounded theory literature when I felt lost and needed reassurance to "absorb data as data, be able to step back or distance one self from it, and then to abstractly conceptualize the data" (Glaser, 1992, p. 11). It is exciting as much as unsettling to know that there may be more discoveries hidden in this data. The complexity existing simultaneously with simplicity of leadership emergence intersecting with a sudden change event will continue to fuel my curiosity and inevitably lead to more study.

The interviews with 15 key individuals who had been involved with and will continue to be involved with critical incidents was enlightening and revealing beyond expectations. It was truly an honor to spend time with these individuals and listen to their stories of commitment, compassion, and responsibility toward humanity. The interviews 
were more revealing than I anticipated, and unexpected patterns fell into place with a degree of consistency that led to the theory articulated in this dissertation.

The cooperation and willingness of all participants to help in this research was complementary. Many of the participants expressed an interest in having access to the results of the study once completed. Telling their stories was an opportunity for their own introspection and reflection. Relationships and connections made in the research process were supportive and ongoing.

The direct questions to the interviewees concerning creativity, courage, and compassion, triggered strong emotional responses in most. No participants affirmed my admitted bias of these concepts sparking at the point of leadership emergence rather; their perceptions helped me to understand how leadership unfolded in a sequence of events that was not linear but looping and random.

Without a doubt, my thinking has been changed as a result of this research. Admittedly, many of the ideas about change and its relationship to leadership found in the literature have become stale and old and replaced by a theory that describes an exciting and spontaneous process focused on humanity. The complex nature of leadership and change revealed in this research triggered a dissatisfaction with most current organizational leadership, communication, and change textbooks that I use to teach graduate leadership courses.

It is my expectation that other leadership and change scientists will be aroused by the theories that arose from this research. The research raised many questions concerning the nature of management, the spontaneous nature of leadership, and the cognitive, 
emotional, physical, and spiritual nature of humanity that is not bound by religion or politics. It is my intention to continue the research and at the same time, hope that these theories will be challenged and pursued by other scientists.

\section{A Brief Recapitulation of the Content}

The first chapter of this dissertation described the research problem and purpose that has been captured in this document. The process of data collection and analysis remained true to the intent articulated in the beginning chapter. The second chapter consisted of a highly detailed literature review that should be considered an integral and necessary component for the reader to appreciate the full scope of the theory that arose from the data. The background literature presented in the second chapter gave the reader an interesting, if not exciting journey into complexity science, naturalistic decision making, and contemporary change and leadership theories. The literature review brings the cadence of this dissertation into current social issues.

Chapter 3 described the details of a grounded theory data collection and analysis plan to be recorded in the following chapter. Chapter 4 , the most relevant portion of the dissertation, described process, findings, and analysis of a research journey that lasted nearly four months. Out of the research, a theory emerged that supported the primary problem of interest and added value to leadership literature. Chapter 5 described implications for leadership and organizational studies and the work's potential impact on social change. The last chapter, this chapter, was intended to plant a deep seed of curiosity and extend a branch of innovative thinking. 
Conclusion

Previous organizational leadership studies have linked change with the function of leadership (Parry, 1998; Poole \& Van de Ven, 2005; Romanelli \& Tushman, 1985;

Wheatley, 2006). Change was thought of as something that can be managed, anticipated, stimulated, thwarted, or created by leadership (Antonakis et al., 2004). But what if the order was reversed and a punctuated change event triggered leadership emergence? This study supported that every time a decision is made by an individual in an emergent circumstance, the path traveled splits in half with consequences of leadership emergence or failure to emerge. Thus, a new way of thinking is presented in this research.

Before the field research began, I was engrossed in a search for complexity science models of change. The discovery of punctuated equilibrium as an alternative way to view organizational change was a personal epiphany. It was at that point my addiction to discovering how this particular alternative view of organizational change might intersect with leadership emergence began. I was greatly inspired by complexity scientists in a collection of articles from Pool and Van de Ven's (2005) Handbook of Organizational Change and Innovation. Untested views of leadership positing it as a spontaneous and humanitarian focused phenomenon described in the works of Bennis $(2004 ; 2007)$ and Wheatley $(1999 ; 2006)$, also contributed to a new theory that took shape in this dissertation.

The naturalistic decision-making framework, a youthful theory, served as the overarching process through which leadership emergence and sudden change could fit together. To understand the complex and dynamic relationship of the parts required a new 
way of thinking about leadership and change as a whole. Leadership, ephemeral in nature, is a core ability that exists in every individual that is spontaneously triggered by a punctuated change event.

The message for organizational leaders is that change and leadership are one interrelated phenomenon. A transient yet dependent phenomenon, leadership and change cannot exist without the other in human and organizational systems. Leadership may be a spontaneous occurrence grounded firmly in humanity. This research has suggested that management is a distinctly separate process from leadership. Although they can exist together, management theory suggests a relationship with incremental and continual change. Punctuated change on the other hand, is the mechanism, the catapult, for a phenomenon that we continue to refer to as leadership.

Explanations of change processes in organizations must often span more than one level of analysis, involve multiple actors or perspectives, and incorporate dynamic generative mechanisms. They must also take into account characteristics of organizational change such as its path dependence, the powerful influence that a single critical event often has on the direction and impacts of change, and the role of human agency in molding change. (Poole \& Van de Ven, 2005, p. 374-375)

The research and analysis presented here posits leadership into that mix by synthesizing the intersection of a significant change event, punctuated equilibrium, and the complexity of leadership emergence in the individual. It is not a definitive, ironclad, or linear pathway to understanding individual leadership behaviors, rather, a contribution to one of the many possibilities of how two phenomena are related. 


\section{REFERENCES}

Adirondack Mountain Club. (2008). Home Page. Retrieved on April 14, 2008, from http://www.adk.org/home-flash.aspx

Antonakis, J., Cianciolo, A., \& Sternberg, R. (2004). Leadership: Past, present, and future. In J. Antonakis, A. Cianciolo, \& R. Sternberg (Eds.), The nature of leadership, 1-15. Thousand Oaks, CA: Sage Publications.

Avolio, B. (2007). Promoting more integrative strategies for leadership theory-building. American Psychologist, 62(1), 25-33. Retrieved from Academic Search Premier.

Bader, P., Kemp, C., \& Zaccaro, S. (2004). Leader traits and attributes. In J. Antonakis, A. Cianciolo, \& R. Sternberg (Eds.), The nature of leadership, 101118. Thousand Oaks, CA: Sage Publications.

Beare, M., \& Lynch, P. (2005). Learning decision making for the outdoors: A naturalistic perspective. In T. Dickson, T. Gray, \& B. Hayllar (Eds.), Outdoor and experiential learning: Views from the top, 210-219. Dunedin, N.Z.: Otago University Print.

Bennis, W. (2007). The challenges of leadership in the modern world: Introduction to the special issue. The American Psychologist, 62(1), 2-5. Retrieved October 11, 2008, from ProQuest Social Science Journals database. (Document ID: 1244409111).

Bennis, W. (2004). The crucibles of authentic leadership. In J.Antonakis, A. Cianciolo, \& R. Sternberg (Eds.), The nature of leadership, 331-342. Thousand Oaks, CA: Sage Publications.

Brown, D. J., Lewis, H., \& Scott, K. A. (2004). Information processing and leadership. In J. Antonakis, A. Cianciolo, \& R. Sternberg (Eds.), The nature of leadership, 125146. Thousand Oaks, CA: Sage Publications.

Byrne, C., Caughron, T., Friedrich, T., \& Mumford, M. (2007). Leader cognition in realworld settings: How do leaders think about crises? Leadership Quarterly, 18(6), 515-543. Retrieved from Business Source Premier.

Carroll, J. S., Klein, G., \& Lipshitz, R. (2006). Introduction to the special issue. Naturalistic decision making and organizational decision making: Exploring the intersections. Organizational Studies, 27(7), 917-923. Retrieved from Business Source Premier. 
Caverly, J. \& Caverly J. (2006). Q \& A: CISM. Retrieved on March 5, 2008, from http://www.crisisoptions.com/CISM.html.

Corbin J. \& Strauss, A. (1990). Basics of qualitative research: Grounded theory procedures and techniques. Newbury Park, CA: Sage Publications.

Corley, K., \& Shah, S. (2006). Building better theory by bridging the quantitativequalitative divide. Journal of Management Studies, 42(8), 1821-1835. doi: 10.1111/j.1467-6486.2006.00662.x

Creswell, J. W. (2007). Qualitative inquiry \& research design: Choosing among five approaches $\left(2^{\text {nd }}\right.$ ed.). Thousand Oaks, CA: Sage Publications.

Davenport, T. (2003). Whatever happened to complexity theory? Trends and Ideas, article reprint \# T0310B. Harvard Business School Publishing. Purchased from Harvard Business On-Line on October 8, 2007.

Dooley, K. (2004). Complexity science models of organization change and innovation. In M. Poole \& A Van de Ven (Eds). Handbook of organizational change and innovation, 354 - 373. Oxford, UK, New York, N.Y.: Oxford University Press.

Drazin, R., Glynn, M. A., \& Kazanjian, R.K. (2004). Dynamics of structural change. In M. Poole \& A. Van de Ven (Eds.), Handbook of organizational change and innovation, 161- 189. New York: Oxford University Press.

Endsley, M. R., \& Garland, D. J. (2000). Situation awareness: Analysis and measurement. Mahwah, NJ: Lawrence Erlbaum Associates.

Frieze, D. \& Wheatley, M. (2008). Emergence. Leadership Excellence, 25(5), 10-10. Retrieved August 17, 2008, from Business Source Premier.

Foti, R. \& Hauenstein, N. (2007). Pattern and variable approaches in leadership emergence and effectiveness. Journal of Applied Psychology, 92(2), 347-355. Retrieved August 29, 2008, from Business Source Premier database.

Galloway, S. (2007). Experience and medical decision making in outdoor leaders. Journal of Experiential Education, 30(2), 99-116. Retrieved from Academic Search Premier.

Gersick, C. (1991). Revolutionary change theories: A multilevel exploration of the punctuated equilibrium paradigm. Academy of Management Review, 16(1), 10-36. Retrieved from Business Source Premier.

Giuliani, R. W., \& Kurson, K. (2002). Leadership. New York: Hyperion. 
Glaser, B. G. (1978). Theoretical sensitivity advances in the methodology of grounded theory. Mill Valley, CA: Sociology Press.

Glaser, B. G., \& Strauss, A. L. (1967). The discovery of grounded theory; Strategies for qualitative research. Chicago: Aldine Publishers.

Goulding, C. (2002). Grounded theory a practical guide for management, business and market researchers. London: Sage Publications.

Gould, S. J. (2007). Punctuated equilibrium. Cambridge, MA: Belknap Press of Harvard University Press.

Gould, S. J. (2002). The structure of evolutionary theory. Cambridge, MA: Belknap Press of Harvard University Press.

Guastello, S. J. (2007). Non-linear dynamics and leadership emergence. The Leadership Quarterly, 18(4), 357-369. Retrieved from SUNY Science Direct

Kan, M. \& Parry, K. (2004). Identifying paradox: A grounded theory of leadership in overcoming resistance to change. The Leadership Quarterly, 15(2004), 467-491. Retrieved from Business Source Premier.

Klein, G. A. (2000). Analysis of situation awareness from critical incident reports. In M. R. Endsley \& D. J. Garland's (Eds.) Situation awareness: Analysis and measurement, 51-72. Mahwah, NJ: Lawrence Erlbaum Associates.

Lengbeyer, L. (2005). Selflessness \& cognition. Ethical Theory \& Moral Practice, 8(4), 411-435. Retrieved from Academic Search Premier.

Massimilian, D. \& McKee, A. (2006). Resonant leadership: A new kind of leadership for the digital age. Journal of Business Strategy, 27(5), 45-49. Retrieved from the ProQuest database.

Moerschell, L. (2008). Research methodologies. Unpublished manuscript.

Myers, P. Z. (2007). A short sharp slice of evolutionary history: Thirty-five years after they first appeared in print, provoking howls of protest, Stephen Jay Gould's idea on evolution are as compelling and essential as ever [Review of the book Punctuated Equilibrium]. New Scientist, 194(2603), 54-56. Retrieved from Business Source Premier.

Parry, K. (1998). Grounded theory and social process: A new direction for leadership research. Leadership Quarterly, 9(1), 85. Retrieved from Business Source Premier. 
Poole, M. (2004). Central issues in the study of change and innovation. In M. Poole \& A Van de Ven (Eds). Handbook of organizational change and innovation, 3-31. Oxford, UK, New York, N.Y.: Oxford University Press.

Poole, M. \& Van de Ven, A. (2004). Theories of organization change and innovation processes. In M. Poole \& A Van de Ven (Eds). Handbook of organizational change and innovation, 374-397. Oxford, UK, New York, N.Y.: Oxford University Press.

Reed, J. (2007). Appreciative inquiry research for change. Thousand Oaks: Sage Publications.

Robinson, S. (2007). Punctuated equilibrium models in organizational decision making. In G. Morçöl,(Ed.) Handbook of decision making. Boca Raton: CRC/Taylor \& Francis Group, 133-149.

Romanelli, E. \& Tushman, M. (1985). Organizational evolution: A metamorphosis model of convergence and reorientation. Organizational Behavior, 7, 171-223.

Schneider, M. \& Somers, M. (2006). Organizations as complex adaptive systems: Implications of complexity theory for leadership research. Leadership Quarterly, 17(4), 351-365. Retrieved from Science Direct.

Singleton, R \& Strait, B. (2005). Approaches to social research. NY: Oxford University Press.

Sternberg, R. (2007). A systems model of leadership. American Psychologist, 62(1), 3442. Retrieved from EBSCOhost database.

Van Vugt, M. (2006). Evolutionary origins of leadership and followership. Personality \& Social Psychology Review (Lawrence Erlbaum Associates), 10(4), 354-371. Retrieved August 30, 2008, doi:10.1207/s15327957pspr1004_5

Wheatley, M. (2006). Leadership lessons from the real world. Leader to Leader, 2006(41), 16-20. Retrieved from the ProQuest database.

Zaccaro, S. (2007). Trait-based perspectives of leadership. American Psychologist, 62(1), 6-16. Retrieved from Academic Search Premier, CSA PsycArticle. 


\section{APPENDIX A: SURVEY}

\section{Leadership Emergence Survey}

\section{IMPORTANT! WE NEED YOUR CONSENT FIRST - PLEASE READ THIS.}

You are invited to take part in a research study that investigates how leadership characteristics emerge during an outdoor adventure challenge. You were chosen for the study because of your role as student, former student, faculty, or field guide in wilderness education. Please read this form and ask any questions you have before agreeing to be part of the study. This study is being conducted by a researcher named Linda Moerschell, who is a doctoral student in Applied Management and Decision Science at Walden University. Her specialization is leadership and organizational change.

Procedures: If you agree to be in this study, you will be asked to read and respond to a short survey that contains a vignette and 18 multiple choice questions.

Voluntary Nature of the Study: Your participation in this study is voluntary. This means that everyone will respect your decision of whether or not you want to be in the study. The researcher, Linda Moerschell, will not treat you differently if you decide not to be in the study. If you decide to join the study now, you can still change your mind later. If you feel stressed during the study you may stop at any time.

Risks and Benefits of Being in the Study: There are no known risks to you.

Compensation: There will be no compensation for your participation.

Confidentiality: Any information you provide will be kept anonymous. You will not be asked to identify yourself on the survey instrument. The researcher will not use your information for any purposes outside of this research project. Also, the researcher will not include your name or anything else that could identify you in any reports of the study.

Contacts and Questions: The researcher's name is Linda Moerschell. The researcher's faculty advisor is Dr. Teresa Lao. You may ask any questions you have now via email. Or if you have questions later, you may contact the researcher via phone at 315-265-8122 or 315-267-3489 or by email at Imoersch@twcny.rr.com or the advisor at 210-372-1356 or by email at teresa.lao@waldenu.edu. If you want to talk privately about your rights as a participant, you can call Dr. Leilani Endicott. She is the Director of the Research Center at Walden University. Her phone number is

1-800-925-3368, extension 1210.

You may print a copy of this form to keep. 
Statement of Consent:(Refer to Question 1 below)

\section{I have read the above information. I have received answers to any questions $I$ have at this time. I am 18 years of age or older, and I consent to participate in the study.}

I have read the above information. I have received answers to any questions I have at this time. I am 18 years of age or older, and I consent to participate in the study. Yes

r

No

\section{Outdoor Adventure Vignette}

You are on a backpacking day trip with six other hikers. You and two others in the group are experienced hikers and the other four adults are first time hikers. The group climbs to the top of the summit, with an elevation of 4,624 feet, without incident. The forecast was for a clear and cool day. The two experienced hikers get excited about hiking the neighboring peak, which would add three additional miles to the trip. The others in the group do not have the stamina or interest to climb the second peak. You agree to stay with the others and explore the summit while the two experienced hikers split from the group and head for the neighboring peak. They estimate their return in two hours. The group agrees upon a rendezvous point just below the first summit.

Almost two hours after the group split up, you notice storm clouds beginning to gather and move toward your location. You suggest that the hikers get off the summit and head to the rendezvous point. Judging by the closing gap in seconds between seeing lightning and hearing thunder, you know the storm will be directly overhead in minutes. The storm begins and brings hail and torrential rain. Two of the hikers in the group take cover under a tall pine tree and the other two sit on their backpacks isolating their bodies from the rock surface in case of a lightning strike. Shortly the group is soaked from the rain and smarting from the hail. One person in the party is complaining of chills, indicating pre-hypothermic conditions. Water begins to rush down the slope from the summit and the trail below is deteriorating. There is no sign of the other two hikers. 
2. What would you do?

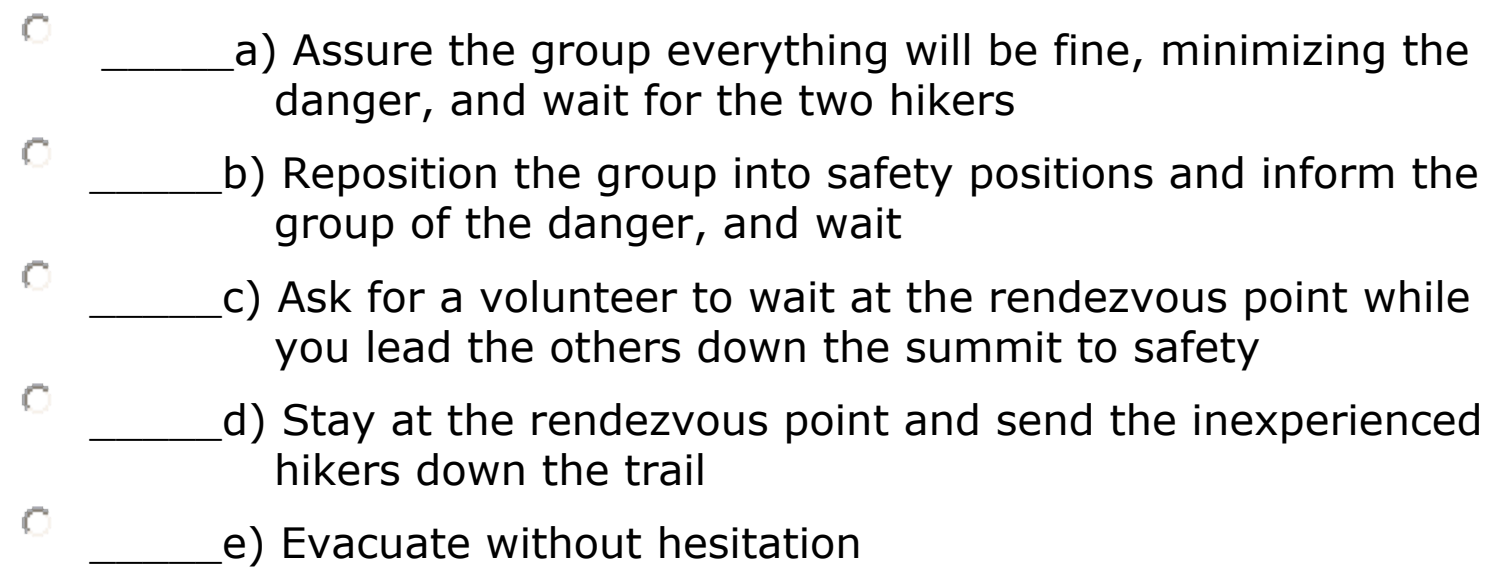

3. How would you describe your attitude before you noticed the storm approaching?
c
a) Cooperative
c b Responsible
c c) Selfish
c d) Selfless
c e) Decisive
c
f) Anxious

4. How would you describe your attitude when you noticed the storm was approaching?
c a) Cooperative
c b) Responsible
c c Selfish
c d) Selfless
c e Decisive
c f Anxious 
5. How would you describe your attitude after you moved the group and the storm hit?

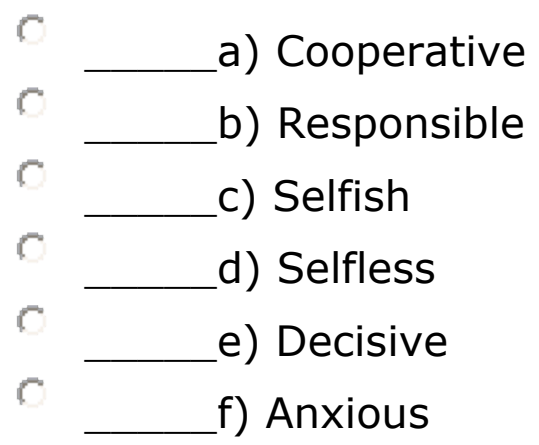

6. Thinking back to Question \#1, suppose you decided to evacuate without hesitation but one of the hikers argues that the group should wait at the rendezvous point. Would you
(
r
a) discuss options with the group?
c
b) evacuate the group without discussion?
c) try to convince the hiker who wants to wait of the danger of waiting?
c
c
d) leave the hiker who disagrees behind to wait?
e) evacuate all or none?

7. What emotions were you feeling toward the inexperienced hikers when the storm hit?
c

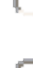
a) Fear
b) Frustration
c
c) Trust
c
d) Empathy
e) Hope 
8. What emotions were you feeling for the two hikers who took a side trip?

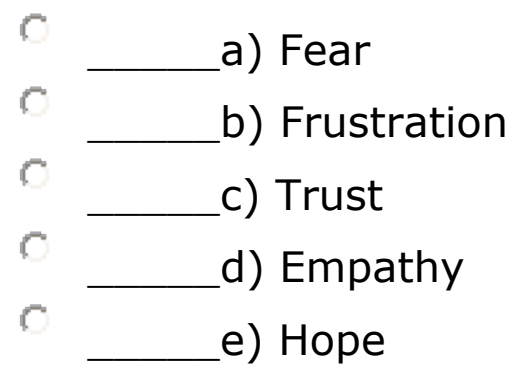

9. What was your highest priority when you made your decision in Question \# 1 (when the storm was raging overhead?)

a) The safety of the inexperienced hikers group

b) The safety of the missing hikers

c) Your own safety

d) The belief that the storm would increase in intensity

e) The belief that the storm would pass quickly

10. Do you perceive that your decision is associated with:
a) the high cost of failure
b) the success of keeping everyone safe
c) the irreversibility of your decision
d) the benefit of the majority
e) the unknown

11. You have compassion toward your fellow hikers.
$c$ a) strongly agree
c b) agree
$c$ c) uncertain
$r$ d) disagree 
c

e) strongly disagree

12. Once you choose a course of action that you believe is best for the majority, you do so at risk to yourself.
C
a) strongly agree
c
b) agree
c) uncertain
r
d) disagree
C
e) strongly disagree

13. Once you choose a course of action that you believe is best for the inexperienced group, you do so knowing that at least one of the six hikers could be in harms way.
C a s strongly agree
b b) agree
c c) uncertain
C d) disagree
c e strongly disagree

14. As the most experienced hiker thinking about the safety of the group, do you think it is your responsibility to make a decision...
c a) Immediately
b) Within a few minutes with personal deliberation
c) Within a few minutes after a group discussion
d) Eventually
e) Not at all


15. As the most experienced hiker in the group, would you assume a leadership position...

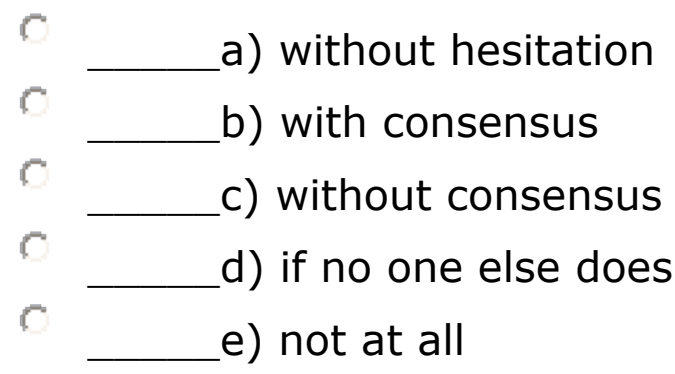

16. Cell phones rarely work in this mountain range. If you were to try to communicate with the missing group how would you do it?
c a try your cell phone in spite of the raging storm
(
c
c
b) ask someone in your party to go find them
c) shout for them
d) ask someone else to try his or her cell phone
e) try to call the emergency rescue number stored on your phone

17. How would you describe yourself on a day trip similar to the one in the story? (you can choose more than one answer)
$\Gamma$
a) Adaptable
$\Gamma$
b) Compassionate
$\Gamma$
c) Creative
$\Gamma$
d) Motivated
$\Gamma$
e) Courageous

18. If you can imagine yourself in this scenario, or if you have ever been in a similar situation, would you
c
a) just know everything would be OK 


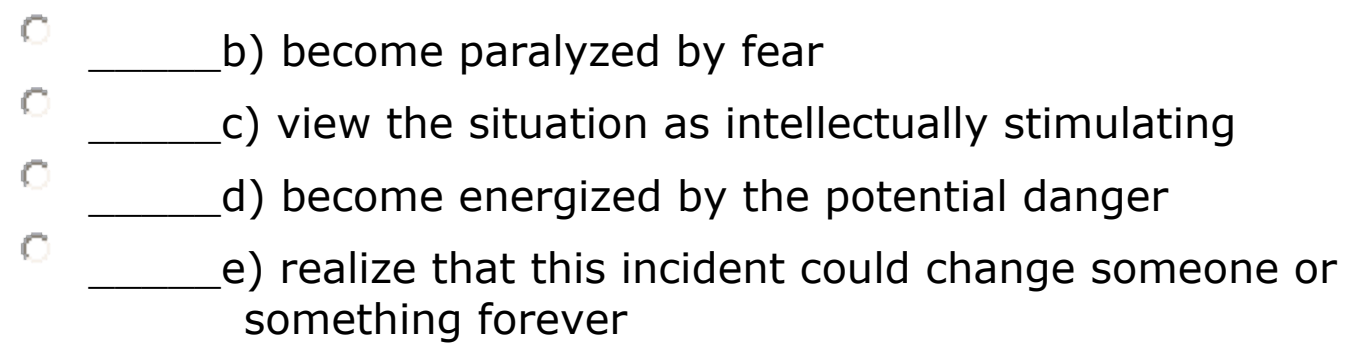

19. In the critical situation described earlier, what would be your most prominent characteristic? In other words, what do you consider your strongest personal assets in a critical situation?

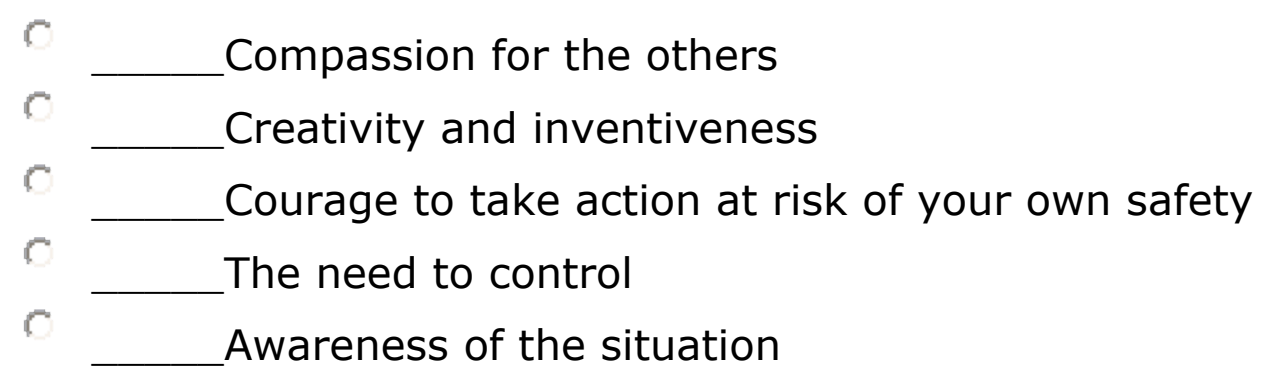

Thank you so much for taking this imaginary trip and survey! You are almost done. Please tell me......

20. Are you currently enrolled in any wilderness education course?

$$
\text { r Yes }
$$

21. Are you a faculty member, field instructor, or leadership trainer?
C Yes
No 
22. If you are a faculty member, instructor, or trainer, approximately how may years of experience do you have in wilderness leadership training?

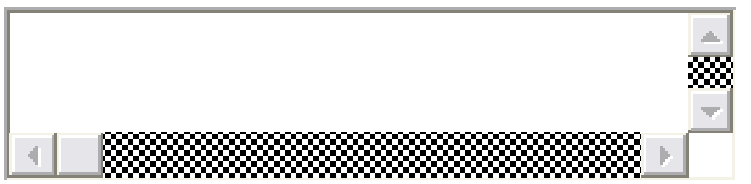

23. Do you have any wilderness leadership training or certifications? If you answered yes to this question, please list your current training and certifications.

r Yes

No 
I. Demographic Information

1. What is your title?

2. How many years of experience do you have in this field?

3. In your professional capacity have you ever been involved in a critical incident, an unexpected challenge, an emergency medical event, a natural or manmade disaster?

I describe the format of the interview and explain that they may draw from a different critical incident (CI) for each of the four parts. I offer the prompts if needed.

I would like you to focus on one particular event that stands out in your mind to frame your answers to these questions. You may draw from other Cl's if it seems appropriate to do so.

Please describe the CI. Approximately how long was it before you were involved (minutes, hours, days) after the actual event?

The first questions will explore your perceptions of official leadership in unexpected events.

1. If you interacted with leadership officials, or just one designated leader during this event, can you describe their actions?

2. Can you describe what you perceived to be their strongest attributes?

a. Prompt: decisiveness, ingenuity, awareness of others?

3. Can you describe what you perceived to be their weakest characteristics?

a. Prompt: Lack of concern for others, inability to assess the situation

4. Can you describe their decision making process?

5. Describe their behavior in terms of attitudes toward the people at risk.

6. Describe their behavior in terms of their subordinates. 
The next questions will probe your perceptions of unofficial and unlikely leaders that emerged during these events. Is the event the same as the above event? If not, describe this event.

7. What were the circumstances that triggered leadership behavior in the individual?

8. How rapid was this emergence?

9. Please describe how you were able to identify that this individual was taking the lead?

10. Can you describe what you perceived to be their strongest attributes?

a. Prompt: decisiveness, ingenuity, awareness of others?

11. Can you describe what you perceived to be their weakest characteristics?

a. Prompt: Lack of concern for others, inability to assess the situation?

12. Can you describe their decision making process?

13. Describe their behavior in terms of attitudes toward the people at risk.

14. Describe their behavior in terms of others in the group.

The third set of questions explores your personal leadership role in these situations. Is the event the same as the above event? If not, describe this event.

15. If you interacted with leadership officials, or just one designated leader during this event can you describe their actions?

16. Can you describe what you perceived to be your strongest attributes?

17. Can you describe what you perceived to be your weakest characteristics?

18. Can you describe your decision making process?

19. Describe your behavior in terms of attitudes toward the people at risk.

20. Describe your behavior in terms of their subordinates.

This last set of questions will explore your opinions about the relationship among the following concepts.

21. From your point of view, do you think there is a relationship between a sudden and unexpected change event and the emergence of leadership? 
22. If so, what attributes would signal or indicate the sudden rise in leadership ability in an individual?

23. Do you perceive a relationship among leadership emergence, a critical incident, and decision making? If so, can you describe that?

24. What role does creativity have in leadership during a CI?

25. What place does compassion have in leadership during a CI?

26. You have/have not said anything about courage in an individual, what is your perception of the relationship between courage and leadership?

27. Last question: Do you have any additional thoughts about a CI and leadership emergence or any opinions or comments that you would like to add? 


\section{APPENDIX C: CONCEPT IDENTIFICATION CHART}

\section{Concept Identification and Grouping: Main Themes}

Step 4 of the coding process attempted to group dominant concepts and their underlying properties according to frequently occurring evidence of that theme based on verbatim quotations from the interview transcripts.

Memo: The continuum is as follows. As critical incident occurs that simulates a sudden and unexpected change event. Many interviewed agreed that al individuals have the potential to be a leader but some choose not to. The first thing to code is the motivation not to emerge as a leader, or in other words, those that do not. Therefore an initial distinction in terms of motivation has to be made between these two individual types.

\section{Why Individuals Do Nothing}

fear of failure

freeze, become paralyzed

choose flight instead of fight

don't have desire to step up

no prior experience in situation

deficient core values

lack of self confidence

no compassion

lack of courage
Memo: Next, there are those that do and that is the focus of this research. Leadership emergence in those individuals will be broken down into themes of motivation to respond, the most prominent personality traits and or characteristics which are descriptors of what the individua was feeling and thinking at the critical moment, and the

decision making process. which begins immediately and continues through the change.
Memo: Motivation, decision making, and prominent characteristics (positive and negative) will be broken out in terms of the most frequently identified indicators in rapid leadership emergence. In addition to these 4 themes a 5 th theme of consequences of decision making leading to success or failure has to be identified.
Memo: Out of the three indicators that were expected to be indicators of LE will be treated separately. They lie on the continuum but are NOT evidence of LE at the critical moment. Compassion lies on both ends of the continuum but is cut off during the actual $\mathrm{Cl}$ Creativity was linked to leadership effectiveness rather than leadership emergence, and courage seems to be the sum total of the process.

creativity - not first or most
$\quad$ prominent trait
has more to do with effectiveness
the ability to find alternative
solutions and resources -
emotional and physical
courage - the sum total of why
leadership emerges in the
individual
don't try leadership without it!
risking your own safety to help
the ability to stand by your
decision whether right or wrong
going outside your comfort zone
Compassion - very complex
and difficult to contain
has to be a cut off point after Cl
begins
zero impact depending on sit.
has to be balanced with
dispassion
where indiv stands in the end
is a trigger for LE
must have separation to
function effectively as leader
without it is failure of leadership




\section{APPENDIX D: SURVEY RESPONSES ALIGNED BY THEMES}

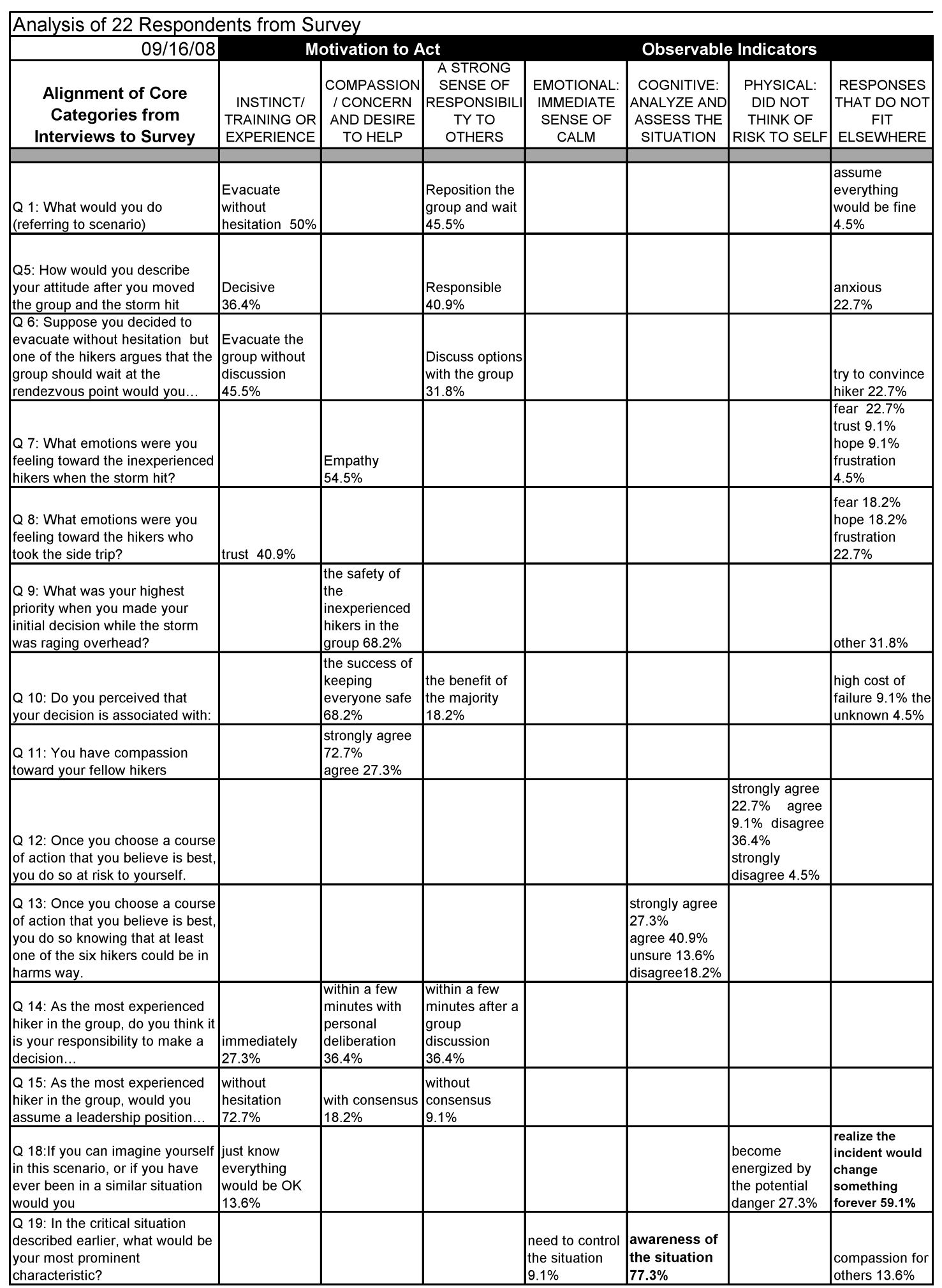


CURRICULUM VITAE

FOR LINDA MOERSCHELL

\section{EDUCATION}

Walden University, Minneapolis, MN

$\mathrm{PhD}$, Applied Management and Decision Sciences, specialization in Leadership and Organizational Change.

Proposal defended on May 19 th $^{\text {th }} 2008$.

Dissertation Defense on October 30, 2008.

Dissertation Title: The Intersection of Punctuated Equilibrium and Leadership Emergence Within the Framework of Naturalistic Decision making

Clarkson University, Potsdam, NY

May 2003

MBA (Master of Business Administration)

State University of New York at Potsdam, NY

May 1982

BA (Bachelor of Art) in English Literature

ACADEMIC WORK EXPERIENCE AT SUNY POTSDAM

\section{Instructor, Department of English and Communication $\quad$ Fall 2004 to present \\ Instructor, Department of Information and Communication Technology Spring 2006 to present}

Courses Designed and Taught while at SUNY Potsdam

Needs Assessment (IT 658): Spring 2006, 2007, and 2008

This graduate course directs students to work with ideas and practices that are part of the organizational and academic decision making process. Students focus on using concepts and skills in various work applications including instructional development, organizational process, and idea building.

Organizational Communication (IT 505): Fall 2006 and 2008

This graduate course investigates the structure and nature of organizational communication and the factors affecting the internal flow of information and 
distribution methods. Workplace relationships, problem solving, and policy formation are among the topics covered in this course.

Systems Models of Leadership: (course proposal submitted May 2007)

This course, not yet offered, is a hybrid of experiential learning and classroom discussion. Specific topics drawn from contemporary literature include leadership development, experiential learning theory, multiple intelligences theory, creative leadership, and the synthesis of wisdom, intelligence, and creativity.

Business and Professional Communication (Comm 206): Fall 2005; 2006 \& 2007; Spring 2006 \& 2007; Summer 2006, 2007, 2008.

This speaking intensive course is a process-oriented course that I designed to bridge the gap between the classroom and the professional world through activities, lectures, journal keeping, and peer review of student speeches.

Basic Principles of Speech (Comm 106): Two sections every Spring and Fall semester since Fall of 2004.

This introductory public speaking course includes speaking technique and audience analysis, persuasive and informative presentations, research, evidence building, and idea organization. Emphasis is placed on developing critical thinking and listening skills in the student.

Survey of Human Communication Labs (Comm 105): Three 1-hour sections per week since Spring of 2005.

The Survey of Human Communication lab is an abbreviated version of Comm 106 with a focus on freshmen speaking requirements. It is a companion course to the 3-credit lecture given by another professor.

\section{Related Professional Experience while at SUNY Potsdam}

Member of the Student Liaison Committee in the Department of English and Communication. Serving with three other faculty members, this committee is charged with the task of maintaining student relationships through judging, selecting, and presenting annual awards to recipients in students in the department since the Fall of 2008.

Co-organizer for a series of multiethnic faculty training conferences through Associated Colleges and the office of Global Studies entitled Teaching Strategies for the Multiethnic Classroom. Fall 2006. 
Faculty presenter for The Chinese Student Learning Profile, October 24, 2006, as part of the Teaching Strategies for the Multiethnic Classroom series in the Learning and Teaching Excellence Center (LTEC) at SUNY Potsdam.

Principle investigator for classroom projects in Needs Assessment (IT 658). Certificate issued in March 2007 through SUNY Potsdam's Institutional Review Board (IRB).

Guest lecturer for three classes in Essential Practices of Music Business for the Crane Institute for Music Business during the Fall 2007 semester.

Member of a Freshman Interest Group (FIG) entitled Speaking of Different Cultures with four other faculty members Fall 2007 and Fall 2008 semesters.

Coordinator of a Learning Community entitled Professional Communication Connections with two other faculty members. Over a period of two years, the faculty engaged in semi-regular meetings to develop programming and coordinate learning activities between the departments of Business and English \& Communication.

ADDITIONAL ACADEMIC WORK EXPERIENCE OTHER THAN SUNY POTSDAM

Adjunct Instructor, Department of Speech and Theater

St. Lawrence University, Canton, NY

Spring 2005

Adjunct Instructor, Department of Communication and Media, Fall 2004 \& Spring 2005, Clarkson University, Potsdam, NY

Healthcare Career Instructor/Case Manager

Summer 2004

St. Lawrence-Lewis BOCES, Canton, NY

PUBLICATIONS AND LECTURES

"Resistance to Technological Change in Academia: Two Case Studies" submitted to Current Issues in Education in July of 2008 (currently under review).

"The Chinese Student Learning Profile" submitted to The Journal of English as Second Language (TJESL). Accepted pending revisions in May 2008 (in progress).

Featured Speaker, Honoring the Divine Miss Ruth

National Museum of Dance, Saratoga Springs, NY. January 2005 


\section{RELATED PROFESSIONAL EXPERIENCE}

Director, Rural Health Training Center

$1997-2003$

Center for Extended Studies

SUNY Canton, Canton, NY

A combination of entrepreneurship, marketing skill, fund raising, and fiscal management was needed to serve as director of the Rural Health Training Center. This grant-funded project hosted continuing professional education for health care professionals.

\section{Related Professional Experience while at SUNY Canton}

Organizer of several trainings in Critical Incident Stress Debriefing using the Mitchell Model through the International Critical Incident Stress Foundation that led to the creation of CISM teams in area hospitals and schools in northern New York.

Founding board member and interim secretary for the Northern Area Health Education Center (NAHEC) created through SUNY Potsdam's Merwin Rural Services Institute as part of the New York State Area Health Education Center (AHEC) project.

Author and Principal investigator of a Rural Utilities Services Federal Technology Grant for Distance Learning and Telemedicine that supplied a telemedicine unit at Clifton Fine Hospital in Star Lake and Voice-over Internet Protocol (VOIP) connectivity and equipment at SUNY Canton.

Author and Principal investigator of a Health Resources \& Services Administration's (HRSA) Bureau of Health Professions Federal Grant for Rural Allied Health Professional's Continuing Education.

Coordinator of educational and entertainment events at the grand opening of the Borders, Books \& Music store at the Salmon Run Mall in Watertown, NY in the Fall of 2002.

Entrepreneur and Coordinator of a partnership with the University of Buffalo's Dental School to supply continuing dental education to the St. Lawrence County Dental Association through video conferencing technology. 
Professional Development while at SUNY Canton

Invited participant at Senator Hillary Clinton New Technologies for New York Summit. Hosted by the Canandaigua Chamber of Commerce, Canandaigua, New York, November 2002.

Presenter and participant in the annual meeting of The Continuing Education Association of New York (CEA/NY). In Buffalo, NY in 2000, and in Saratoga Springs, NY, 2001.

Practice Development Director

1994-1997

Equimed, Inc.

State College, PA

As practice development director of the Winter and Reddy Cancer Treatment Center affiliated with Claxton-Hepburn hospital and Alice Hyde hospital. My primary role was to recruit patient referrals and to develop patient support, education, and cancer prevention programs.

Related Professional Experience while at Equimed, Inc.

Producer and Host of Cancer Facts, a monthly cable television show that featured interviews with physicians and specialists in the field of cancer prevention and care.

Coordinator of preventative cancer screenings over a two county area to include frequent events held at the Akwasasane Mohawk clinic on the Mohawk reservation in Hogansburg, NY.

President of Studio D. Advertising, Inc.

1985-1994

Potsdam, NY

Studio D Advertising was an advertising agency that I began as a part time venture in 1985. It grew to include advertising design, marketing consultation, direct mail services, and a full multi-media production facility. 